\title{
RELIABILITY-BASED ULTIMATE LIMIT STATE DESIGN OF MICROPILES IN ONTARIO SOILS
}

\author{
by \\ Alexandre P. R. P. Almeida, \\ B.Eng., Federal University of Goias, 2014 \\ A thesis \\ presented to Ryerson University \\ in partial fulfillment of the \\ requirements for the degree of \\ Master of Applied Science \\ in the program of \\ Civil Engineering \\ Toronto, Ontario, Canada, 2019 \\ (C) Alexandre P. R. P. Almeida, 2019
}




\section{AUTHOR'S DECLARATION}

I hereby declare that I am the sole author of this thesis. This is a true copy of the thesis, including any required final revisions, as accepted by my examiners.

I authorize Ryerson University to lend this thesis to other institutions or individuals for the purpose of scholarly research.

I further authorize Ryerson University to reproduce this thesis by photocopying or by other means, in total or in part, at the request of other institutions or individuals for the purpose of scholarly research.

I understand that my thesis may be made electronically available to the public. 


\title{
RELIABILITY-BASED ULTIMATE LIMIT STATE DESIGN OF MICROPILES IN ONTARIO SOILS
}

\author{
Alexandre P. R. P. Almeida \\ Master of Applied Science, 2019 \\ Department of Civil Engineering \\ Ryerson University
}

\begin{abstract}
The design practice of micropiles in Ontario soils under the ultimate limit state was improved through both statistical and reliability analyses of a database of 40 micropile load tests. Micropile design is extremely dependent on engineering experience and judgement due to the lack of an accurate estimation of the bond strength. The FHWA manual of micropiles only provides wide ranges of bond strength in different ground conditions. Micropile load tests were conducted by Keller Foundations Ltd and collected for this study. From a statistical analysis, Fuller and Hoy's method was selected as the best method to estimate the failure load from non-failed tests. Adjusted parameters were given to predict the bond strength of micropiles. A method was proposed to estimate the contributions from the cased length and the tip to the total resistance. In the end, a reliability analysis was conducted and the resistance factors were recalibrated.
\end{abstract}




\section{ACKNOWLEDGEMENTS}

This research was only made possible with generous funding and resources provided by the Ontario Centres of Excellence (OCE) and Keller Foundations Ltd.

A special thanks to Dr. Jinyuan Liu, my supervisor, for believing in me since the beginning and for guiding me throughout my graduate studies with valuable insights and important suggestions. Also, I am extremely grateful for being one of his students and having the opportunity to learn great practical lessons for life.

I would like to thank Mr. Jim Bruce and Mr. Naresh Gurpersaud from Keller Foundations Ltd. for their technical support and sharing the database of micropile load tests. This research would not be possible without the available data. In addition, I would like to express my gratitude to Mr. Naresh Gurpersaud for granting me an internship during the course of this research. I learned much more on practice with Keller Foundations Ltd.

I would like to also thank my former supervisor in Brazil, Dr. Mauricio Sales, who always encouraged me to pursue graduate studies and work in the geotechnical field. My former supervisor at Engesol Engenharia de Solos in Brazil, Mr. Daniel Dias, I sincerely thank you for mentoring me inside the amazing world of Geotechnical Engineering.

My wife, Mrs. Ana Paula Gontijo Almeida, thank you for supporting me during all times in these past two years. Without your support and love, I would not have moved to another country and completed this study.

I am grateful for my parents, Mr. Marcio Almeida and Mrs. Maria Regina Almeida, and their support, assistance, and love throughout my whole life.

I appreciate the assistance from Mr. Markus Jesswein, Mr. Moulay Youssef, and Ms. Niloofarsadat Heirani for their help with the data collection and digitization.

Ultimately, I wish all the best to all members of this wonderful research team. 


\section{TABLE OF CONTENTS}

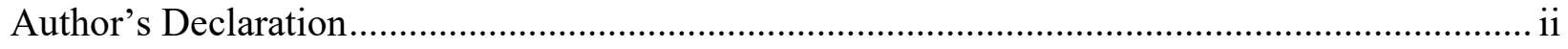

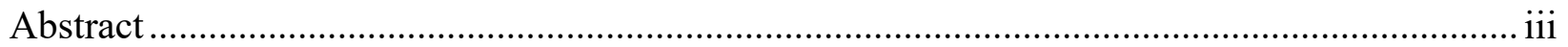

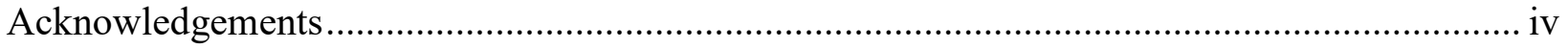

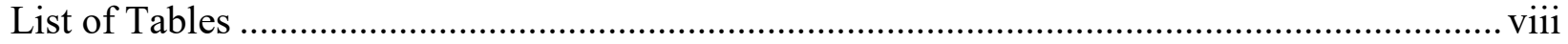

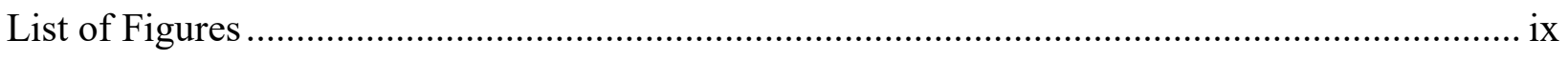

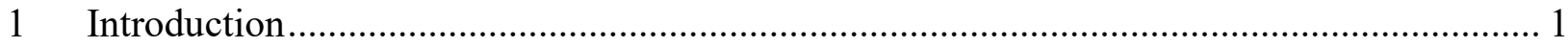

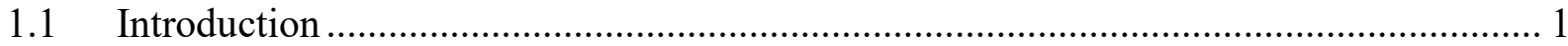

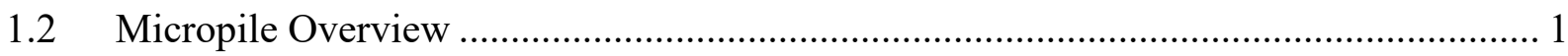

$1.3 \quad$ Database of Micropile Load Tests ...................................................................... 1

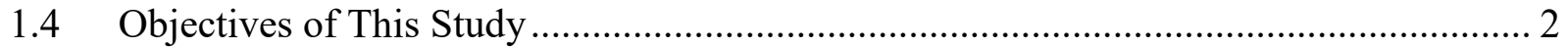

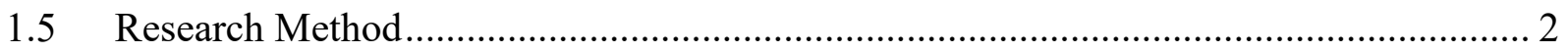

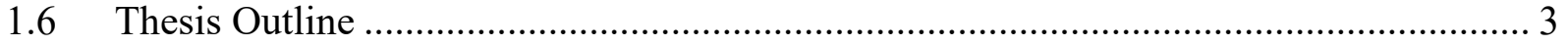

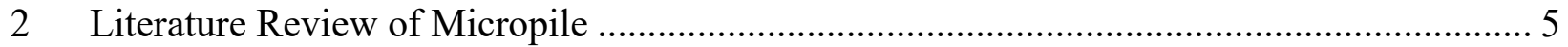

2.1 General Micropile Specifications ....................................................................... 5

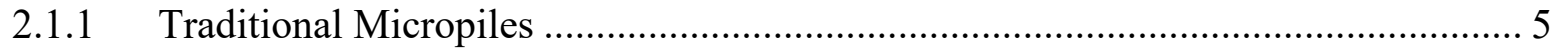

2.1.2 Continuous Grout-Flush Micropiles ...................................................................... 7

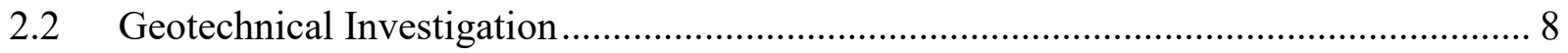

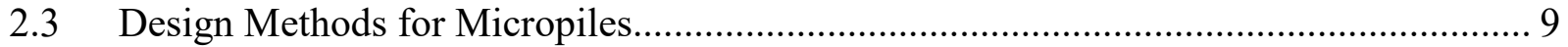

2.3.1 Federal Highway Administration...................................................................... 9

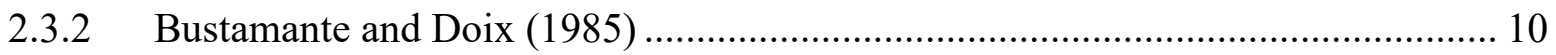

2.3.3 Comparison between These Two Methods .................................................... 11

2.3.4 $\quad \alpha$ and $\beta$ Methods for Side Resistance............................................................. 11

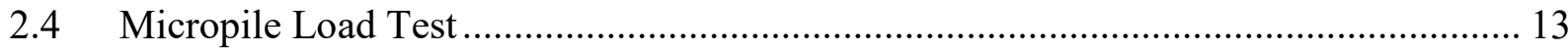

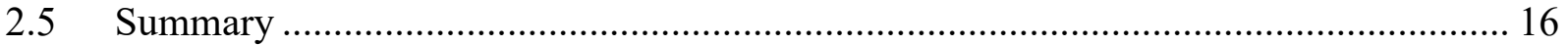

3 Statistical Analysis of Methods for Micropile Failure Identification .............................. 17

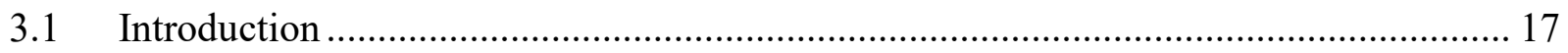

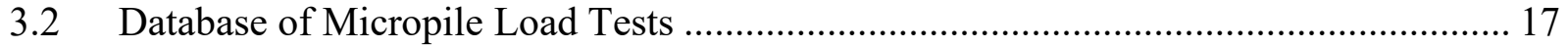

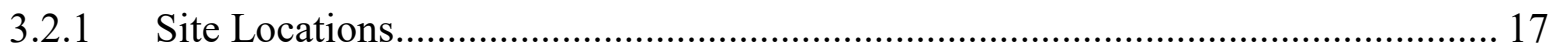


3.2.2 Soil Conditions and Micropile Geometries......................................................... 18

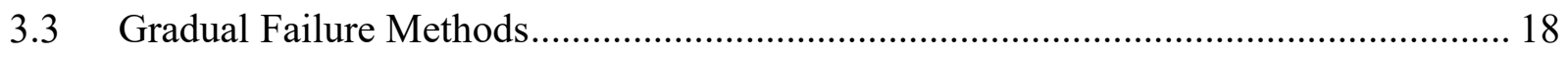

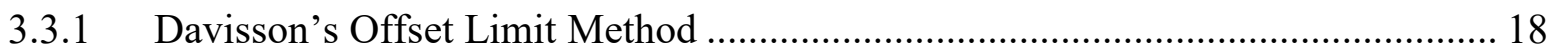

3.3.2 Fuller and Hoy's Method ................................................................................ 19

3.3.3 Butler and Hoy's Method..................................................................................... 19

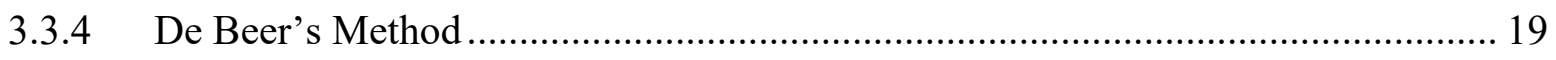

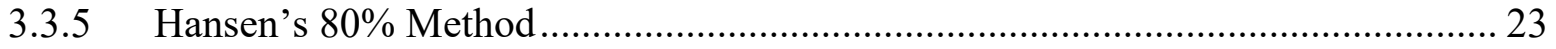

3.4 Extrapolation of the Load-Displacement Curve.......................................................... 24

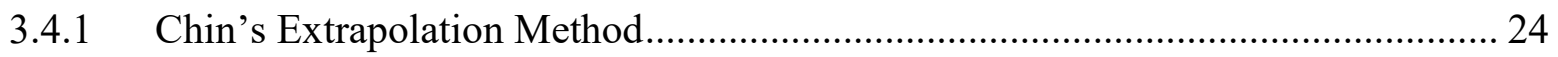

3.4.2 Van Der Veen's Extrapolation Method .......................................................... 25

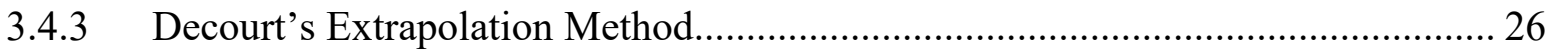

3.5 Combination of Extrapolation and Gradual Failure Methods ……................................ 28

3.6 Interpreted Failure Load from Test Results ……………………………………....... 28

3.7 Statistical Analysis of Failure Methods Applied to Micropiles ...................................... 29

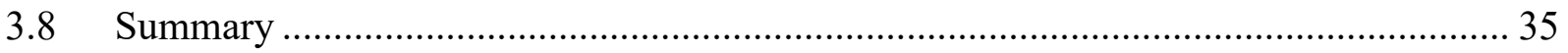

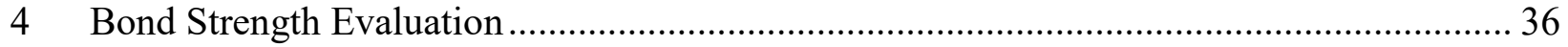

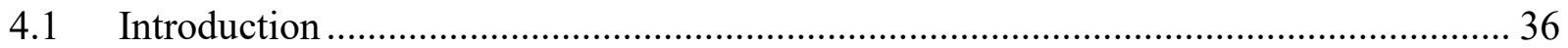

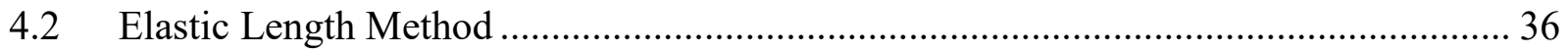

4.2.1 Concept of the Method........................................................................................... 36

4.2.2 Prediction of the Elastic Settlement......................................................................... 37

4.2.3 Modification of the Elastic Length Method.......................................................... 37

4.3 Methodology and Results of Bond Stress Prediction...................................................... 39

4.3.1 Load-Transfer Distribution .............................................................................. 39

4.3.2 Loading Sequence of a Load Test...................................................................... 40

4.3.3 Axial Resistance of the Cased length..................................................................... 43

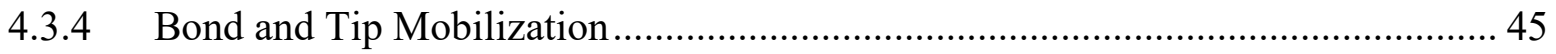

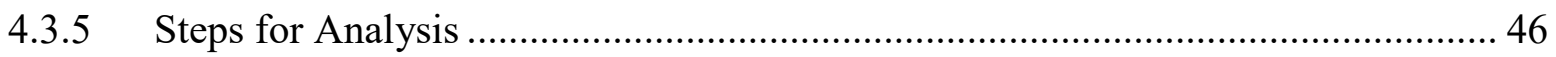

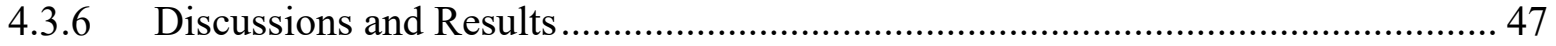

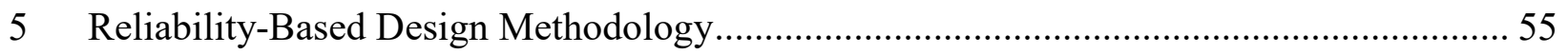

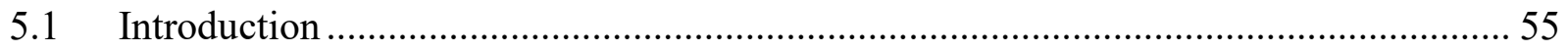

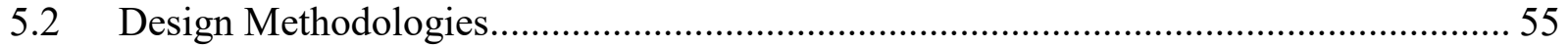




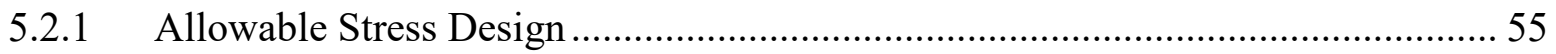

5.2.2 Load and Resistance Factored Design ................................................................. 55

5.3 Limit State Function and Probability of Failure............................................................. 56

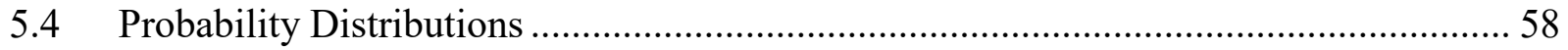

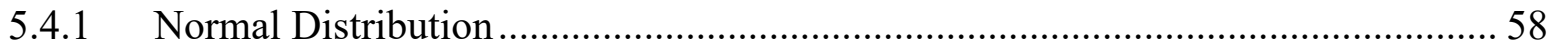

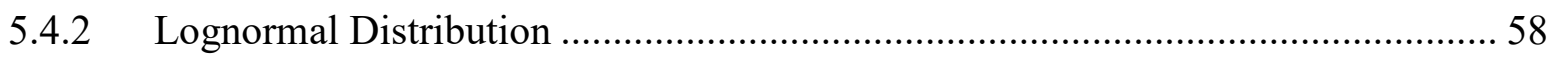

5.4.3 3-Parameter Lognormal Distribution............................................................... 59

5.5 Assessment of the Probability Distribution Function of an Event .................................. 59

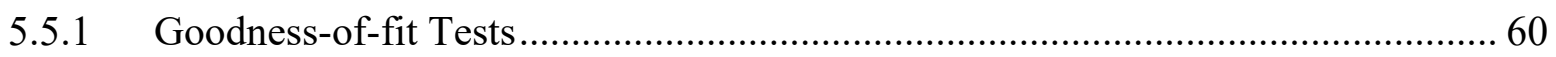

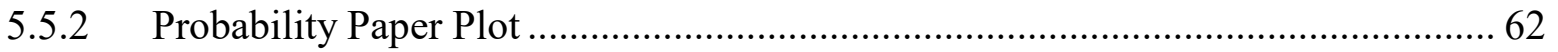

5.5.3 Results of PDF Assessment for the Bias Distribution of the Foundation

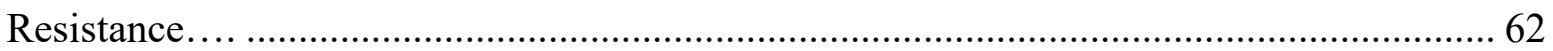

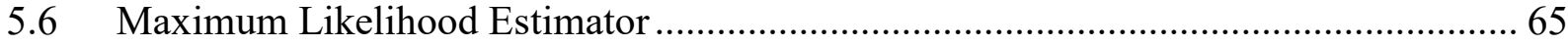

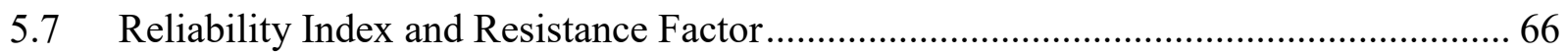

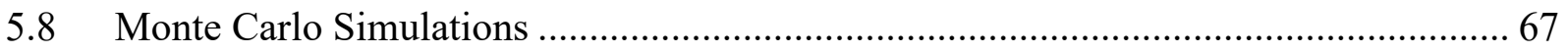

5.9 Codes and Standards Parameters and Requirements....................................................... 69

5.10 Reliability Analysis of Design Methods for Micropiles............................................. 70

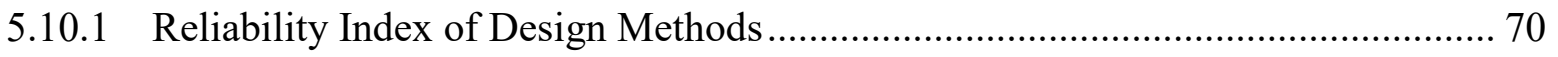

5.10.2 Recalibration of the Resistance Factor ………..................................................... 75

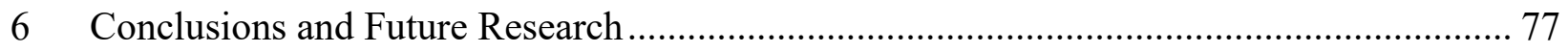

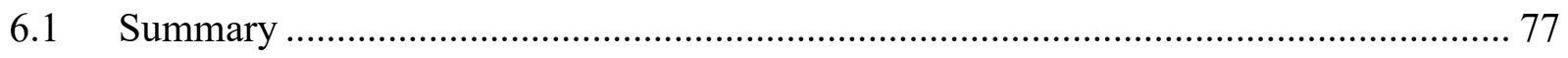

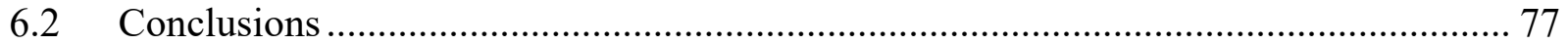

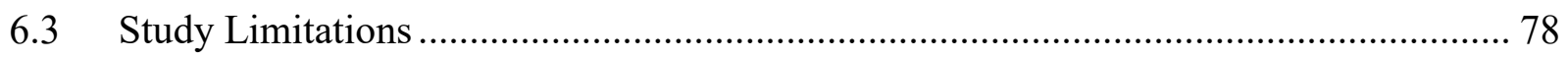

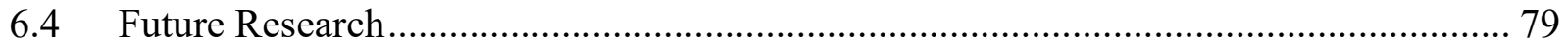

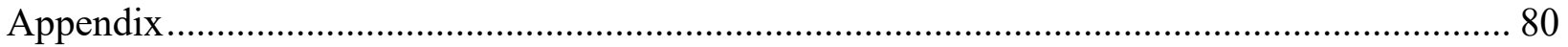

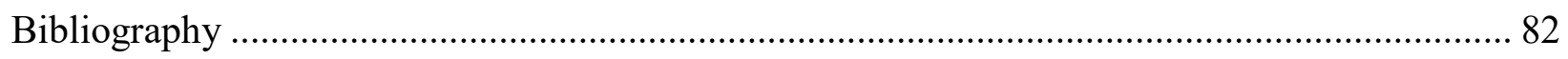




\section{LIST OF TABLES}

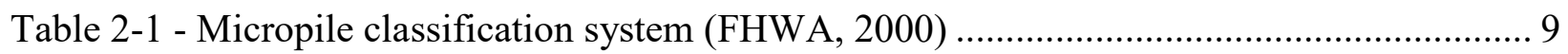

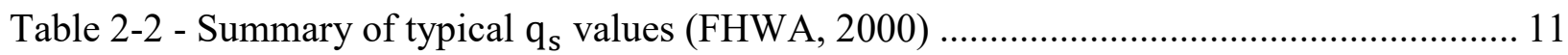

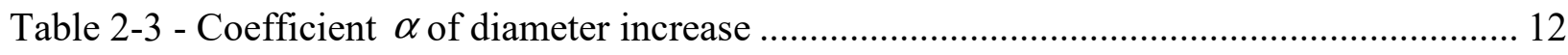

Table 2-4 - Comparison between FHWA and Bustamante and Doix (1985) ............................. 13

Table 3-1 - Summary of soil conditions and micropile geometries for each site ......................... 20

Table 3-2 - Scenarios of all possible methods combination ........................................................ 30

Table 3-3 - Failure load results calculated through extrapolation methods and gradual failure

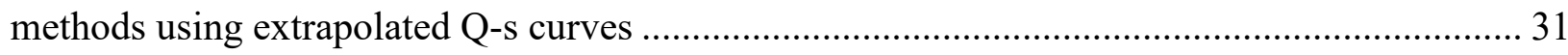

Table 3-4 - Failure load results calculated through gradual failure methods using extrapolated Q-s

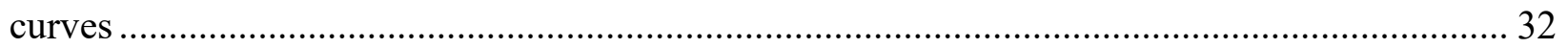

Table 4-1 - Parameters of load mobilization along the micropile depth.................................... 43

Table 4-2 - Comparison between results of Elastic Length method and Decourt's method ........ 49

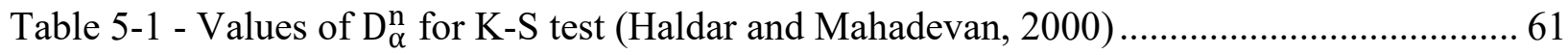

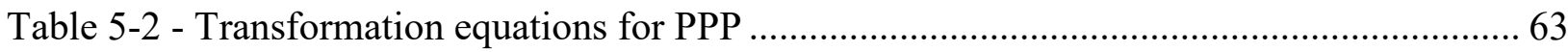

Table 5-3 - P-value for GoF tests and PPP $\mathrm{R}^{2}$ for the considered design methods ....................... 64

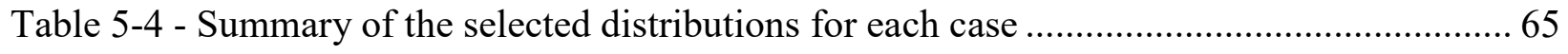

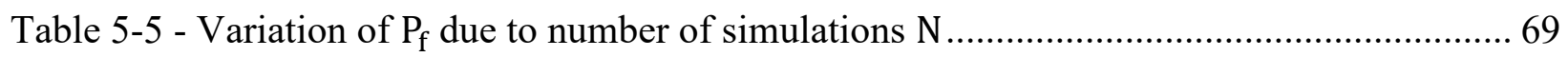

Table 5-6 - Required parameters for reliability analysis according to different codes.................. 69

Table 5-7 - Parameters for modelling the applied loads .......................................................... 70

Table 5-8 - Values of the parameters for each probability distribution ......................................... 71

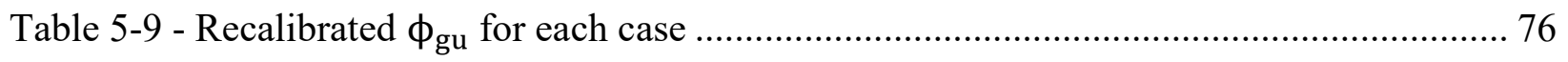

Table 6-1 - Suggested values of $\mathrm{q}_{\mathrm{s}}$ for each micropile type....................................................... 78 


\section{LIST OF FIGURES}

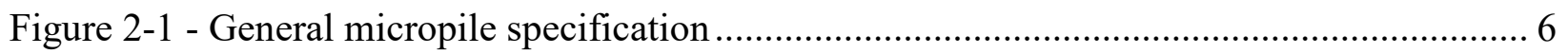

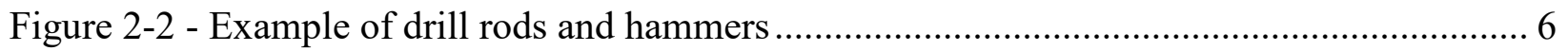

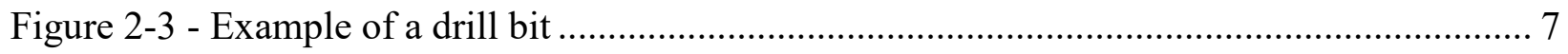

Figure 2-4 - CGF micropile setup (Bruce et al., 2018)........................................................ 8

Figure 2-5 - Correlation between $\mathrm{N}$ value and $\mathrm{q}_{\mathrm{s}}$ for (a) sands and gravels and (b) for silts and

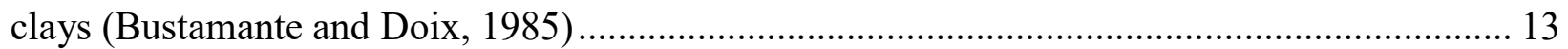

Figure 2-6 - Example of a compression test in a micropile (Gurpersaud, 2018) ......................... 15

Figure 2-7 - Minimum distances in plan from reference and reaction beams to the tested pile... 15

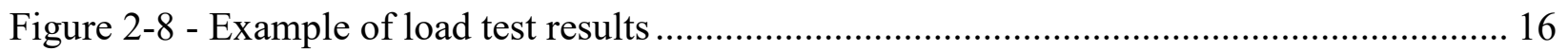

Figure 3-1 - Site Locations in Ontario (Google Earth, 2018) ……........................................... 17

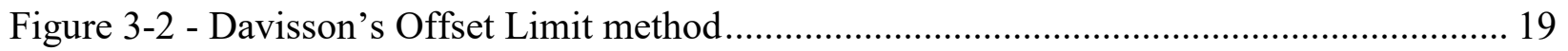

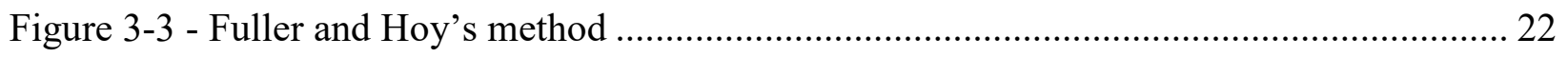

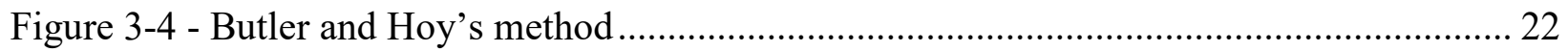

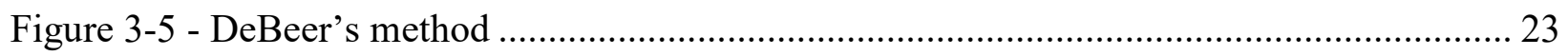

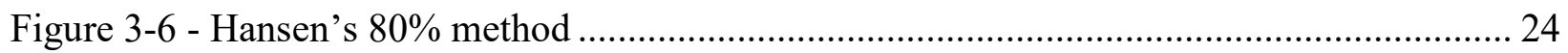

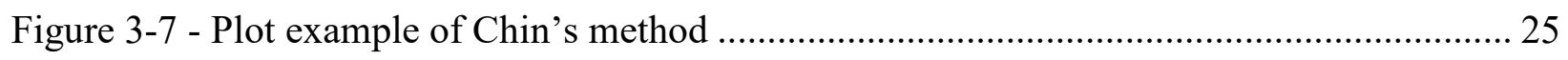

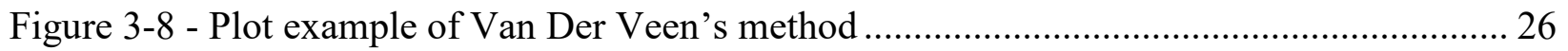

Figure 3-9 - Plot example of Décourt's Extrapolation method.................................................... 27

Figure 3-10 - Logarithmic plot of Décourt's Extrapolation method........................................... 27

Figure 3-11 - Typical load test results: selection and extrapolation of data for further analyses 28

Figure 3-12 - Example of combination between extrapolation and gradual failure methods....... 29

Figure 3-13 - Boxplot of load variability for all studied micropiles ........................................... 35

Figure 4-1 - Values of $\xi$ for load-transfer distributions (A) to (D) after Vesic (1977) .................. 38

Figure 4-2 - Illustration of $\Delta \mathrm{Q}$ and Se interpreted for the $3^{\text {rd }}$ loading cycle .............................. 39

Figure 4-3 - Evolution of stress and load-transfer distributions along the cased length or the bond

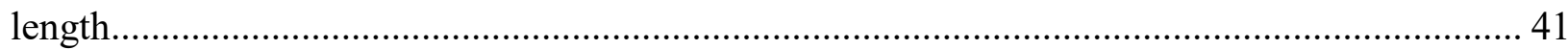

Figure 4-4 - Sequence of load mobilization along the micropile depth..................................... 42

Figure 4-5 - Estimating $\mathrm{R}_{\text {cas,i }}$ range from (a) determining the mobilization line of the cased length

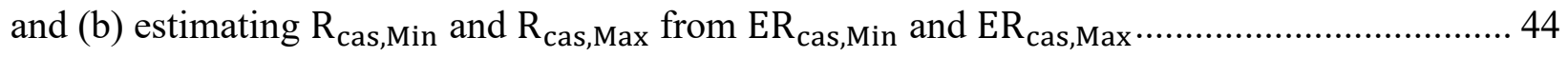

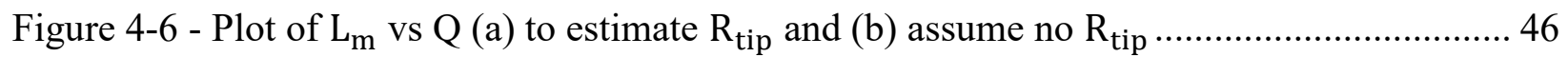

Figure 4-7 - Estimation of $R_{\text {tip,fail }}$ by Decourt's Extrapolation method........................................ 47

Figure 4-8 - Plot between $\mathrm{q}_{\mathrm{s}}$ and $\mathrm{N}$ value for Type A micropiles............................................ 50

Figure 4-9 - Plot between $\mathrm{q}_{\mathrm{s}}$ and $\mathrm{N}$ value for Type B micropiles ............................................... 50

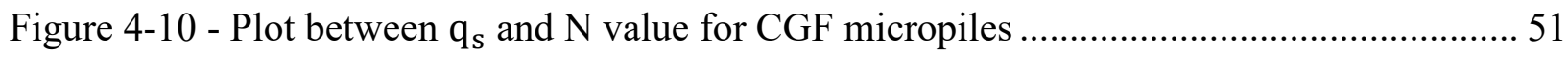

Figure 4-11 - Plot between $\mathrm{q}_{\mathrm{s}}$ and $\mathrm{N}$ value for Type D micropiles........................................... 51

Figure 4-12 - Plot of (a) $\alpha$ vs $L / D_{\text {eq }}$ and (b) $\beta$ vs $L / D_{\text {eq }}$ for Type A micropiles........................... 53

Figure 4-13 - Plot of $\beta$ vs L/D $\mathrm{D}_{\text {eq }}$ for Type B micropiles ......................................................... 53 


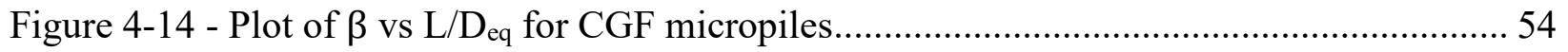

Figure 4-15 - Plot of $\beta$ vs $L / D_{\text {eq }}$ for Type $D$ micropiles ....................................................... 54

Figure 5-1 - (a) PDF and (b) CDF of a 3-Parameter Lognormal distribution............................. 59

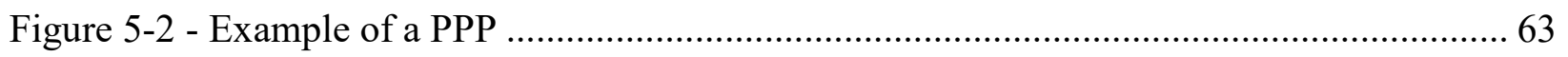

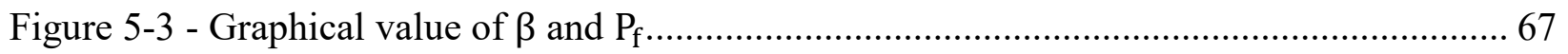

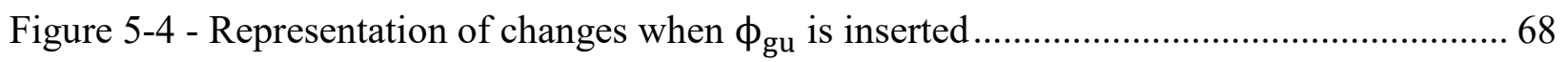

Figure 5-5 - $\beta$ achieved by the FHWA design method according to the AASHTO requirements.

Figure 5-6 - $\beta$ achieved by the FHWA design method according to the CHBDC requirements . 72 Figure 5-7 - $\beta$ achieved by the FHWA design method according to the NBCC requirements .... 72 Figure 5-8 - $\beta$ achieved by the Suggested Parameters according to the AASHTO requirements. 73 Figure 5-9 - $\beta$ achieved by the Suggested Parameters according to the CHBDC requirements .. 73 Figure 5-10 - $\beta$ achieved by the Suggested Parameters according to the NBCC requirements ... 74

Figure 5-11 - $\beta$ achieved by Bustamante and Doix (1985)................................................ 74 


\section{INTRODUCTION}

\subsection{INTRODUCTION}

First introduced by Fernando Lizzi in the 1950s, micropiles have been increasingly applied in several different projects. They are a very good solution for infrastructure repair and seismic retrofit (Cadden et al., 2004). With structures reaching their design life, repairs must be made in order to secure the minimal reliability levels prescribed by codes. Although developments in drilling techniques, equipment capabilities and high-quality materials, their geotechnical design did not follow the same trend. The Federal Highway Administration (FHWA) published a few manuals to assist engineers with both construction techniques and geometries design. Geotechnical parameters, nonetheless, are still highly associated with one's experience and judgement because of many uncertainties are involved in the design and construction of a micropile. Different drilling techniques, presence of casing, pressure application during grouting operations are some of the factors that make micropile different from conventional piles. The main goal of this study is to provide an optimized design of micropiles in Ontario. This can definitely benefit foundation engineers to provide safe and economical solutions with micropiles.

\subsection{Micropile OVERVIEW}

Micropiles were first developed by Fernando Lizzi in the 1950s in the post-war Europe. It has arrived in North America in 1973, but it its wide usage was only seen after mid-1980s (FHWA, 2000). A micropile is a small-diameter pile, usually with a diameter smaller than $300 \mathrm{~mm}$. It is constructed by first drilling a borehole, then placing a central reinforcement, and ultimately grouting the drilled hole with or without pressure- or post-grouting. As a deep foundation element, micropiles can resist both static and seismic loading. Furthermore, they can be used to improve the stability of slopes and excavations via direct or indirect loading according to FHWA (2000).

Micropile is a viable solution to many engineering problems due to its installation process with low energy, use of small drilling equipment for restricted access work, ease of installation in rock and stiff soil, and high axial capacity. Drilling under artesian pressure is also possible with micropiles by balancing the water pressure with the grout specific weight (Bruce et al., 2018).

\subsection{Database of Micropile Load Tests}

Load testing is a regular requirement of projects with micropiles. Because of the high uncertainties involved with this technique, FHWA (2000 and 2005) recommends that every project has to carry out at least one verification test and a few proof tests. The verification test serves to verify the geotechnical capacity of the micropile and is conducted during the design phase. The proof test, 
however, has the purpose of validating the contractor's procedures and techniques. Both of them are conducted in the same manner, but verification tests are usually carried out to higher loads.

A database with 56 micropile projects was obtained from Keller Foundations Ltd. Tests were carried out all across the province of Ontario. The procedures of a load test are basically measuring the settlement generated by an applied load. Results are obtained in form of a load-displacement curve. Failure methods can be applied to the load-displacements curves to obtain the failure load of the micropile. This failure load can be compared with geotechnical in-situ tests to develop better parameters for design of micropiles in Ontario.

\subsection{ObJeCTIVES OF THIS STUdY}

The ultimate goal of this study is to enhance the design methods for micropiles in Ontario under the ultimate limit state in terms of a reliability analysis. In the literature, there are many available methods to analyze the failure of a pile through analysis of a load-displacement curve. Additionally, few of them are able to extrapolate the curve, when the true failure has not been achieved during testing. Extrapolation may bring more uncertainty to the system. Thus, the first goal of this study is to define a suitable failure method which is able to identify the failure of micropile load tests which did not reach a failure state.

Although micropiles are commonly designed considering only the skin frictional resistance along the embedded region (bond length), contributions from the upper region (cased length) and from the tip of the micropile may occur in a load test. Therefore, the second goal of this study is to isolate the bond capacities of the micropiles in the database to generate better parameters for micropile design.

Ultimately, the reliability of micropiles has to be verified according to guidelines prescribed by structural codes. A total of three methods are discussed in this study, namely the FHWA design method, Bustamante and Doix (1985), and the Suggested Parameters in Chapter 4 of this study. Their reliability indices are evaluated by the following codes: American Association of State Highway and Transportation Officials (AASHTO), the Canadian Highway Bridge Design Code (CHBDC), and the National Building Code of Canada (NBCC). Also, recalibrated resistance factors are provided for these three design methods to follow the requirements of the corresponding codes.

\subsection{ResearCH Method}

In order to achieve the above goals, the study was divided into 4 different phases:

1) Data processing

- a database was obtained containing micropile load tests, specifications, Standard Penetration Test (SPT) results, and site reports from Keller Foundation Ltd; 
- sites in the database were selected based on load testing quality and availability of SPT boreholes near the test;

- failure load was established according to several different failure methods; and

- ultimate load was predicted using the FHWA design method and Bustamante and Doix (1985).

2) Statistical analysis of failure methods

- failure load of each considered method were normalized and compared through a statistical analysis; and

- the best method was selected for further analyses.

3) Bond strength analysis

- the capacity of the cased length is predicted using the Elastic Length concept;

- tip mobilization is predicted using Decourt's method and the Elastic Length method; and

- suitable bond stress parameters are provided and compared with parameters from the FHWA design method and Bustamante and Doix (1985).

4) Reliability analysis

- the reliability index achieved by the FHWA design method, Bustamante and Doix (1985), and the Suggested Parameters from the strength analysis were calculated. It was used the requirements by the AASHTO, the CHBDC, and the NBCC; and

- the resistance factor for the 3 mentioned design methods were recalibrated to comply with the requirements of the AASHTO, the CHBDC, and the NBCC.

\subsection{Thesis OUTLINe}

This thesis discusses the micropile singularities, procedures for micropile load tests, and several aspects on the axial capacity of a micropile pile. The current design methods and identification of failure load in a load-displacement curve were explained. Statistical, strength, and reliability analyses were applied to evaluate current design methods and to also generate better parameters for design.

Chapter 1 introduces the background, research objectives, and methods applied in this research.

Chapter 2 contains an overview of micropile and load test procedures. Current micropile design methods for the ultimate capacity are discussed in detail, and procedures and specifications of micropile load tests are examined.

Chapter 3 presents the characteristics of the database, discusses several methods to determine the failure load, explore the combination of gradual failure methods with extrapolation methods, and statistically analyzes the best method to identify failure in a load-displacement curve of a micropile. 
Chapter 4 provides the concepts behind the Elastic Length method. The methodology and results of the strength analysis are also discussed. Better design parameters are suggested.

Chapter 5 includes a reliability analysis of the design methods. The reliability index achieved by the design codes are provided and a recalibration of the resistance factor for each design method is conducted.

Chapter 6 summarizes the final discussions and conclusions of the investigation. The best design parameters are proposed to determine the axial capacity, and recommendations for future research. In addition, the limitations of this study are discussed. 


\section{LITERATURE REVIEW OF MICROPILE}

\subsection{General Micropile Specifications}

\subsubsection{Traditional Micropiles}

The length of a micropile is usually divided into two different regions: the cased length and the bond length. The former is usually situated in a weak soil zone. The casing provides buckling resistance and grout confinement. The latter is located in the bearing strata. Due to high values of shear resistance generated along the soil-micropile interface, micropile is considered to be a highcapacity pile. In addition, a diameter expansion can occur in the cased length due to grout returning to surface through an annulus, and in the bond length, because of pressure application.

The geotechnical capacity of a micropile is governed by the grout-to-ground adhesion within the bond zone. The cased length is the part of the micropile responsible for transferring the load from the pile cap to the bond length. The load transfer occurs primarily by friction along the bond length and tip contribution is usually neglected due to the small area of the tip (FHWA, 2000).

Figure 2-1 illustrates the main features of a micropile. The central rebar reinforcement and the casing, located in the cased length, contribute for stress and buckling resistance. Still in the cased length, two grout regions are identified: the one confined by the casing and the other situated in the annulus. This latter may or may not exist. If it does, it is generated by the grout return from the bottom of the micropile to the surface during grouting operations. Along the bond length, however, it is only found the presence of the central reinforcement (extended from the cased length) and the grout body.

Although steel reinforced, bored piles are usually structurally designed so that the compressive load is fully resisted by the concrete portion. Micropile design, nonetheless, considers the contribution of the high-capacity steel to resist most of the applied load (FHWA, 2000).

Micropiles greatly differ from bored piles and shafts because of drilling and grouting techniques employed in a micropile installation along with different structural specification (grout and highcapacity steel). Drilling occurs with a drill bit attached to drill rods with or without temporary casing for soil stability. Debris are transported by pressurized fluid, such as mud, water, or air to the surface. The central reinforcement is placed as a full piece by crane, and then the grout operations occurs. It is important to notice that there are different types of drill bits for different types of soils or rocks. Additional procedures are pressure- or post-grouting. Figures 2-2 and 2-3 exemplifies drill rods, hammers, and a drill bit. 


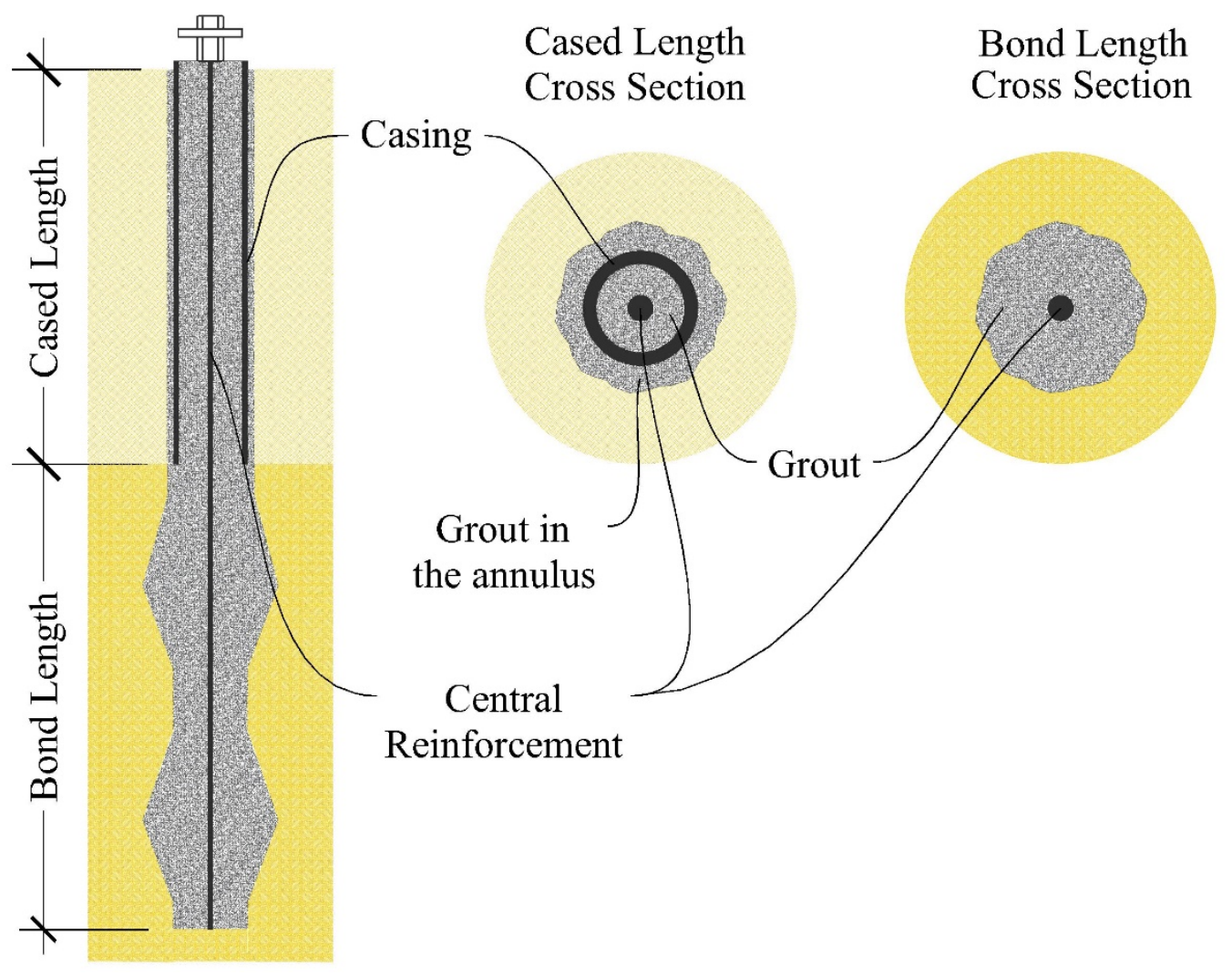

Figure 2-1 - General micropile specification

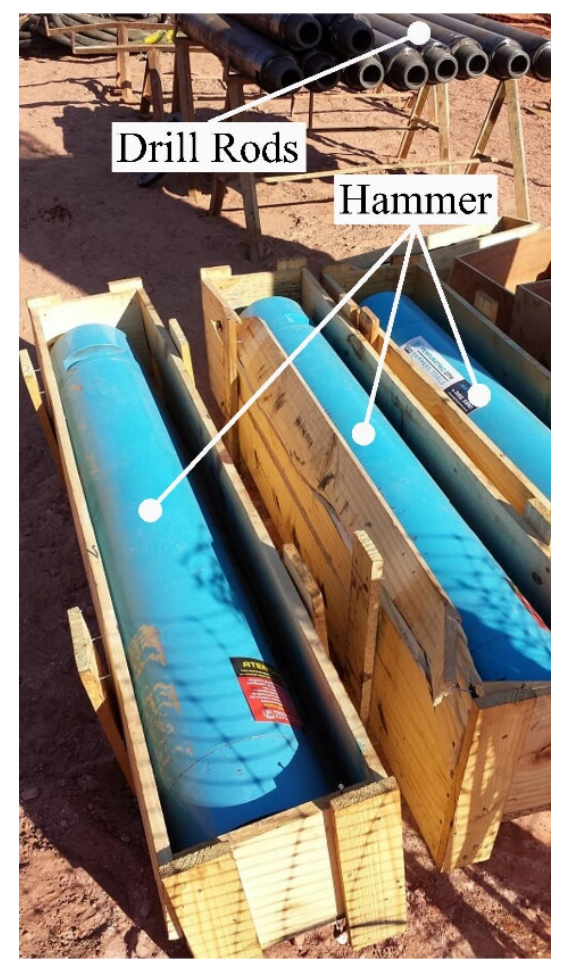

Figure 2-2 - Example of drill rods and hammers 


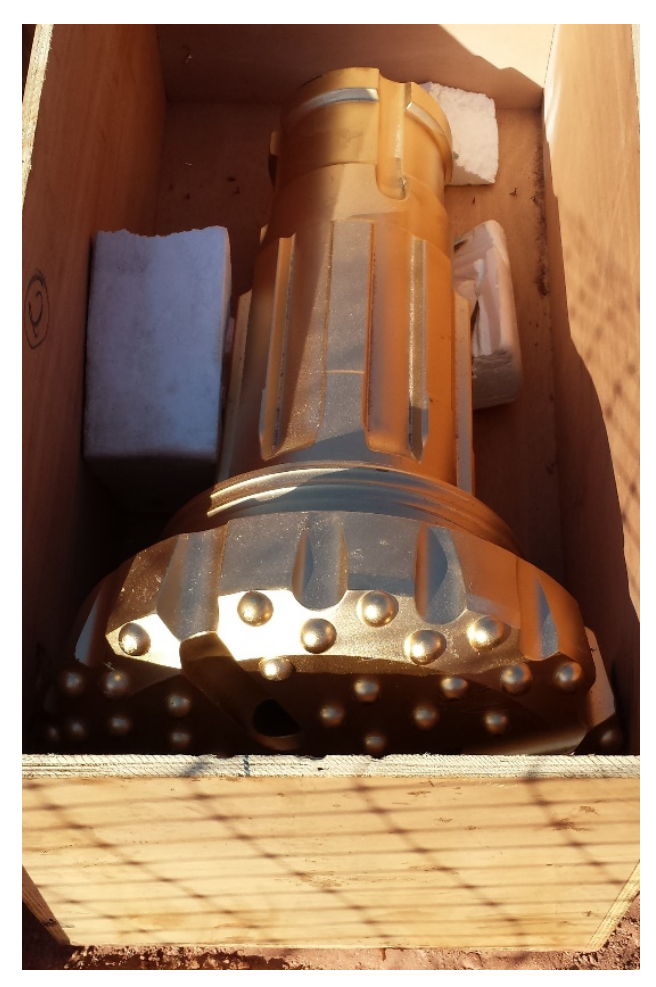

Figure 2-3 - Example of a drill bit

Furthermore, Bustamante and Doix (1985) explains that the final micropile diameter should be higher than the drill bit diameter, since, in pressure- and post-grouted micropiles, the grout is pressurized, generating a higher bonding between the pile and the soil, and a diameter expansion.

\subsubsection{Continuous Grout-Flush Micropiles}

Bruce and Gurpersaud (2009) defines the continuous grout-flush method (CGF) as grouting operations in parallel with borehole drilling advancement and also central reinforcement placement. Then, the annulus is constantly stabled, due to being always filled. The drill bit is sacrificially left in place, and the drill rods are the central steel reinforcement bars. Hence, once the micropile depth is achieved and the drilling grout is replaced by the structural one, the micropile installation is completed. Debris are removed through the grout circulation within the borehole. Figure 2-4 demonstrates its configuration.

Although the FHWA does not include CGF micropiles in their guidelines, the AASHTO included this type of micropile in their design guidelines as the Type E micropile (AASHTO, 2012). It is also sometime called by the industry as self-boring or hollow-bar micropile. 


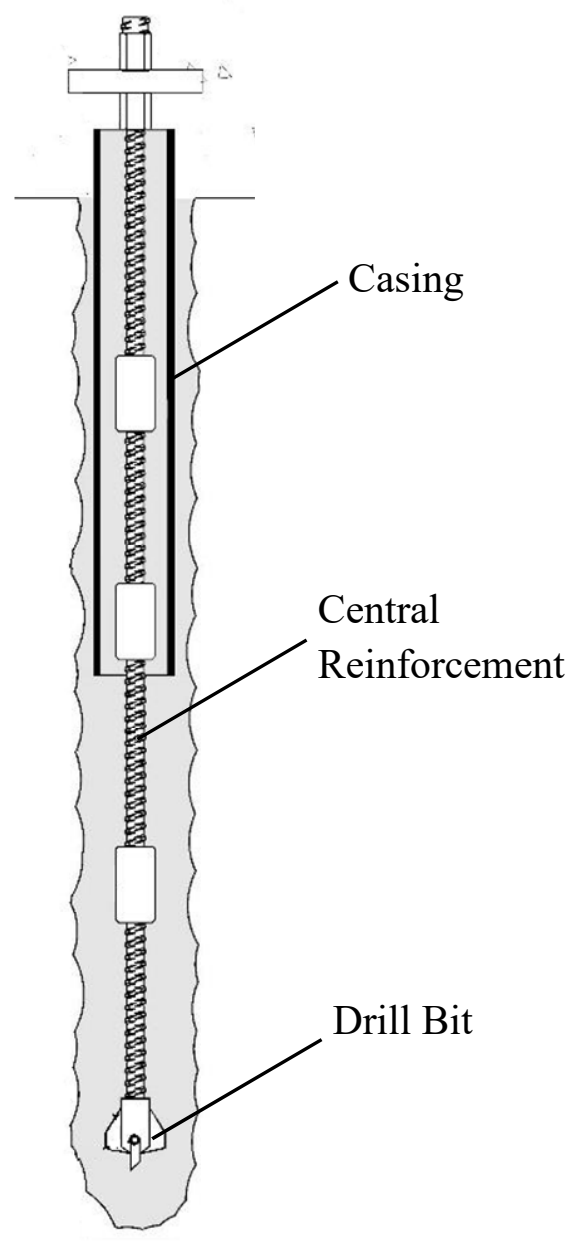

Figure 2-4 - CGF micropile setup (Bruce et al., 2018)

This method has been increasingly applied due to its faster installation process. Also, it has been successfully applied to overcome the artesian pressure when drilling under this circumstance (Bruce et al., 2018).

\subsection{GEOTECHNICAL INVESTIGATION}

Geotechnical investigation phase is the first stage of every geotechnical design. Lab and in-situ tests provide information to understand the subsurface condition in terms of soil type, strength parameters, presence of water and/or contaminants, and many other aspects. Standard Penetration Test (SPT), Cone Penetration Test (CPT), Vane Shear Test (VST), Dilatometer Test (DMT), and Pressuremeter Test (PMT) are some examples of in-situ tests. This research focuses solely on the SPT because it is the only test available for the geotechnical investigation of the sites present in the database. 
The SPT consists of inserting a sampler into the soil by hammer blows to the top of the drill rod. The hammer weight is $622.72 \mathrm{~N}$, and the dropping height is $0.762 \mathrm{~m}$ for each blow. It is recorded the number of blows required to advance three intervals of $152.4 \mathrm{~mm}$ of the spoon sampler. The sum of the last two intervals gives the standard penetration number ( $\mathrm{N}$ value). The sampler is withdrawn from the borehole and a soil sample is recovered to characterize the soil (Das, 2016). The SPT thus provides two main soil properties: soil type and soil resistance (empirically measured by $\mathrm{N}$ value). Also, the groundwater table (GWT) is measured in the same borehole.

\subsection{DESIGN METHODS FOR MiCROPILES}

This section discusses three current design methods for micropiles in the ultimate limit state (ULS): the FHWA design method, Bustamante and Doix (1985), and the $\alpha$ and $\beta$ methods for side resistance. The first two methods are exclusive for micropiles and they also classify micropiles in distinct categories.

\subsubsection{Federal Highway Administration}

Because of the great increase of micropiles usage in North America during the mid-1980s, and vast application in transportation structures, the FHWA developed a micropile manual to facilitate and speed the implementation of micropiles in the United States of America (FHWA, 2000).

This manual classifies micropiles in 4 categories associated with different grouting methods. Table 2-1 summarizes the main classification system.

Table 2-1 - Micropile classification system (FHWA, 2000)

\begin{tabular}{|c|c|c|}
\hline Case Type & Construction Type & Description \\
\cline { 2 - 3 } & A & Grout placed under gravity head only (not pressurized) \\
\cline { 2 - 3 } Case 1 & B & $\begin{array}{c}\text { Grout placed under pressure as temporary casing is } \\
\text { withdrawn }\end{array}$ \\
\cline { 2 - 3 } & D & $\begin{array}{c}\text { Grout is placed under gravity head and prior to hardening } \\
\text { of the primary grout, another grout injection is made }\end{array}$ \\
\hline Case 2 & N/A & $\begin{array}{c}\text { Grout is placed under gravity head and after hardening of } \\
\text { the primary grout, another grout injection is made. Also } \\
\text { allows the use of a packer so that specific horizons can be } \\
\text { treated }\end{array}$ \\
\hline
\end{tabular}

Case 2 micropiles are those responsible for strengthening the soil mass globally. This type is not discussed in the FHWA manual, and thus not considered herein. Case 1 micropiles are those designed to act individually. They may be installed in groups though (FHWA, 2000). 
Micropiles types C and D are referred as Injection Globale et Unitaire (IGU) and Injection Répétitive et Sélective (IRS) according to Bustamante and Doix (1985) (see item 2.3.2). Type C is normally used only in France and were not found in the database of this study.

The manual also mentions sub-types of micropiles and drilling methods, but they are only pertained to micropile installation and do not influence the micropile design. Thus, they are not discussed in this study.

CGF micropile load tests were carried out as part of the French National Research Project (FOREVER) (Ischebeck, 2010). Ischebeck (2010) showed that this type of micropile fulfills the requirements of the type IRS in terms of bond stress values. Because of the high relationship between the enlarged grout body diameter and the drill bit diameter, high skin friction values are generated with this method. It was also suggested to use Bustamante and Doix (1985) as design method for this type of micropile.

CGF micropile does not properly follow one of the 4 micropile types described in Table 2-1. It is then commonly assumed CGF parameters to be equal to parameters for the Type B micropile. However, Gómez et al. (2008), Abdlrahem and El Naggar (2016), and Abd Elaziz and El Naggar (2014) found that type B assumption underestimates the CGF micropile ultimate capacity. Since CGF micropiles have similar capacity as IRS micropiles. This study considers CGF micropile to be calculated with the same parameters for Type D and IRS micropiles.

Equation 2-1 computes the ultimate geotechnical axial capacity of a micropile, $R_{u l t}$, where $D_{b}$ is the final diameter of the bond length, and $L_{b}$ is the bond length. Table 2-2 provides values of the grout-to-ground ultimate bond stress, $q_{s}$, for each micropile type. These values have a wide range to choose from. This shows how dependent this type o pile is on one's experience when selecting suitable values of $q_{s}$ for design.

$$
R_{u l t}=q_{s} \pi D_{b} L_{b}
$$

\subsubsection{Bustamante and Doix (1985)}

Bustamante and Doix (1985) correlates the $\mathrm{N}$ value of a soil with its $q_{s}$. This value also depends on the grout method and soil type. They divided micropile into two categories of grout method: Injection Globale et Unitaire (IGU) and Injection Répétitive et Sélective (IRS). The main difference between them is the manner in which the grout is pressurized. In the former alternative, the pressure is applied globally through a sleeved grout pipe, therefore the bond zone is not isolated from the cased length during this operation. During the installation of the latter one, however, the pressure may be applied locally through the use of a packer. Also, the pressure application can be repeated in IRS micropiles. 
Table 2-2 - Summary of typical $q_{s}$ values (FHWA, 2000)

\begin{tabular}{|c|c|c|c|c|}
\hline \multirow{2}{*}{ Soil Description } & \multicolumn{4}{|c|}{ Grout-to-Ground Bond Ultimate } \\
\cline { 2 - 5 } & Type A & Type B & Type C & Type D \\
\hline Silt \& Clay - some sand (soft, medium plastic) & $35-70$ & $35-95$ & $50-120$ & $50-145$ \\
\hline Silt \& Clay - some sand (stiff, dense to very dense) & $50-120$ & $70-190$ & $95-190$ & $95-190$ \\
\hline Sand - some silt (fine, loose-medium dense) & $70-145$ & $70-190$ & $95-190$ & $95-240$ \\
\hline $\begin{array}{c}\text { Sand - some silt, gravel (fine-coarse, medium-very } \\
\text { dense) }\end{array}$ & $95-215$ & $120-360$ & $145-360$ & $145-385$ \\
\hline Gravel - some sand (medium-very dense) & $95-265$ & $120-360$ & $145-360$ & $145-385$ \\
\hline $\begin{array}{c}\text { Glacial Till - silt, sand, gravel (med.-very dense, } \\
\text { cemented) }\end{array}$ & $95-190$ & $95-310$ & $120-310$ & $120-335$ \\
\hline
\end{tabular}

Equation 2-2 calculates $R_{u l t}$ according to Bustamante and Doix (1985), where $D$ is the diameter of the drill bit and $\alpha$ is a coefficient to consider the diameter expansion during micropile grouting. Table 2.3 provides values for $\alpha$ according to each method (IRS or IGU). It is worth noticing that the conditions imposed by the fourth column in this table must be satisfied to take this diameter increase into account. Figure 2-5 illustrates the charts used to determine $q_{s}$ based on the $\mathrm{N}$ value of sands, gravels, clays, and silts.

$$
R_{u l t}=\alpha q_{s} \pi D L_{b}
$$

\subsubsection{Comparison between These Two Methods}

It is clear that both methods are similar to some extent. Table 2-4 summarizes the equivalency between these two methods. It can also be noted that both methods do not consider contributions from neither the cased length nor the micropile tip.

\subsection{4 $\alpha$ and $\beta$ Methods for Side Resistance}

The $\alpha$ and $\beta$ methods have been traditionally applied to large-diameter drilled shafts and driven piles. It is also one of the methods indicated by the Canadian Foundation Engineering Manual (CFEM) (Canadian Geotechnical Society (CGS), 2006) for deep foundations. Jeon and Kulhawy (2001) suggested to apply these methods for micropiles. They evaluated 21 micropiles. 13 of them 
were embedded in sands and the other 8 in clays. These micropiles were installed without cased length. Equation 2-3 shows the expression for the computation of the side resistance, $Q_{s}$, according to the $\alpha$ method (applicable to clays) and Equation 2-4 for the $\beta$ method (applicable to sands).

$$
\begin{aligned}
& Q_{s}(\alpha)=\pi D \alpha \int_{0}^{D} s_{u}(z) d z \\
& Q_{s}(\beta)=\pi D \int_{0}^{D} \beta \sigma_{a v}(z) d z
\end{aligned}
$$

Eq. 2-4

where $s_{u}(z)$ is the undrained shear strength, $\sigma_{a v}(z)$ is the average effective stress, $\alpha$ and $\beta$ are empirical factors related to the adhesion along the interface grout-soil and to the construction method. It was reported an increase in $\alpha$ values ranging from 1.5 to 2.5 and $\beta$ from 1.5 to 6.0 for micropiles when compared to drilled shaft (Jeon and Kulhawy, 2001). Additionally, they did not found any influence of the micropile type (between Types $\mathrm{B}, \mathrm{C}$, and $\mathrm{D}$ ) on $\alpha$ or $\beta$. Type A and CGF micropiles were not considered in their study. Similarly to the previous methods, $Q_{s}$ is assumed to be equal to $R_{u l t}$ for micropiles.

\begin{tabular}{|c|c|c|c|}
\hline \multirow{2}{*}{ Soil } & \multicolumn{2}{|c|}{ Coefficient $\alpha$} & \multirow{2}{*}{ Minimal quantity of grout } \\
\hline & IRS & IGU & \\
\hline Gravel & 1.8 & 1.3 to 1.4 & $1.5 \mathrm{x}$ Volume of Bond Length \\
\hline Sandy Gravel & 1.6 to 1.8 & 1.2 to 1.4 & $1.5 \mathrm{x}$ Volume of Bond Length \\
\hline Gravelly Sand & 1.5 to 1.6 & 1.2 to 1.3 & $1.5 \mathrm{x}$ Volume of Bond Length \\
\hline Coarse Sand & 1.4 to 1.5 & 1.1 to 1.2 & $1.5 \mathrm{x}$ Volume of Bond Length \\
\hline Medium Sand & 1.4 to 1.5 & 1.1 to 1.2 & $1.5 \mathrm{x}$ Volume of Bond Length \\
\hline Fine Sand & 1.4 to 1.5 & 1.1 to 1.2 & $1.5 \mathrm{x}$ Volume of Bond Length \\
\hline \multirow{2}{*}{ Silty Sand } & \multirow{2}{*}{1.4 to 1.5} & \multirow{2}{*}{1.1 to 1.2} & (1.5 to 2.0 ) $\times$ Volume of Bond Length for IRS \\
\hline & & & $1.5 \mathrm{x}$ Volume of Bond Length for IGU \\
\hline \multirow{2}{*}{ Silt } & \multirow{2}{*}{1.4 to 1.6} & \multirow{2}{*}{1.1 to 1.2} & $2.0 \mathrm{x}$ Volume of Bond Length for IRS \\
\hline & & & $1.5 \times$ Volume of Bond Length for IGU \\
\hline \multirow{2}{*}{ Clay } & \multirow{2}{*}{1.8 to 2.0} & \multirow{2}{*}{1.2} & (2.5 to 3.0) x Volume of Bond Length for IRS \\
\hline & & & (1.5 to 2.0$) \times$ Volume of Bond Length for IGU \\
\hline
\end{tabular}

Table 2-3 - Coefficient $\alpha$ of diameter increase 
Table 2-4 - Comparison between FHWA and Bustamante and Doix (1985)

\begin{tabular}{|c|c|}
\hline FHWA Type & Bustamante and Doix (1985) \\
\hline Type A & - \\
\hline Type B & - \\
\hline Type C & IGU \\
\hline Type D & IRS \\
\hline
\end{tabular}

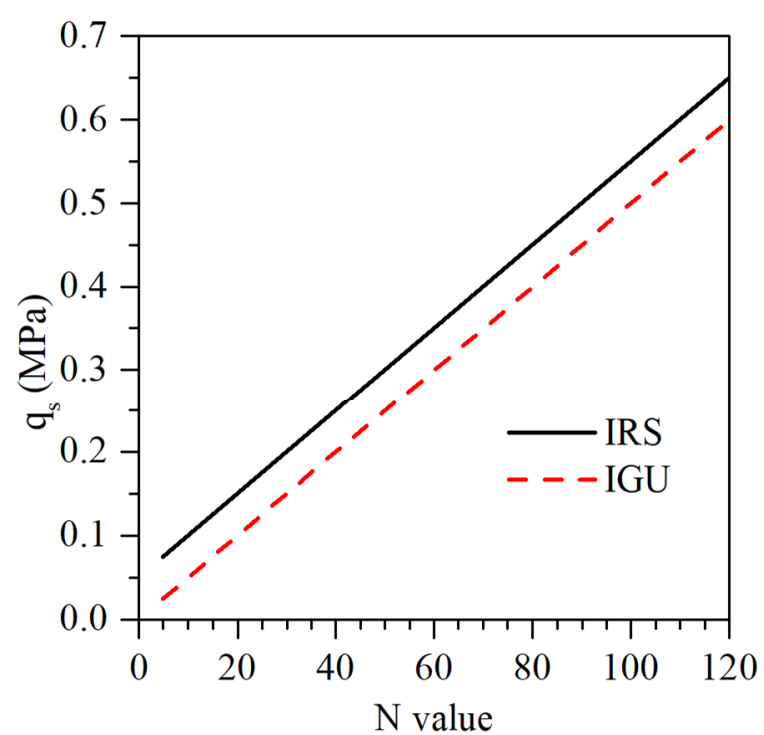

(a)

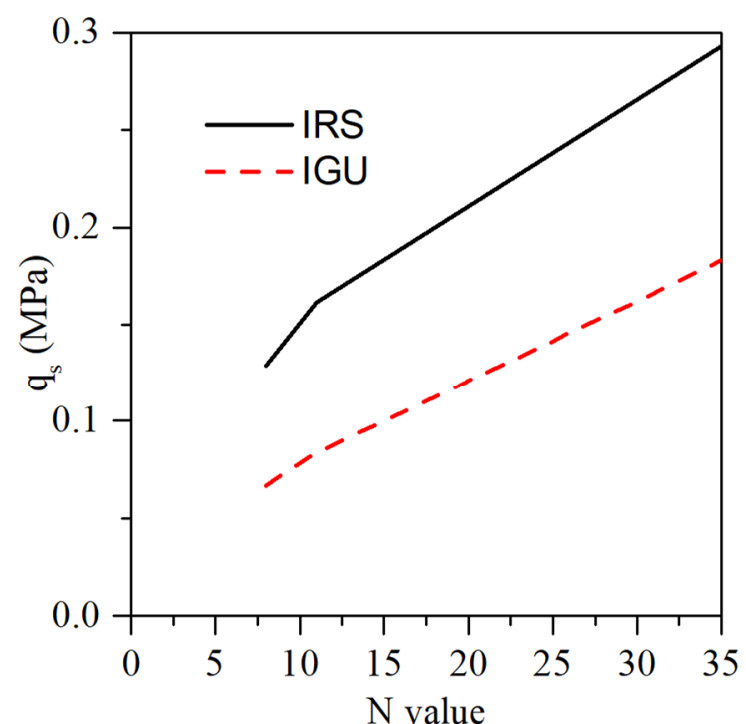

(b)

Figure 2-5 - Correlation between $\mathrm{N}$ value and $q_{s}$ for (a) sands and gravels and (b) for silts and clays (Bustamante and Doix, 1985)

\subsection{MicRopile LOAD TEST}

A pile load test is conducted by recording the displacement which is generated in a pile when subjected to incremental loading. The test type has its core on the quick test described by the ASTM D1143 and D3689 (ASTM, 2013a and 2013b). However, some modifications are suggested specifically for micropiles, such as different time intervals of load application and addition of creep testing. Procedures for micropiles are not standardized yet, so each project should follow its own specifications (FHWA, 2000).

According to FHWA (2005), the usual procedure is to apply incremental loads in cycles (loading and unloading phases). The first load increment is called Alignment Load (AL), which is equal to 5 to $10 \%$ of the Design Load (DL). The settlement generated by this load is not considered in the results since its purpose is solely to align the loading system. The following load increments should be equal to $15 \%$ DL with a holding time of at least 2.5 minutes. The creep test should be at least 
10 minutes long. However, this value can be higher dependent on the creep criterion. It is worth noticing that this study does not discuss creep behavior, nor structural failure.

Figure 2-6 illustrates a compression test setup. Its main components are: a reaction system, made of cribbing for tension tests, or reaction piles connected to a reaction beam for either compression or tension tests; the main beam to transfer loading from the reaction system to the tested pile; the measurement system made of a load cell and dial gauges connected to a reference beam; and the loading system which contains the hydraulic jack connected to a hydraulic pump.

Figure 2-7 depicts the minimum distance requirements from the reference and reaction beams to the tested piles (ASTM, 2013a and 2013b). These requirements are necessary to avoid induced settlement in both tested pile and supports of the reference beam.

The main purpose of this type of test is to verify whether the foundation element can safely sustain the design load without failing after a certain factor of safety is applied. According to FHWA (2000), "Failure is the inability to maintain constant test load without excessive displacement. Excessive movement is often taken as the slope of the load-displacement curve exceeding $0.15 \mathrm{~mm} / \mathrm{kN}$." Although the FHWA does not mention it in its manual, this concept of failure was defined by Fuller and Hoy (1970). This failure method is discussed deeper in the item 3.3.2.

Commonly, two types of load tests are conducted: verification testing and proof testing. The former has the purpose of validating the load carrying capacity and grout-to-ground bond values adopted in design. The latter serves to validate the contractor installation methods. The acceptability criteria for the verification load test is achieving with a factor of safety equal to at least 2.5 prior to failure (which regularly is adopted as 2.0 instead of 2.5), and for proof test it should be greater or equal to 1.67 (FHWA, 2000).

Figure 2-8 exemplifies a test result from a micropile load test. It has a total of 7 loading cycles in this test with a Maximum Test Load (MTL) of 200\% DL. The alignment load is also illustrated. 


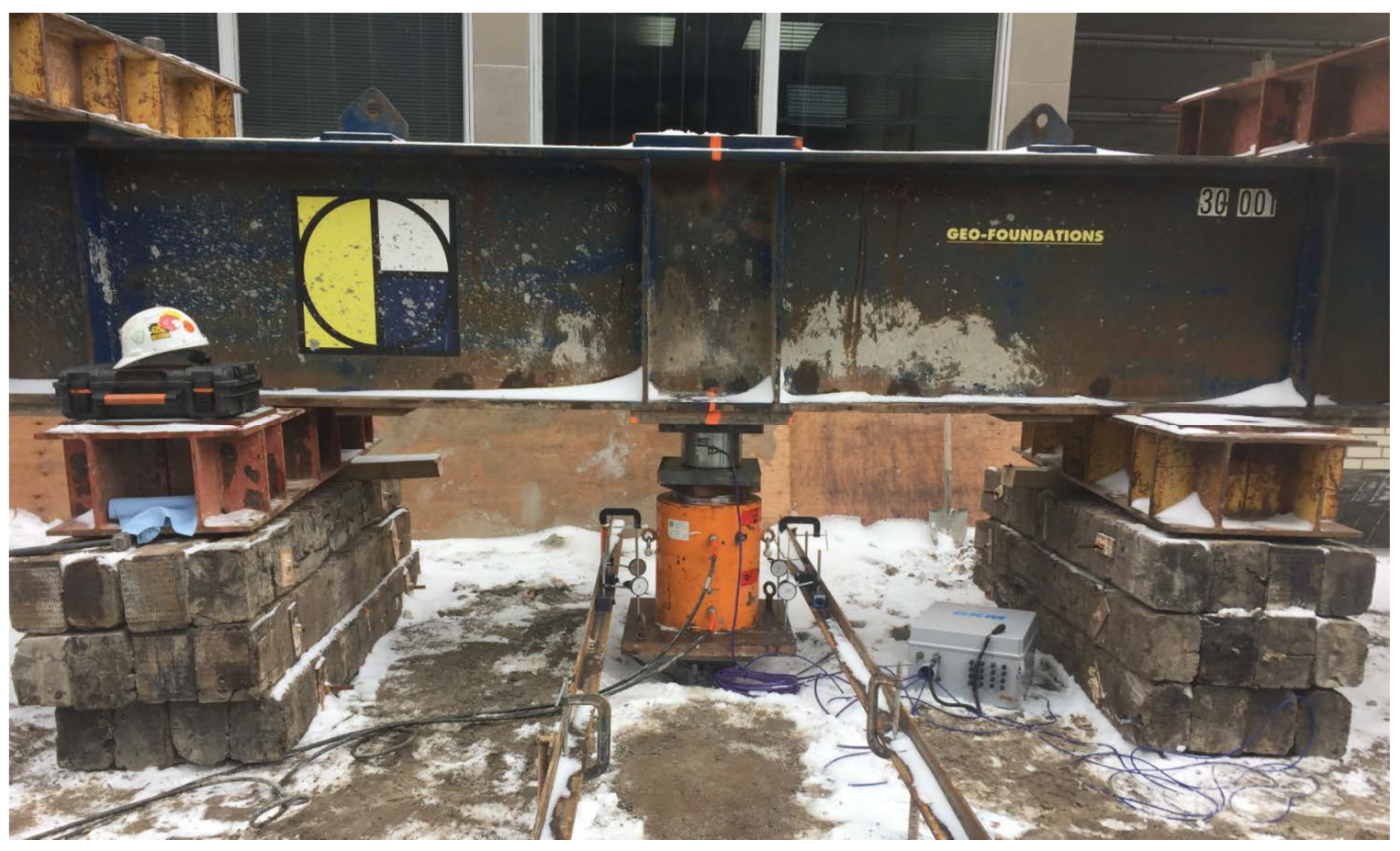

Figure 2-6 - Example of a compression test in a micropile (Gurpersaud, 2018)

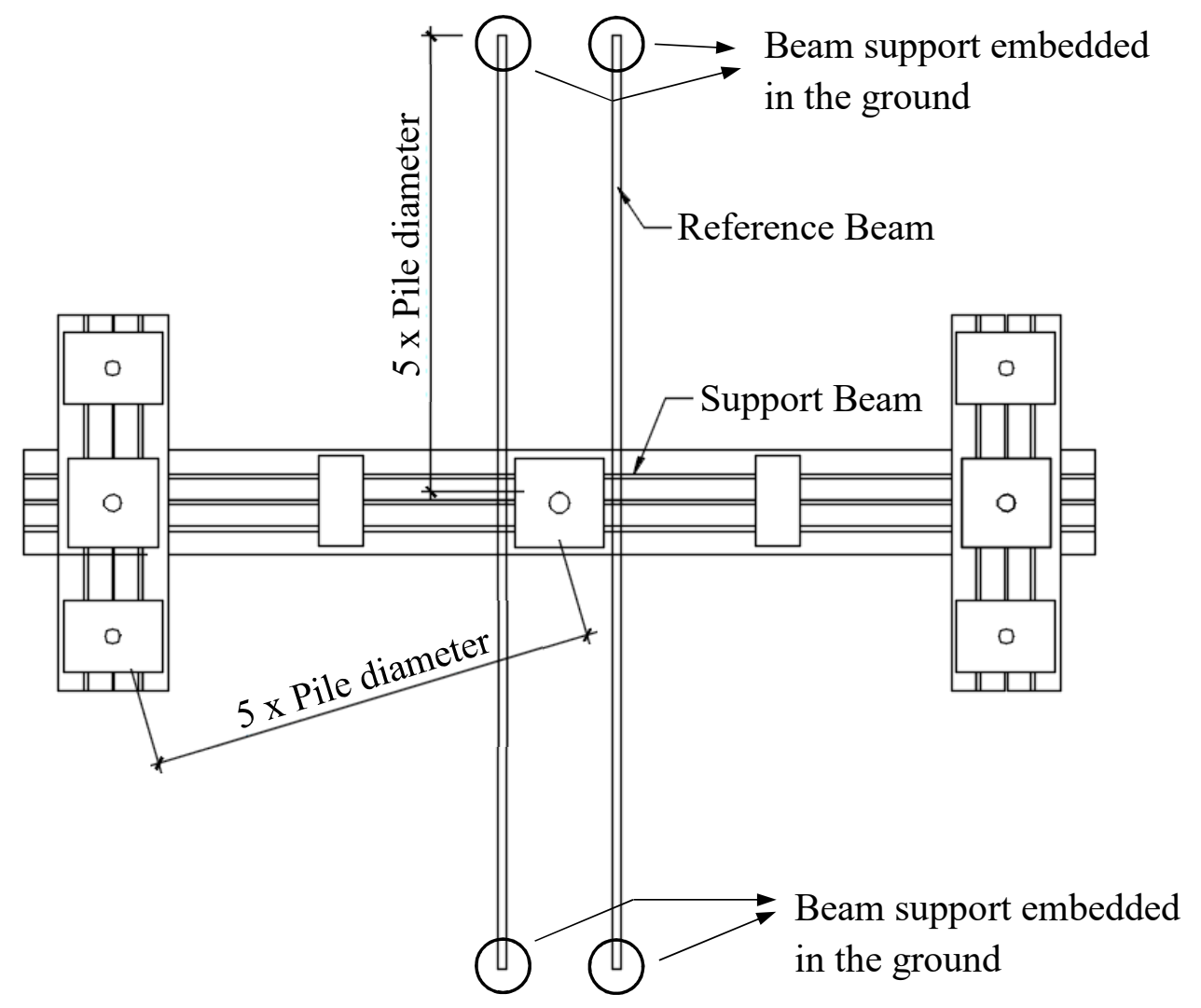

Figure 2-7 - Minimum distances in plan from reference and reaction beams to the tested pile 


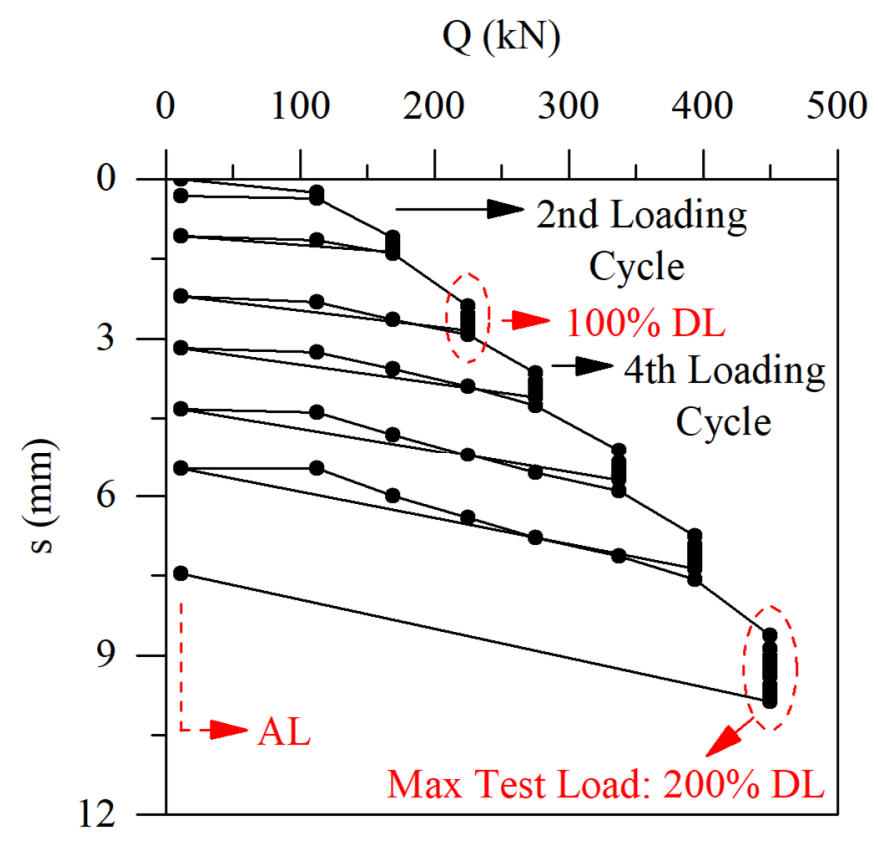

Figure 2-8 - Example of load test results

\subsection{SUMMARY}

Micropiles have different structural concepts when compared to drilled shafts, driven piles, or bored piles. The cased length with a higher stiffness than the rest of the micropile length and characteristics of the grouting operations make this a unique technique. The FHWA provides a very simple manner to estimate the ultimate capacity of a micropile in the ULS. However, there is a wide range of possible values that designers can adopt during calculation. Thus, this technique is highly dependent on judgement and experience. Bustamante and Doix (1985) brought an important correlation with $\mathrm{N}$ value to estimate the bond stress of a micropile. Nonetheless, it was calibrated for French procedures and might not necessarily be the same for Ontario soils. In addition, this method is only applicable to Type C (not common in North America) and Type D micropiles. The $\alpha$ and $\beta$ methods are widely used for other types of piles, but there is a lack of parameters for micropiles. This method can also be used in micropiles with suitable parameters. Important information of the micropile behaviour can be extracted from load tests. Hence, parameters for prediction of the ultimate capacity can be improved through analysis of load test results. 


\section{STATISTICAL ANALYSIS OF METHODS FOR MICROPILE FAILURE IDENTIFICATION}

\subsection{INTRODUCTION}

This research had access to a database of 56 micropile projects provided by Keller Foundation Ltd, operating at the time of load testing as Geo-Foundation Contractors. The database for analysis only considered projects with a reasonable quality of testing (free of pump problems or vibrations nearby) and with availability of SPT in the vicinity of the load test. Thus, 40 load tests were selected for analysis, which were formed of 14 tremie-grouted micropiles (Type A), 6 pressuregrouted micropiles (Type B), 8 continuous grout-flush micropiles (CGF), and 12 post-grouted micropiles (Type D).

In order to analyze the micropiles in the ULS, a suitable method to identify the failure load of micropiles needs to be established. Analyzing the results of pile load tests can be done by many different methods available in the literature. Generally, the results provided by them vary significantly. Hence, to avoid the use of a preferred method based only on subjectivity, a statistical analysis is conducted in this chapter to compare these different methods in analyzing micropile load tests and identify the best method to be used for the subsequent analyses.

\subsection{Database of Micropile LoAd Tests}

\subsubsection{Site Locations}

Figure 3-1 shows the location of the 13 sites in Ontario considered for this study.

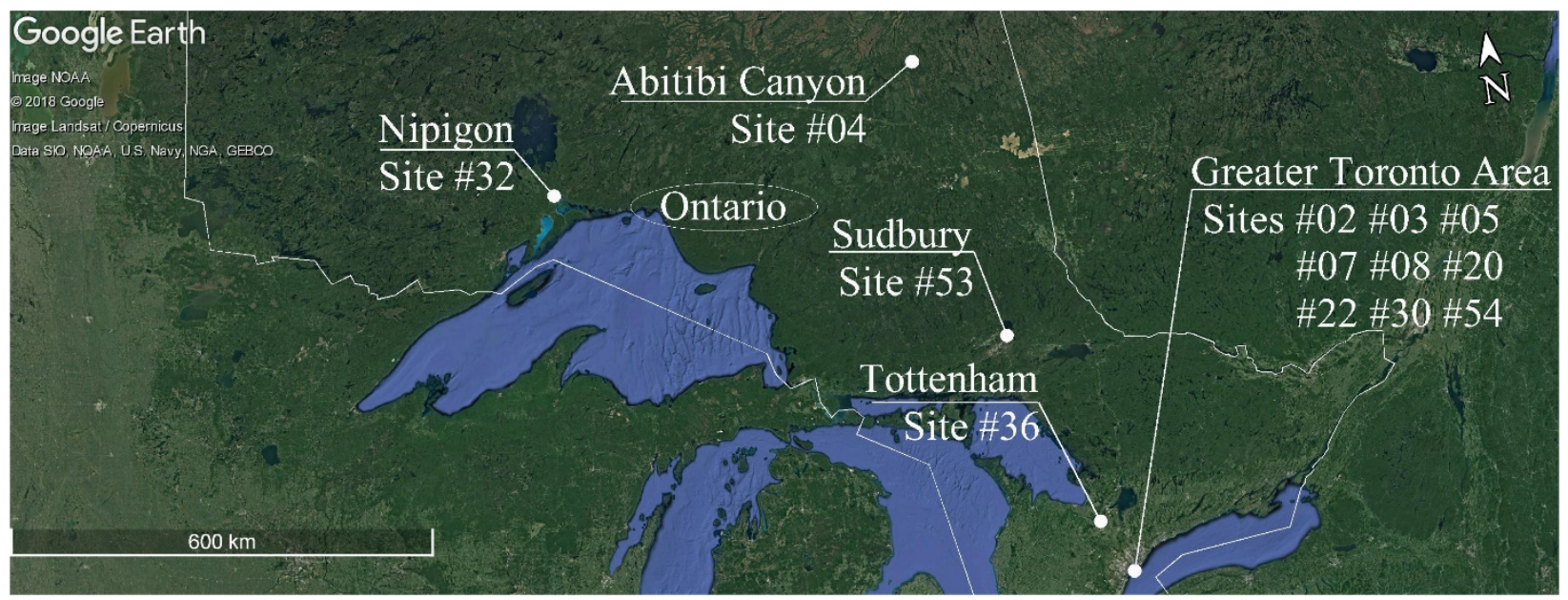

Figure 3-1 - Site Locations in Ontario (Google Earth, 2018) 


\subsubsection{Soil Conditions and Micropile Geometries}

Some projects had more than one SPT borehole. It was considered then the closest borehole to the load test. Some N values were as high as 100 blows. However, N values were limited to 60 in this study to avoid reliability issues with high $\mathrm{N}$ values in cobble and boulder rich soils in Ontario. Table 3-1 provides the summary of the soil condition and micropile geometries verified throughout the database.

Some micropiles had their cased length unbounded. This means that loading cannot be transferred to the soil in the vicinity of the cased length. This is usually done by installing a compressible void form in the boundaries of the cased length and the bond length, and also breaking the bond between the casing and the soil by injecting bentonite-cement in the annulus.

\subsection{Gradual Failure Methods}

In practical terms, the plunging failure never occurs in pile load tests because the definition of infinite displacement is impossible to reach in a real test. Also, there is a high caution regarding worker's safety. Carrying out load tests up to the geotechnical failure can generate dangerous situations due to the high energy in the system which increases the probability of accidents. Hence, there are some methods which establishes the failure of a pile based on a gradual state of failure by achieving a certain condition. These methods, nevertheless, are unable to extrapolate the Q-s curve.

\subsubsection{Davisson's Offset Limit Method}

The failure load, $R_{\text {ult }}$, according to Davisson (as cited in Fellenius, 2001) is defined as the intersection of the offset elastic line, as shown in Equation 3-1, and the Q-s curve. Figure 3-2 depicts this method.

$$
s=\frac{Q L}{E A}+\frac{D}{120}+4
$$

where $S$ is the pile head displacement in mm, $Q$ is the applied load in $\mathrm{kN}, L$ is the pile embedded length in $\mathrm{mm}, E A$ is the micropile equivalent axial stiffness in $\mathrm{kN} / \mathrm{mm}^{2}$ (due to different stiffness in the cased and bond lengths), and $D$ is the micropile diameter in $\mathrm{mm}$. 


\subsubsection{Fuller and Hoy's Method}

Fuller and Hoy (1970) determines the failure load by the point on the Q-s curve that corresponds to a slope of $0.14 \mathrm{~mm} / \mathrm{kN}$. This study considered this value to be equal to $0.15 \mathrm{~mm} / \mathrm{kN}$ as recommended by FHWA (2005). This is shown in Figure 3-3.

\subsubsection{Butler and Hoy's Method}

Butler and Hoy (as cited in Fellenius, 1980) establishes the failure load when the $0.15 \mathrm{~mm} / \mathrm{kN}$ line and the initial straight portion of the Q-s curve intercept each other. Figure 3-4 exemplifies this situation.

\subsubsection{De Beer's Method}

Another possible approach to determining the failure load is described by De Beer (as cited in Fellenius, 1980). It is proposed to plot the pile head displacement against the applied load in a double logarithm manner. When two straight lines are obtained, their interception defines the proposed failure load. Figure 3-5 illustrates this.

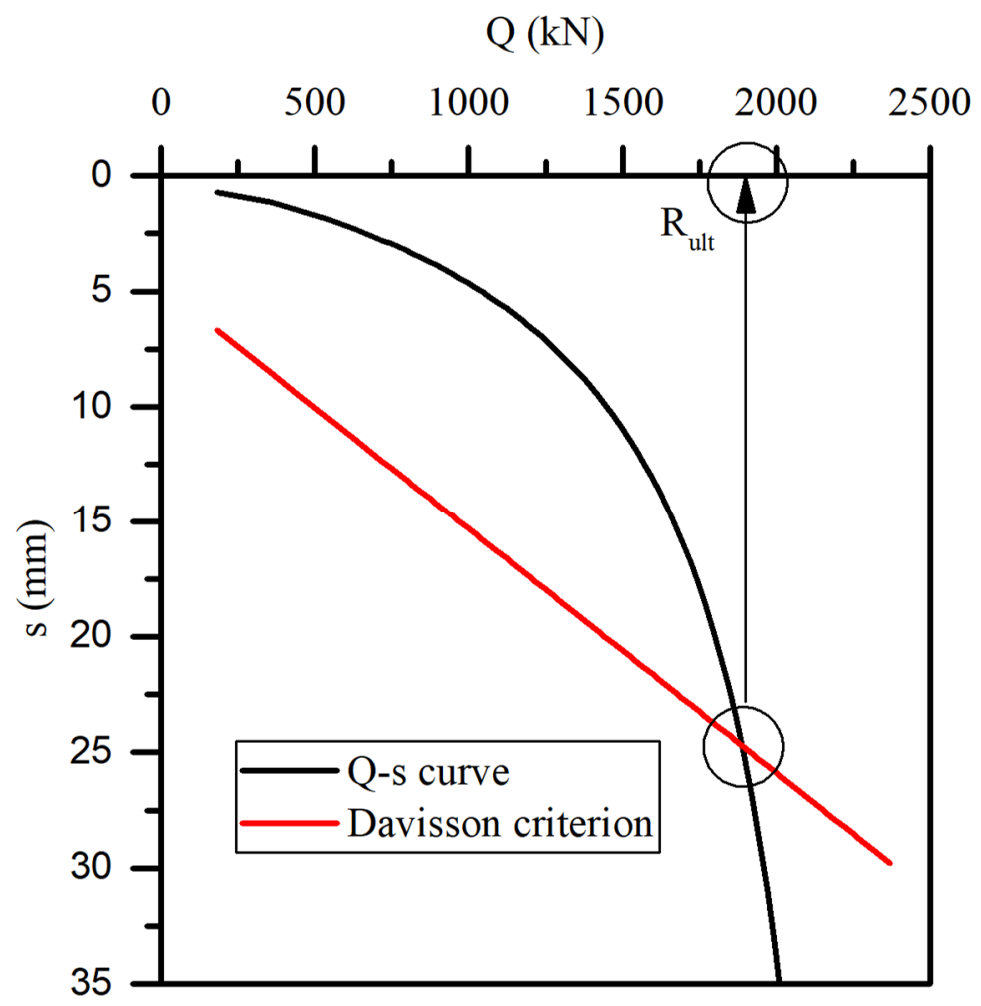

Figure 3-2 - Davisson's Offset Limit method 
Table 3-1 - Summary of soil conditions and micropile geometries for each site

\begin{tabular}{|c|c|c|c|c|c|c|c|c|c|c|c|c|c|}
\hline \multirow{3}{*}{ Site } & \multirow{3}{*}{ Pile } & \multirow{3}{*}{ Type } & \multirow{3}{*}{$\begin{array}{c}A r^{1} \\
\left(\mathbf{m m}^{2}\right)\end{array}$} & \multicolumn{6}{|c|}{\begin{tabular}{|l} 
Cased Length \\
\end{tabular}} & \multicolumn{4}{|c|}{ Bond Length } \\
\hline & & & & \multicolumn{4}{|c|}{ Geometries } & \multicolumn{2}{|c|}{ Soil Conditions } & \multicolumn{2}{|c|}{ Geometries } & \multicolumn{2}{|c|}{ Soil Conditions } \\
\hline & & & & Ubd $^{2}$ & $\begin{array}{c}\text { OD } \\
(\mathrm{mm})\end{array}$ & $\begin{array}{l}\text { Thk }^{3} \\
\text { (mm) }\end{array}$ & $\begin{array}{c}\mathbf{L} \\
(\mathbf{m})\end{array}$ & Soil Type & $\begin{array}{c}\text { SPT } \\
\mathbf{N}^{4}\end{array}$ & $\begin{array}{c}\text { OD } \\
(\mathrm{mm})\end{array}$ & $\begin{array}{c}\mathbf{L} \\
(\mathbf{m})\end{array}$ & Soil Type & $\begin{array}{c}\text { SPT } \\
\mathrm{N}^{4}\end{array}$ \\
\hline \multirow{3}{*}{2} & TP2 & A & 645 & $\mathrm{~N}$ & 220 & 9.0 & 3.00 & Sand & 31 & 220 & 4.50 & Silty Clay & 38 \\
\hline & TP3 & $\mathrm{A}$ & 645 & $\mathrm{~N}$ & 220 & 9.0 & 3.00 & Sand & 35 & 220 & 4.50 & Silty Sand/Clay & 49 \\
\hline & TA & A & 3168 & $\mathrm{~N}$ & 220 & 0.0 & 4.60 & Sand & 25 & 220 & 4.50 & Silty Clay & 38 \\
\hline \multirow{2}{*}{3} & TR1 & CGF & 726 & $\mathrm{Y}$ & 114 & 0.0 & 3.00 & Fill & 2 & 114 & 7.50 & Silty Sand/Clay & 11 \\
\hline & MP-7 & $\mathrm{D}$ & 1452 & $\mathrm{~N}$ & 193 & 12.7 & 9.47 & Sandy Silt & 31 & 193 & 8.32 & Sandy Silt & 50 \\
\hline 4 & LT1 & $\mathrm{B}$ & 3168 & $\mathrm{~N}$ & 273 & 15.1 & 6.00 & Sand & 19 & 273 & 10.00 & Sand/Gravelly Sand & 16 \\
\hline \multirow{2}{*}{5} & LT1 & $\mathrm{A}$ & 4400 & $\mathrm{Y}$ & 400 & 12.7 & 15.00 & Silt & 50 & 279 & 5.00 & Clayey Silt Till/Sand & 60 \\
\hline & LT2 & $\mathrm{A}$ & 4469 & $\mathrm{Y}$ & 400 & 12.7 & 20.00 & Silt/Sand & 53 & 279 & 7.50 & Sand/Silty Sand & 60 \\
\hline 7 & TP9 & CGF & 644 & $\mathrm{~N}$ & 219 & 10.0 & 2.80 & Sandy Silt & 23 & 90 & 5.00 & Sandy Silt & 49 \\
\hline \multirow{2}{*}{8} & LTS & CGF & 5501 & Part. & 324 & 8.0 & 2.73 & Fill & 10 & 175 & 8.63 & Sand & 49 \\
\hline & LTN & CGF & 5501 & $\mathrm{Y}$ & 324 & 8.0 & 4.00 & Fill & 12 & 175 & 10.00 & Sand & 35 \\
\hline \multirow{4}{*}{20} & $2 \mathrm{~T}$ & $\mathrm{~A}$ & 1019 & $\mathrm{~N}$ & 125 & 0.0 & 9.60 & Silty Sand & 38 & 125 & 5.00 & Silt/Sand & 40 \\
\hline & $3 T$ & $\mathrm{~A}$ & 1452 & Deb. & 150 & 8.0 & 9.00 & Silty Sand & 37 & 150 & 6.50 & Silt/Sand & 40 \\
\hline & $6 \mathrm{~T}$ & A & 1019 & $\mathrm{~N}$ & 125 & 0.0 & 9.60 & Sand & 16 & 125 & 5.00 & Silt/Sand & 44 \\
\hline & $15 \mathrm{~T}$ & $\mathrm{~A}$ & 1019 & $\mathrm{~N}$ & 125 & 0.0 & 9.60 & Sand & 31 & 125 & 5.00 & Silt/Sand & 56 \\
\hline \multirow{2}{*}{22} & LT3 & CGF & 1337 & - & - & - & - & - & - & 115 & 6.10 & Sand/Sand Till & 43 \\
\hline & LT4 & CGF & 1337 & - & - & - & - & - & - & 115 & 6.10 & Sand/Sand Till & 36 \\
\hline 30 & LT1 & $\mathrm{A}$ & 590 & $\mathrm{~N}$ & 273 & 8.0 & 3.66 & Fill & 5 & 203 & 4.50 & Silty Clay Till & 13 \\
\hline \multirow{8}{*}{32} & C-E-2 & $\mathrm{D}$ & 3168 & $\mathrm{~N}$ & 273 & 13.0 & 11.30 & Fill (Sand)/Silt & 29 & 273 & 15.20 & Silt & 59 \\
\hline & LR-E-2 & $\mathrm{B}$ & 3168 & $\mathrm{~N}$ & 273 & 0.0 & 0.00 & Fill (Sand)/Silt & 0 & 273 & 27.50 & Silt & 47 \\
\hline & R-E-2 & $\mathrm{B}$ & 3168 & $\mathrm{~N}$ & 273 & 0.0 & 0.00 & Fill (Sand)/Silt & 0 & 273 & 25.40 & Silt & 46 \\
\hline & C-W-1 & $\mathrm{B}$ & 3168 & $\mathrm{~N}$ & 273 & 13.0 & 6.70 & Sand & 27 & 273 & 9.40 & Sand & 46 \\
\hline & LR-W-1 & $\mathrm{B}$ & 3168 & $\mathrm{~N}$ & 273 & 0.0 & 6.70 & Sand & 27 & 273 & 9.10 & Sand & 46 \\
\hline & R-W-1 & $\mathrm{B}$ & 3168 & $\mathrm{~N}$ & 273 & 0.0 & 0.00 & Sand & 0 & 273 & 16.10 & Sand & 40 \\
\hline & P1-31 & $\mathrm{D}$ & 3168 & $\mathrm{~N}$ & 273 & 13.0 & 4.74 & Fill (Sand)/Silt & 35 & 273 & 14.10 & Silt & 58 \\
\hline & P1-34 & $\mathrm{D}$ & 3168 & $\mathrm{~N}$ & 273 & 13.0 & 4.75 & Fill (Sand)/Silt & 35 & 273 & 14.08 & Silt & 58 \\
\hline
\end{tabular}


Table 3-1 - Summary of soil conditions and micropile geometries for each site (continued)

\begin{tabular}{|c|c|c|c|c|c|c|c|c|c|c|c|c|c|}
\hline \multirow{3}{*}{ Site } & \multirow{3}{*}{ Pile } & \multirow{3}{*}{ Type } & \multirow{3}{*}{$\begin{array}{c}\mathbf{A r}^{1}{ }^{2} \\
\left(\mathbf{m m}^{2}\right)\end{array}$} & \multicolumn{6}{|c|}{\begin{tabular}{|c|} 
Cased Length \\
\end{tabular}} & \multicolumn{4}{|c|}{ Bond Length } \\
\hline & & & & \multicolumn{4}{|c|}{ Geometries } & \multicolumn{2}{|c|}{ Soil Conditions } & \multicolumn{2}{|c|}{ Geometries } & \multicolumn{2}{|c|}{ Soil Conditions } \\
\hline & & & & $\mathbf{U b d}^{2}$ & $\begin{array}{c}\text { OD } \\
(\mathrm{mm})\end{array}$ & $\begin{array}{l}\text { Thk }^{3} \\
(\mathbf{m m})\end{array}$ & $\begin{array}{c}\mathbf{L} \\
(\mathbf{m})\end{array}$ & Soil Type & $\begin{array}{c}\text { SPT } \\
\mathbf{N}^{4} \\
\end{array}$ & $\begin{array}{c}\text { OD } \\
(\mathrm{mm})\end{array}$ & $\begin{array}{c}\mathbf{L} \\
(\mathbf{m})\end{array}$ & Soil Type & $\begin{array}{c}\text { SPT } \\
\mathbf{N}^{4} \\
\end{array}$ \\
\hline \multirow{8}{*}{32} & P2-2 & $\mathrm{D}$ & 3168 & $\mathrm{~N}$ & 273 & 13.0 & 6.98 & Gravel/Sand & 44 & 273 & 12.80 & Sand/Silt & 41 \\
\hline & P2-7 & $\mathrm{D}$ & 3168 & $\mathrm{~N}$ & 273 & 13.0 & 6.81 & Gravel/Sand & 45 & 273 & 12.72 & Sand/Silt & 41 \\
\hline & P2-8 & $\mathrm{D}$ & 3168 & $\mathrm{~N}$ & 273 & 13.0 & 7.98 & Gravel/Sand & 41 & 273 & 11.68 & Sand/Silt & 43 \\
\hline & P2-11 & $\mathrm{D}$ & 3168 & $\mathrm{~N}$ & 273 & 13.0 & 7.03 & Gravel/Sand & 44 & 273 & 12.75 & Sand/Silt & 41 \\
\hline & P3-3 & $\mathrm{D}$ & 3168 & $\mathrm{~N}$ & 273 & 13.0 & 8.29 & Sand & 28 & 273 & 9.13 & Sand & 46 \\
\hline & P3-10 & $\mathrm{D}$ & 3168 & $\mathrm{~N}$ & 273 & 13.0 & 8.35 & Sand & 28 & 273 & 9.13 & Sand & 46 \\
\hline & P3-18 & $\mathrm{D}$ & 3168 & $\mathrm{~N}$ & 273 & 13.0 & 8.47 & Sand & 29 & 273 & 9.32 & Sand & 46 \\
\hline & P3-24 & $\mathrm{D}$ & 3168 & $\mathrm{~N}$ & 273 & 13.0 & 8.46 & Sand & 29 & 273 & 9.66 & Sand & 46 \\
\hline 36 & LT1 & CGF & 1337 & $\mathrm{~N}$ & 130 & 10.0 & 2.70 & Clayey Silt/Silt & 29 & 130 & 9.00 & Silt/Clayey Silt & 26 \\
\hline \multirow{4}{*}{53} & TP1 & A & 3168 & $\mathrm{~N}$ & 194 & 13.8 & 10.67 & Fill (Sand) & 40 & 194 & 14.02 & Sand & 56 \\
\hline & TP3 & $\mathrm{A}$ & 3168 & $\mathrm{Y}$ & 194 & 0.0 & 5.18 & Fill (Sand) & 46 & 194 & 4.90 & Sand & 60 \\
\hline & C1 & $\mathrm{A}$ & 1452 & $\mathrm{~N}$ & 194 & 0.0 & 12.00 & Fill & 36 & 194 & 6.00 & Sand & 42 \\
\hline & $\mathrm{C2}$ & $\mathrm{A}$ & 1452 & $\mathrm{~N}$ & 194 & 0.0 & 12.00 & Fill/Sand & 36 & 194 & 6.00 & Sand & 44 \\
\hline 54 & TP1 & CGF & 726 & $\mathrm{~N}$ & 115 & 8.0 & 1.20 & Fill & 26 & 115 & 4.60 & Silt Till & 29 \\
\hline
\end{tabular}

${ }^{1} \mathrm{~A}_{\mathrm{r}}$ is the cross-sectional area of the central reinforcement bar

${ }^{2}$ Ubd stands for unbounded cased length, where $\mathrm{Y}$ is unbounded, $\mathrm{N}$ is not unbounded, Part. is partially unbounded, and Deb. is debonded while testing (noise during testing)

${ }^{3}$ Thk is the wall thickness of the casing

${ }^{4} \mathrm{SPT} \mathrm{N}$ is the average $\mathrm{N}$ value along the depth of either cased length or bond length 


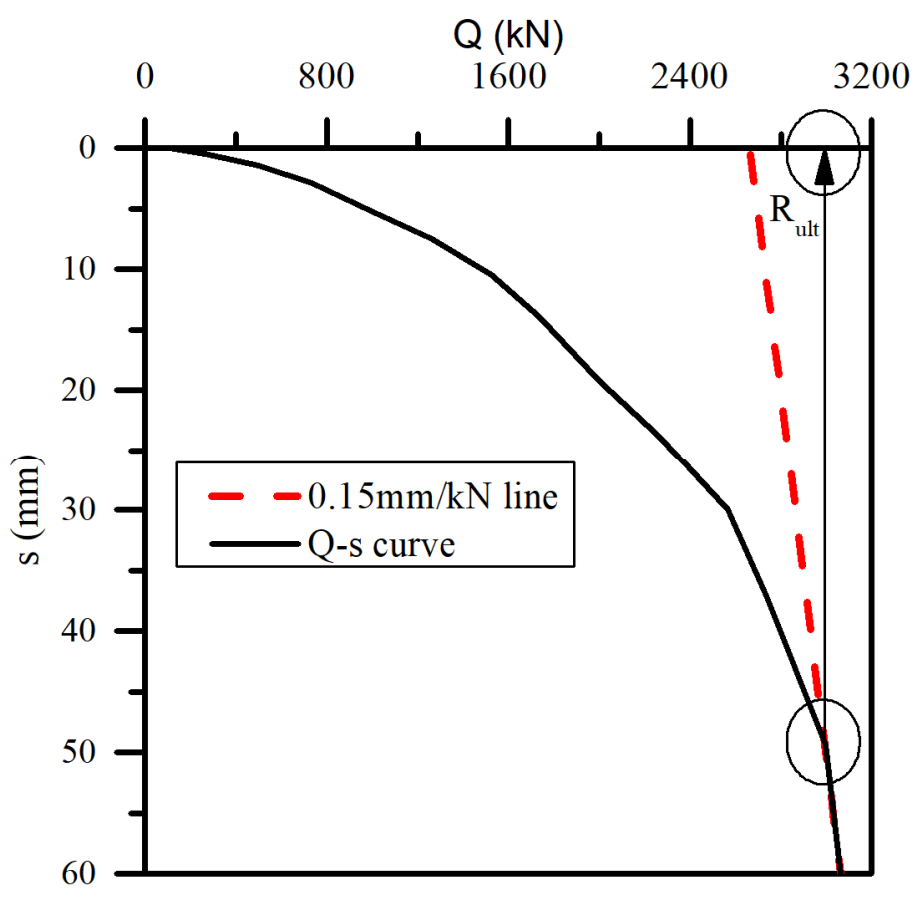

Figure 3-3 - Fuller and Hoy's method

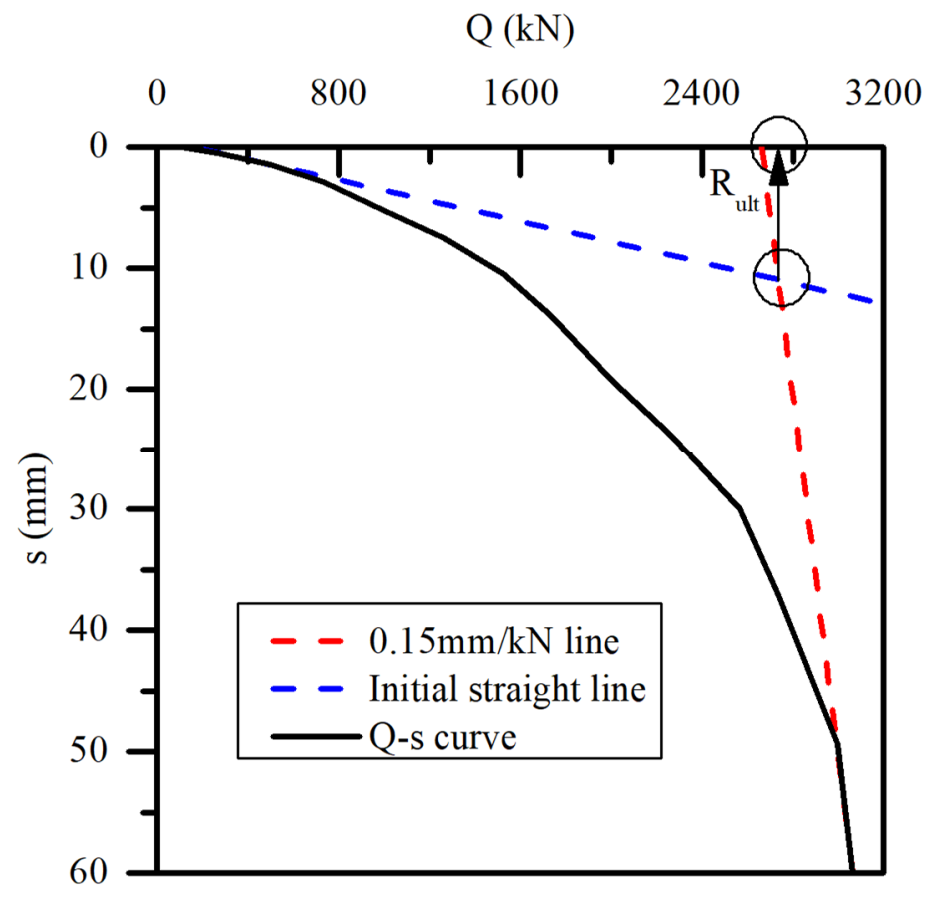

Figure 3-4 - Butler and Hoy's method 


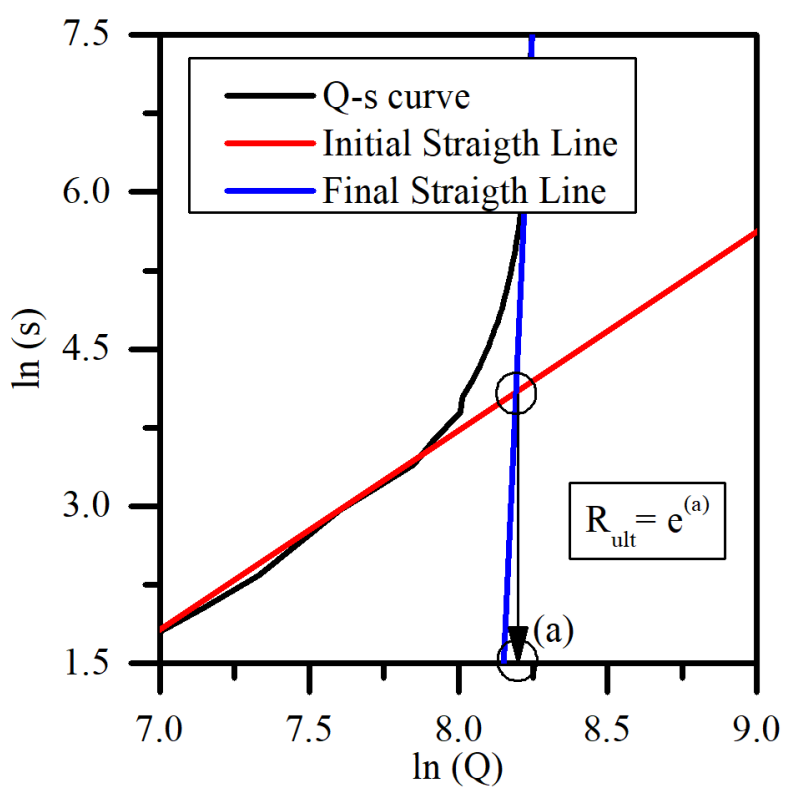

Figure 3-5 - DeBeer's method

\subsubsection{Hansen's 80\% Method}

The last gradual failure method considered in this study was proposed by Hansen (as cited in Fellenius, 1980). According to this method, the failure load is obtained when one fourth of the measured ultimate pile head displacement is generated by $80 \%$ of the failure load. This state can be verified by the plot of the square root of the pile head displacement divided by the applied load, Equation 3-2, against the pile head displacement. Figure 3-6 shows this plot.

$$
y=\frac{\sqrt{s}}{R}
$$

The generated graph begins with some scattered points, and then a line is formed. With the parameters of the straight-line, it is possible to calculate the ultimate geotechnical capacity, as shown in Equation 3-3:

$$
R_{u l t}=\frac{1}{2 \sqrt{C_{1} C_{2}}}
$$

where $C_{1}$ is the slope and $C_{2}$ is the y-intercept of the straight line. 


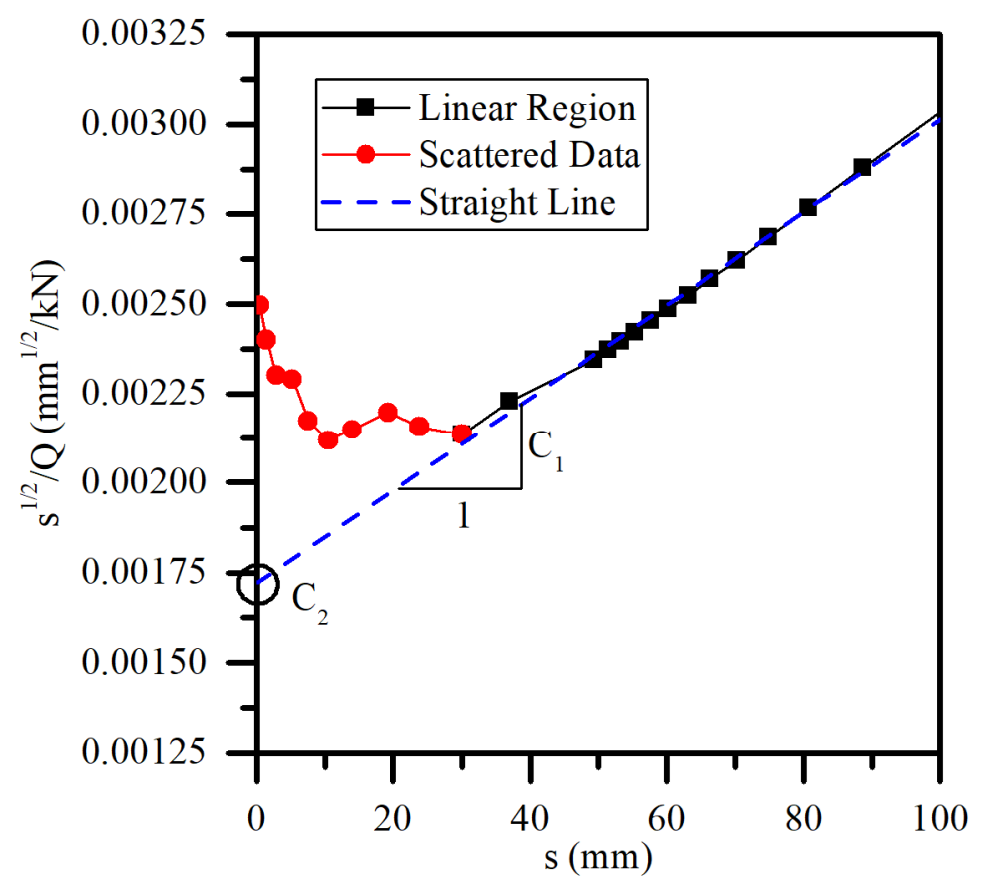

Figure 3-6 - Hansen's 80\% method

\subsection{EXTRAPOLATION OF THE LOAD-DiSPLACEMENT CURVE}

In order to determine the plunging failure load using the micropile load test, the test has to achieve the geotechnical failure. If it does not, the true ultimate load is unknown. In these situations, extrapolation methods can be applied to the Q-s curve, so that the curve is extrapolated and its plunging failure load is estimated. The following extrapolation methods described below are considered in the study.

\subsubsection{Chin's Extrapolation Method}

Chin (1970) proposed a method based on the plot of $s / Q$ against $s$. After some scattered points, a straight line is formed. The plunging load is obtained as the inverse slope of this straight line, which is given in Equation 3-4. The extrapolation of the Q-s curve is possible through the hyperbolical function shown in Equation 3-5. Figure 3-7 illustrates an example of a Chin's plot.

$$
\begin{gathered}
R_{u l t}=\frac{1}{a} \\
Q=\frac{s}{a s+b}
\end{gathered}
$$


where, $a$ is the slope of Chin's line, and $b$ is the y-intercept of Chin's line.

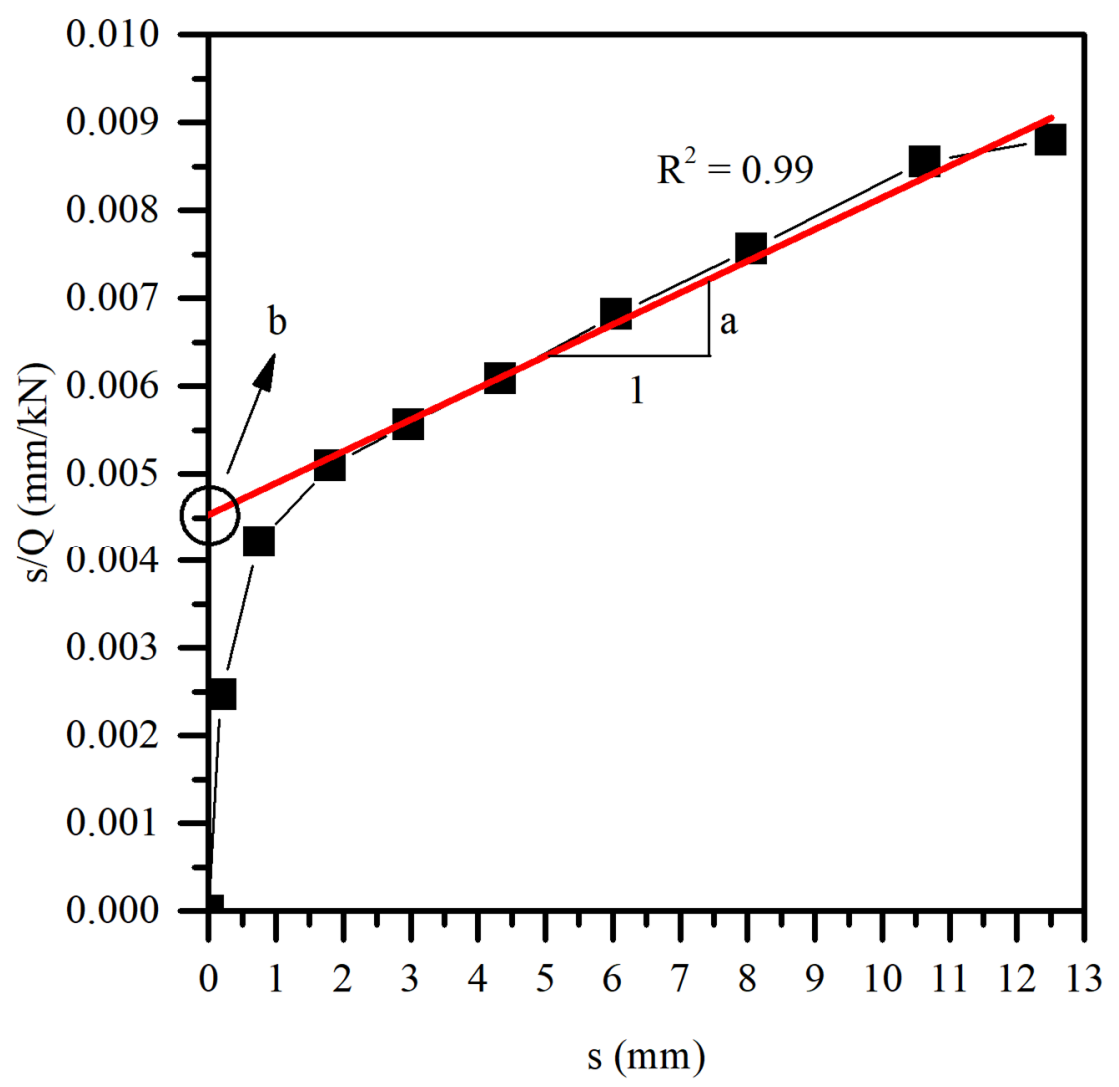

Figure 3-7 - Plot example of Chin's method

\subsubsection{Van Der Veen's Extrapolation Method}

By arbitrarily choosing the ultimate load value, a plot is constructed of $y$, Equation 3-6, against the pile head displacement. Then, an optimization algorithm is applied to find the ultimate load which produces the best fit of the line in the graph (measured by $\mathrm{R}^{2}$ ). The Q-s curve can be extrapolated using Equation 3-7 (Van Der Veen, 1953). Figure 3-8 depicts and example of a Van Der Veen's plot.

$$
\begin{gathered}
y=-\ln \left(1-\frac{Q}{R_{u l t}}\right) \\
s=\frac{-\ln \left(1-\frac{Q}{R_{u l t}}\right)-n}{m}
\end{gathered}
$$

where, $m$ is the slope and $n$ is the y-intercept of the Van Der Veen's line. 


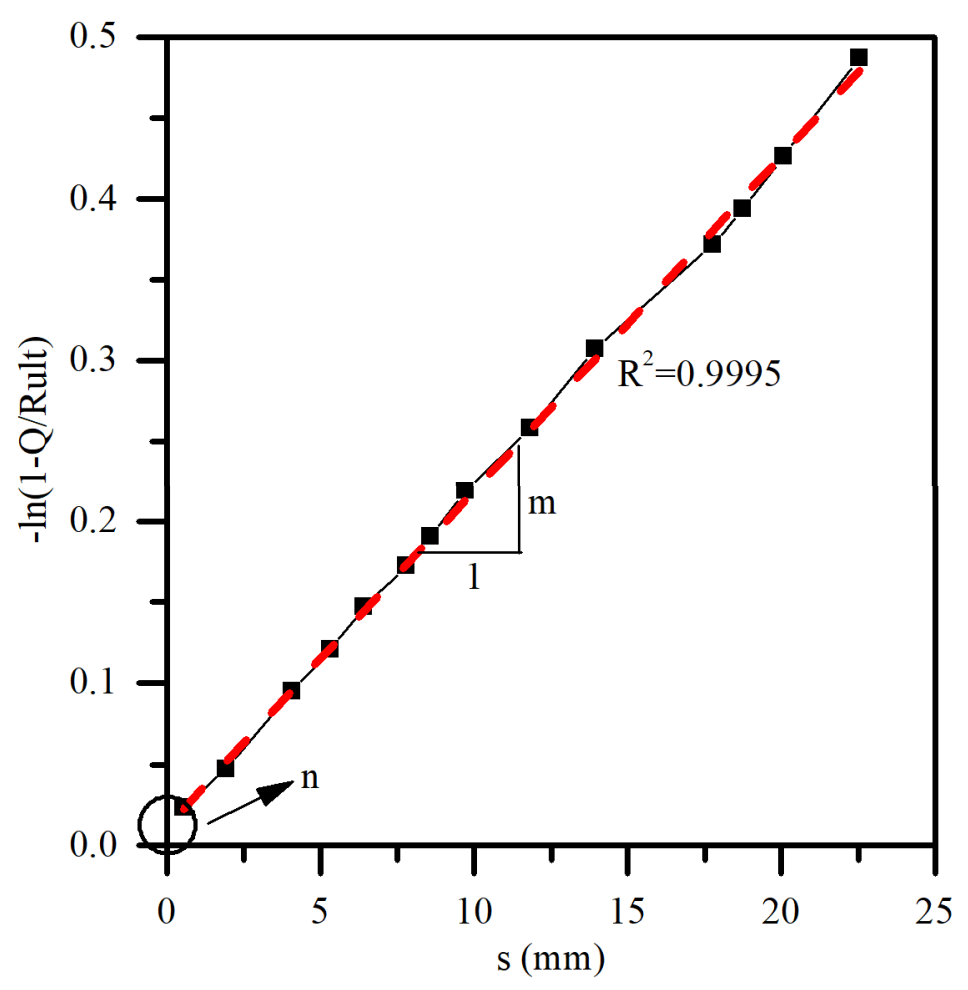

Figure 3-8 - Plot example of Van Der Veen's method

\subsubsection{Decourt's Extrapolation Method}

The last extrapolation method of this study was developed by Décourt (1997). It is similar to Chin's method, but it brought some different concepts. The pile stiffness, $Q / s$, is plotted against $Q$. Two different curves can be identified. Décourt (1997) denominated them as "Lower Bound Limit for the Shaft Frictional Resistance" and "Upper Bound Limit for the Tip Resistance". These two curves are approximately a straight line. Figure 3-9 exemplifies this method.

When the extension of the lines intercepts the horizontal axis (applied load axis), the ultimate value for both the lower bound for the skin frictional resistance and the plunging failure are obtained (Décourt, 2008). This procedure can be explained because of the definition of failure. According to DeBeer (as cited in Décourt, 1997), plunging failure can be defined as:

$$
\frac{Q}{S} \rightarrow 0
$$

Eq. 3-8

The extension of the "Lower Bound Limit for the Shaft Frictional Resistance" can thus provide a mathematical relationship for the value of skin frictional resistance $R_{s k}$ generated from an applied load $Q$ with measured pile head displacement $s$. 
Décourt (2008) also suggests a plot of $\ln (\mathrm{Q} / \mathrm{s})$ versus $\ln (\mathrm{Q})$, shown in Figure 3-10. This provides a better visual effect to localize the "Upper Bound Limit for the Tip Resistance" curve. This curve is spotted when a rough initial pattern is changed by one or two transition points.

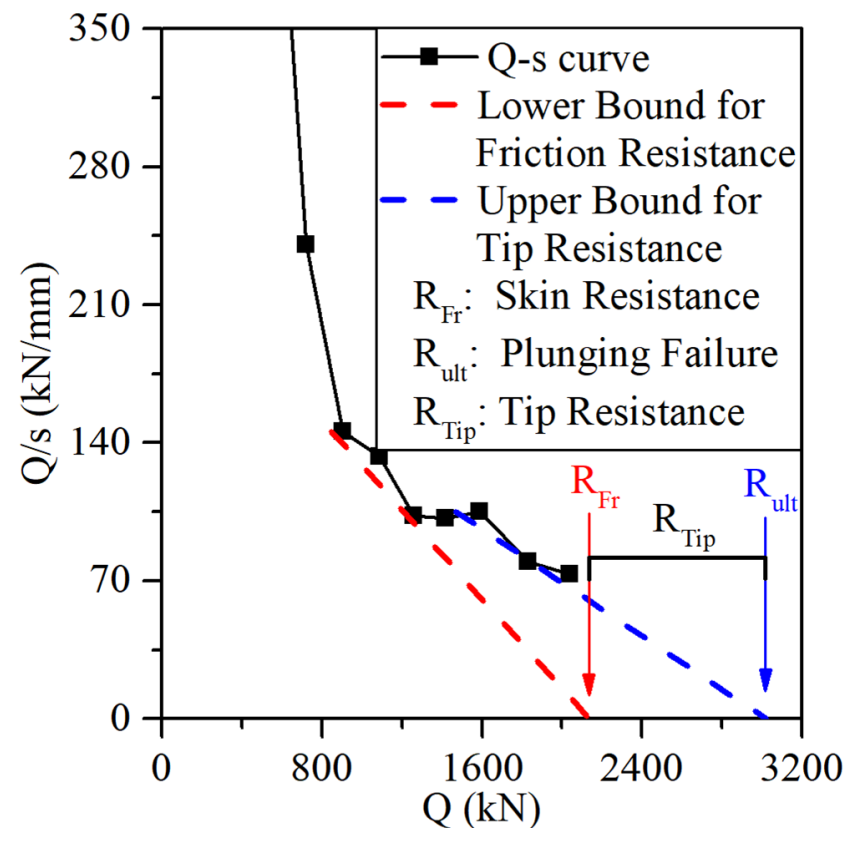

Figure 3-9 - Plot example of Décourt's Extrapolation method

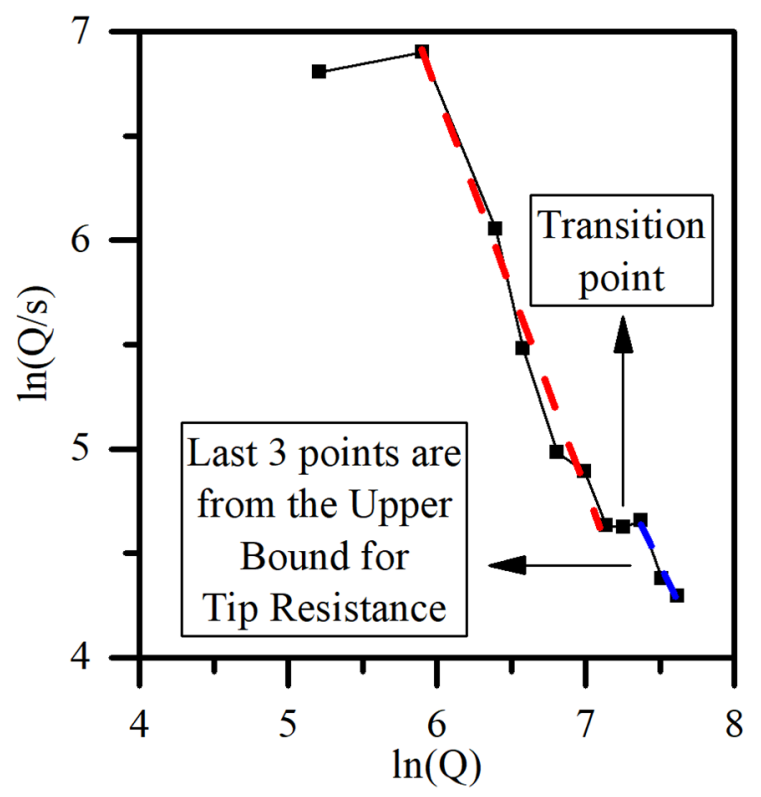

Figure 3-10 - Logarithmic plot of Décourt's Extrapolation method 


\subsection{Combination of EXTRAPOlation ANd Gradual FaILURE Methods}

Relying on the plunging failure from extrapolation methods might be a risky consideration because, nevertheless, the failure would be characterized by a prediction rather than an obtained value from field (Fellenius, 1980). To both mitigate this situation and make an ULS analysis possible, it is proposed to determine failure loads by first extrapolating the Q-s curves and then applying gradual failure methods to these extrapolated Q-s curves. This approach is deemed to be more suitable for this study, since it does not rely on the plunging failure and allows to establish the failure load of non-failed tests (Almeida et al., 2018).

The analysis is conducted by isolating the loading phases from the test data, and then generating the Q-s curve. This is followed by the extrapolation of the Q-s curve, resulting in an extrapolated curve. Figure 3-11 demonstrates this process. Next, gradual failure methods are applied to the resultant extrapolated Q-s curve. Figure 3-12 describes the proposed method for the following gradual failure methods: (a) and (b) Davisson (as cited in Fellenius, 1980); (c) and (d) Butler and Hoy (as cited in Fellenius, 1980); and (e) and (f) Fuller and Hoy (1970).

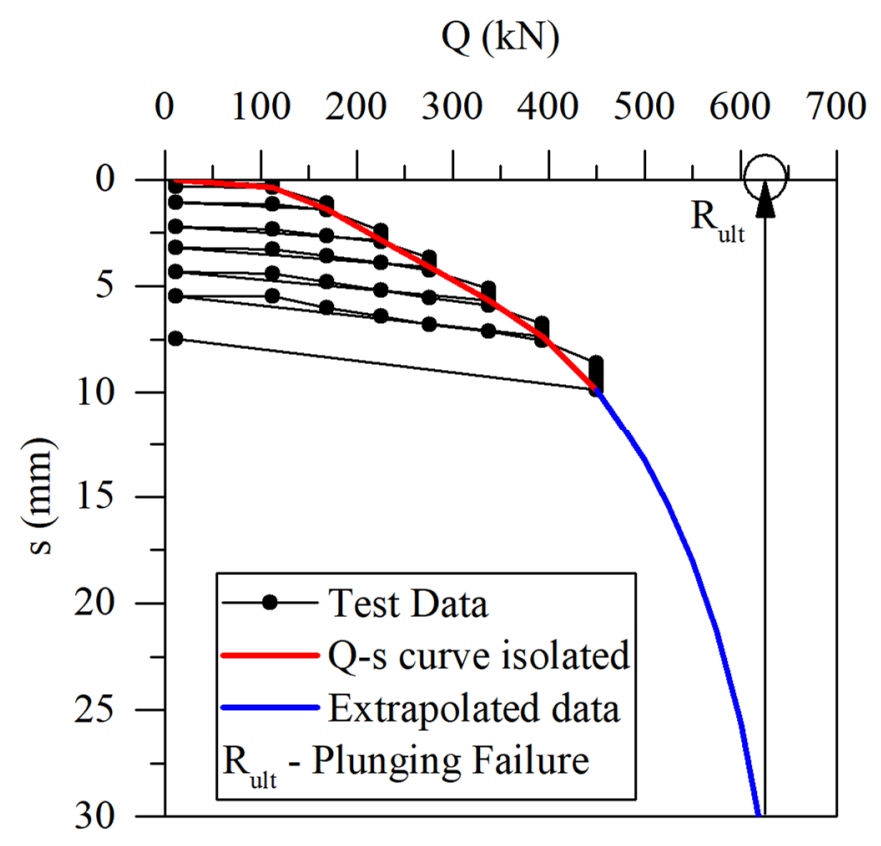

Figure 3-11 - Typical load test results: selection and extrapolation of data for further analyses

\subsection{INTERPRETED FAILURE LOAD FROM TEST RESULTS}

Failure loads were determined for each micropile load test using both plunging load from extrapolation methods and ultimate load from the combination of gradual failure methods with extrapolation methods. Tables 3-2 to 3-4 provide all resultant scenarios and failure loads calculated for each scenario, respectively. 


\subsection{Statistical Analysis of Failure Methods Applied to Micropiles}

In order to establish a suitable failure method from the proposed combination of methods, a statistical analysis was carried out to compare the methods among themselves. The proposed approach for this analysis is to identify a method which does not have a long variation range, meaning that data is concentrated as much as possible near its average. Yet, it should also be near the average of all predicted loads. This provides not only a stable method in terms of variation, but also a method which is neither conservative nor overestimating.

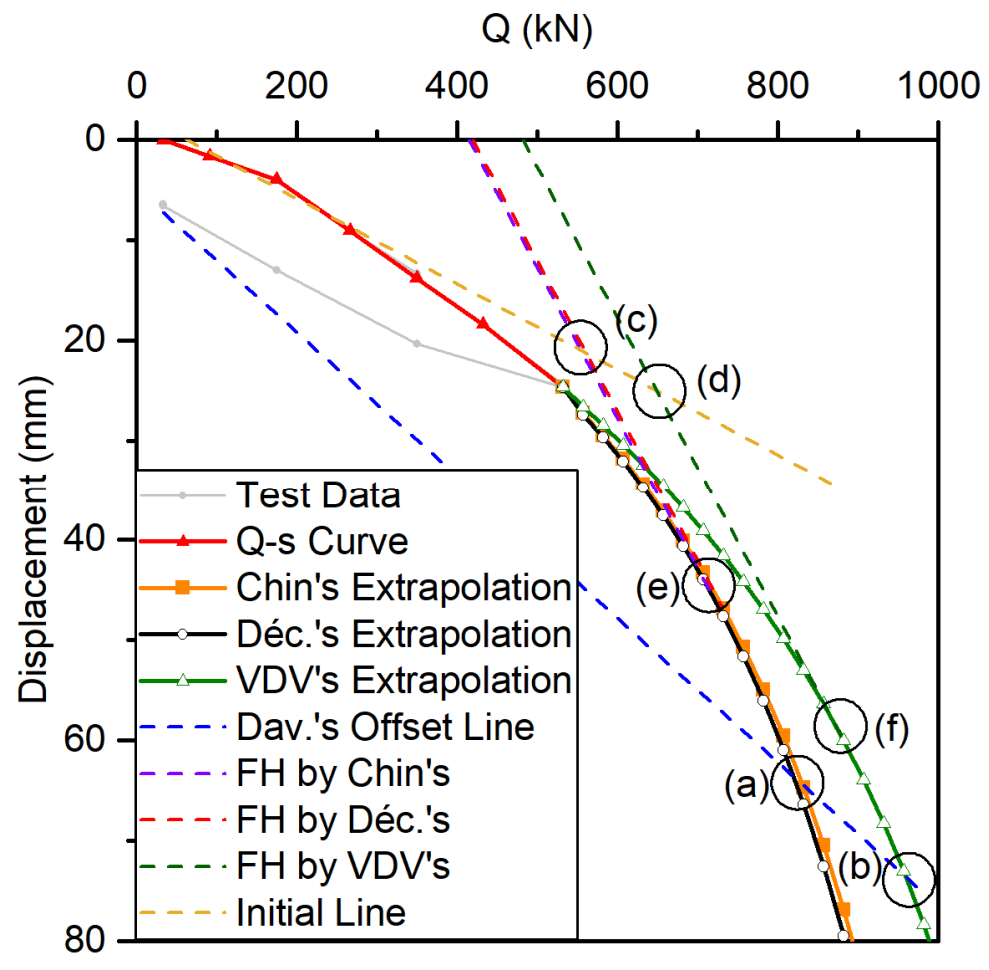

Figure 3-12 - Example of combination between extrapolation and gradual failure methods

A normalization of the data was performed for comparison of the methods. Equation 3-9 gives $N_{R_{p}}$ of a method $p$ equal to the ultimate load of this method $p, R_{u l t, p}$, divided by the average of all methods, $\frac{\sum_{p=1}^{n=15} R_{u l t, p}}{n}$. The normalization through the average is deemed a rational approach which makes it possible to compare different methods among themselves. In this manner, $N_{R_{p}}$ is able to compare micropiles with different geometries and embedded in different soil types. It is worth noticing that although the plunging failure given by extrapolation methods were normalized, their values were not considered in the average of all methods. Thus, the total number of methods, $n$, is equal to 15 in Equation 3-9. 


$$
N_{R_{p}}=\frac{R_{u l t, p}}{\frac{\sum_{p=1}^{n=15} R_{u l t, p}}{n}}
$$

Figure 3-13 shows the boxplot of normalized load variation considering all studied micropiles being part of the same sample space. When $N_{R_{p}}$ of a method $p$ is closer to 1.0 , it means that this method is near the average of all possible failure scenarios throughout the considered cases. Furthermore, if a method has a shorter boxplot, it means that its variation is lower. This box compactness is better achieved in Butler and Hoy's and Fuller and Hoy's methods.

Fuller and Hoy's method, combined with any extrapolation method, provided the best result in terms of the proposed method of evaluation: variation and closeness to the average of all methods. Butler and Hoy's method experienced a similar behavior, but with slightly lower average than Fuller and Hoy's method. Hence, Fuller and Hoy's method is combined with Chin's method to generate the failure load of the micropiles in the database for the subsequent analyses.

De Beer's method combined with Van Der Veen's method provided a reasonable good agreement with the average of methods, but had a higher variability compared to either Butler and Hoy's or Fuller and Hoy's methods. Davisson's method generally provided an underestimation of the failure load, while Hansen's method generated a load similar to the plunging failure.

Table 3-2 - Scenarios of all possible methods combination

\begin{tabular}{|c|c|c|c|}
\hline $\begin{array}{c}\text { Methods } \\
\text { Combination }\end{array}$ & $\begin{array}{c}\text { Chin's Method } \\
\text { (Chin) }\end{array}$ & $\begin{array}{c}\text { Decourt's Method } \\
\text { (Dec) }\end{array}$ & $\begin{array}{c}\text { Van Der Veen's } \\
\text { Method (VDV) }\end{array}$ \\
\hline $\begin{array}{c}\text { Davisson's Method } \\
\text { (Dav) }\end{array}$ & $\begin{array}{c}\text { Davisson \& Chin } \\
(p=1)\end{array}$ & $\begin{array}{c}\text { Davisson \& Decourt } \\
(p=2)\end{array}$ & $\begin{array}{c}\text { Davisson \& Van Der } \\
\text { Veen }(p=3)\end{array}$ \\
\hline $\begin{array}{c}\text { Butler and Hoy's } \\
\text { Method (BH) }\end{array}$ & $\begin{array}{c}\text { Butler and Hoy \& } \\
\text { Chin }(p=4)\end{array}$ & $\begin{array}{c}\text { Butler and Hoy \& } \\
\text { Decourt }(p=5)\end{array}$ & $\begin{array}{c}\text { Butler and Hoy \& } \\
\text { Van Der Veen }(p=6)\end{array}$ \\
\hline $\begin{array}{c}\text { Fuller and Hoy's } \\
\text { Method (FH) }\end{array}$ & $\begin{array}{c}\text { Fuller and Hoy \& } \\
\text { Chin }(p=7)\end{array}$ & $\begin{array}{c}\text { Fuller and Hoy \& } \\
\text { Decourt }(p=8)\end{array}$ & $\begin{array}{c}\text { Fuller and Hoy \& } \\
\text { Van Der Veen }(p=9)\end{array}$ \\
\hline $\begin{array}{c}\text { De Beer's Method } \\
\text { (DB) }\end{array}$ & $\begin{array}{c}\text { De Beer \& Chin } \\
(p=10)\end{array}$ & $\begin{array}{c}\text { De Beer \& Decourt } \\
(p=11)\end{array}$ & $\begin{array}{c}\text { De Beer \& Van Der } \\
\text { Veen }(p=12)\end{array}$ \\
\hline $\begin{array}{c}\text { Hansen's Method } \\
\text { (Han) }\end{array}$ & $\begin{array}{c}\text { Hansen } \& \text { Chin } \\
(p=13)\end{array}$ & $\begin{array}{c}\text { Hansen } \& \text { Decourt } \\
(p=14)\end{array}$ & $\begin{array}{c}\text { Hansen \& Van Der } \\
\text { Veen }(p=15)\end{array}$ \\
\hline Plunging & Chin & Decourt & Van Der Veen \\
\hline
\end{tabular}


Table 3-3 - Failure load results calculated through extrapolation methods and gradual failure methods using extrapolated Q-s curves

\begin{tabular}{|c|c|c|c|c|c|c|c|c|c|c|c|c|c|c|}
\hline \multirow{3}{*}{ Site } & \multirow{3}{*}{ Pile } & \multicolumn{3}{|c|}{ Design } & \multicolumn{4}{|c|}{ Extrapolation Methods (kN) } & \multicolumn{6}{|c|}{ Gradual Failure \& Extrapolation Methods (kN) } \\
\hline & & \multirow{2}{*}{$\mathbf{L} \mathbf{T}^{\mathbf{1}}$} & \multirow{2}{*}{$\begin{array}{l}\mathbf{D L}^{2} \\
(\mathbf{k N})\end{array}$} & \multirow{2}{*}{$\begin{array}{c}\text { MTL }^{3} \\
(\mathbf{k N})\end{array}$} & \multirow{2}{*}{ Chin } & \multicolumn{2}{|c|}{ Decourt } & \multirow{2}{*}{ VDV $^{6}$} & \multicolumn{3}{|c|}{ Davisson \& } & \multicolumn{3}{|c|}{ Butler and Hoy } \\
\hline & & & & & & Plung ${ }^{4}$ & Skin 5 & & Chin & Dec $^{7}$ & VDV $^{6}$ & Chin & Dec $^{7}$ & VDV 6 \\
\hline \multirow{3}{*}{2} & TP2 & $\mathrm{C}$ & 154 & 303 & 704 & 709 & - & 643 & 534 & 536 & 590 & 514 & 517 & 561 \\
\hline & TP3 & $\mathrm{C}$ & 154 & 303 & 622 & 581 & 160 & 680 & 226 & 226 & 226 & 342 & 326 & 428 \\
\hline & TA & $\mathrm{T}$ & 154 & 600 & 931 & 898 & $\mathrm{~N} / \mathrm{A}$ & 784 & 760 & 740 & 763 & 731 & 708 & 721 \\
\hline \multirow{2}{*}{3} & TR1 & $\mathrm{T}$ & 120 & 390 & 978 & 960 & N/A & 731 & 221 & 221 & 221 & 410 & 404 & 434 \\
\hline & MP-7 & $\mathrm{C}$ & 510 & 638 & 1117 & 1106 & - & 861 & 514 & 514 & 514 & 700 & 696 & 691 \\
\hline 4 & LT1 & $\mathrm{T}$ & 710 & 1420 & 2771 & 2727 & N/A & 2204 & 2159 & 2131 & 2136 & 2004 & 1976 & 1956 \\
\hline \multirow{2}{*}{5} & LT1 & $\mathrm{C}$ & 1100 & 2200 & 8784 & 8968 & - & 6978 & 2151 & 2151 & 2151 & 5924 & 6040 & 6024 \\
\hline & LT2 & $\mathrm{C}$ & 900 & 1800 & 4089 & 4089 & - & 4863 & 2485 & 2485 & 3320 & 3027 & 3027 & 4305 \\
\hline 7 & TP9 & $\mathrm{T}$ & 230 & 384 & 830 & 862 & $\mathrm{~N} / \mathrm{A}$ & 565 & 602 & 618 & 544 & 484 & 497 & 453 \\
\hline \multirow{2}{*}{8} & LTS & $\mathrm{T}$ & 1000 & 2000 & 4170 & 4152 & $\mathrm{~N} / \mathrm{A}$ & 3081 & 1966 & 1966 & 1966 & 3000 & 2990 & 2739 \\
\hline & LTN & $\mathrm{T}$ & 1000 & 2000 & 3986 & 3952 & N/A & 3152 & 2008 & 2003 & 2044 & 2851 & 2830 & 2766 \\
\hline \multirow{4}{*}{20} & $2 \mathrm{~T}$ & $\mathrm{~T}$ & 200 & 532 & 1296 & 1272 & N/A & 1186 & 830 & 819 & 960 & 561 & 554 & 648 \\
\hline & $3 T$ & $\mathrm{~T}$ & 116 & 406 & 542 & 532 & N/A & 468 & 332 & 332 & 332 & 301 & 301 & 301 \\
\hline & $6 \mathrm{~T}$ & $\mathrm{~T}$ & 200 & 532 & 1377 & 1370 & N/A & 1327 & 866 & 862 & 1038 & 592 & 589 & 707 \\
\hline & $15 \mathrm{~T}$ & $\mathrm{~T}$ & 200 & 532 & 1674 & 1673 & $\mathrm{~N} / \mathrm{A}$ & 1496 & 947 & 947 & 1122 & 643 & 644 & 768 \\
\hline \multirow{2}{*}{22} & LT3 & C & 360 & 720 & 2502 & 2482 & - & 2654 & 1326 & 1319 & 1708 & 1656 & 1644 & 2208 \\
\hline & LT4 & $\mathrm{C}$ & 360 & 720 & 1201 & 1196 & - & 880 & 1028 & 1024 & 878 & 958 & 954 & 828 \\
\hline 30 & LT1 & $\mathrm{C}$ & 133 & 267 & 292 & 290 & 113 & 273 & 235 & 235 & 235 & 193 & 193 & 193 \\
\hline \multirow{8}{*}{32} & C-E-2 & $\mathrm{C}$ & 1219 & 3060 & 10348 & 10302 & - & 8680 & 5334 & 5318 & 6217 & 7163 & 7134 & 7548 \\
\hline & LR-E-2 & $\mathrm{T}$ & 1196 & 1531 & 8254 & 8264 & N/A & 8263 & 4867 & 4873 & 6873 & 4110 & 4116 & 5733 \\
\hline & R-E-2 & $\mathrm{T}$ & 1196 & 1531 & 4726 & 4663 & N/A & 4975 & 2996 & 2963 & 4153 & 2557 & 2528 & 3553 \\
\hline & C-W-1 & $\mathrm{C}$ & 1201 & 3003 & 4569 & 4569 & 4295 & 3604 & 2960 & 2960 & 2960 & 3535 & 3535 & 3295 \\
\hline & LR-W-1 & $\mathrm{T}$ & 1201 & 1501 & 4696 & 4694 & $\mathrm{~N} / \mathrm{A}$ & 3843 & 2382 & 2382 & 2697 & 2629 & 2629 & 2891 \\
\hline & R-W-1 & $\mathrm{T}$ & 1201 & 1501 & 4251 & 4227 & $\mathrm{~N} / \mathrm{A}$ & 3434 & 2110 & 2103 & 2339 & 2371 & 2359 & 2573 \\
\hline & P1-31 & $\mathrm{T}$ & 1200 & 1560 & 2690 & 2620 & N/A & 2237 & 2012 & 1975 & 2077 & 2095 & 2046 & 2052 \\
\hline & P1-34 & $\mathrm{T}$ & 1200 & 1560 & 2370 & 2330 & N/A & 1914 & 1756 & 1738 & 1758 & 1846 & 1819 & 1755 \\
\hline
\end{tabular}


Table 3-3 - Failure load results calculated through extrapolation methods and gradual failure methods using extrapolated Q-s curves (continued)

\begin{tabular}{|c|c|c|c|c|c|c|c|c|c|c|c|c|c|c|}
\hline \multirow{3}{*}{ Site } & \multirow{3}{*}{ Pile } & \multicolumn{3}{|c|}{ Design } & \multicolumn{4}{|c|}{ Extrapolation Methods (kN) } & \multicolumn{6}{|c|}{ Gradual Failure \& Extrapolation Methods (kN) } \\
\hline & & \multirow{2}{*}{$\mathbf{L T}^{\mathbf{1}}$} & \multirow{2}{*}{$\begin{array}{l}\mathrm{DL}^{2} \\
(\mathrm{kN})\end{array}$} & \multirow{2}{*}{$\begin{array}{c}\text { MTL }^{3} \\
(\mathbf{k N})\end{array}$} & \multirow{2}{*}{ Chin } & \multicolumn{2}{|c|}{ Decourt } & \multirow{2}{*}{$V D V^{6}$} & \multicolumn{3}{|c|}{ Davisson \& } & \multicolumn{3}{|c|}{ Butler and Hoy } \\
\hline & & & & & & Plung ${ }^{4}$ & Skin 5 & & Chin & Dec $^{7}$ & VDV $^{6}$ & Chin & Dec $^{7}$ & VDV $^{6}$ \\
\hline \multirow{8}{*}{32} & P2-2 & $\mathrm{T}$ & 1200 & 1560 & 3705 & 3693 & $\mathrm{~N} / \mathrm{A}$ & 3653 & 1765 & 1763 & 1820 & 2557 & 2550 & 3039 \\
\hline & P2-7 & $\mathrm{T}$ & 1200 & 1560 & 2474 & 2415 & $\mathrm{~N} / \mathrm{A}$ & 2325 & 1651 & 1634 & 1711 & 1800 & 1766 & 1951 \\
\hline & P2-8 & $\mathrm{T}$ & 1200 & 1560 & 2436 & 2420 & $\mathrm{~N} / \mathrm{A}$ & 1954 & 1933 & 1925 & 1874 & 1914 & 1904 & 1780 \\
\hline & P2-11 & $\mathrm{T}$ & 1200 & 1560 & 2671 & 2635 & $\mathrm{~N} / \mathrm{A}$ & 2791 & 1969 & 1952 & 2249 & 2049 & 2025 & 2434 \\
\hline & P3-3 & $\mathrm{T}$ & 1200 & 1560 & 2709 & 2637 & N/A & 2243 & 1613 & 1596 & 1657 & 1980 & 1935 & 1970 \\
\hline & P3-10 & $\mathrm{T}$ & 1200 & 1560 & 2942 & 2907 & N/A & 2298 & 1851 & 1840 & 1880 & 2173 & 2150 & 2043 \\
\hline & P3-18 & $\mathrm{T}$ & 1200 & 1560 & 6128 & 6123 & $\mathrm{~N} / \mathrm{A}$ & 5751 & 1304 & 1304 & 1304 & 3844 & 3841 & 4629 \\
\hline & P3-24 & $\mathrm{T}$ & 1200 & 1560 & 4836 & 4823 & N/A & 3857 & 1155 & 1155 & 1155 & 3029 & 3022 & 3115 \\
\hline 36 & LT1 & $\mathrm{C}$ & 500 & 875 & 1343 & 1374 & 699 & 1327 & 1169 & 808 & 808 & 808 & 902 & 895 \\
\hline \multirow{4}{*}{53} & TP1 & $\mathrm{C}$ & 874 & 2185 & 6925 & 6939 & - & 6939 & 6706 & 3882 & 3887 & 4401 & 4564 & 4572 \\
\hline & TP3 & $\mathrm{T}$ & 477 & 1431 & 3656 & 3576 & $\mathrm{~N} / \mathrm{A}$ & 3576 & 5088 & 2404 & 2365 & 3907 & 2490 & 2441 \\
\hline & $\mathrm{C} 1$ & $\mathrm{~T}$ & 630 & 725 & 2245 & 2274 & N/A & 2274 & 1365 & 1714 & 1733 & 1340 & 1216 & 1230 \\
\hline & $\mathrm{C2}$ & $\mathrm{T}$ & 630 & 725 & 2375 & 2339 & $\mathrm{~N} / \mathrm{A}$ & 2339 & 1864 & 1661 & 1639 & 1739 & 1186 & 1171 \\
\hline 54 & TP1 & $\mathrm{C}$ & 225 & 450 & 776 & 765 & - & 765 & 701 & 459 & 457 & 467 & 496 & 490 \\
\hline
\end{tabular}

Table 3-4 - Failure load results calculated through gradual failure methods using extrapolated Q-s curves

\begin{tabular}{|c|c|c|c|c|c|c|c|c|c|c|c|c|c|}
\hline \multirow{3}{*}{ Site } & \multirow{3}{*}{ Pile } & \multicolumn{3}{|c|}{ Design } & \multicolumn{9}{|c|}{ Gradual Failure \& Extrapolation Methods (kN) } \\
\hline & & \multirow{2}{*}{$\mathbf{L T}^{\mathbf{1}}$} & \multirow{2}{*}{$\begin{array}{l}\mathrm{DL}^{2} \\
(\mathrm{kN})\end{array}$} & \multirow{2}{*}{$\begin{array}{c}\mathbf{M T L}^{3} \\
(\mathbf{k N})\end{array}$} & \multicolumn{3}{|c|}{ Fuller and Hoy \& } & \multicolumn{3}{|c|}{ De Beer \& } & \multicolumn{3}{|c|}{ Hansen \& } \\
\hline & & & & & Chin & Dec $^{7}$ & $\mathrm{VDV}^{6}$ & Chin & Dec $^{7}$ & VDV $^{6}$ & Chin & Dec $^{7}$ & VDV $^{6}$ \\
\hline \multirow{3}{*}{2} & TP2 & $\mathrm{C}$ & 154 & 303 & 583 & 583 & 617 & 637 & 624 & 538 & 686 & 680 & 698 \\
\hline & TP3 & $\mathrm{C}$ & 154 & 303 & 393 & 373 & 530 & 517 & 513 & 614 & 574 & 555 & 716 \\
\hline & TA & $\mathrm{T}$ & 154 & 600 & 800 & 770 & 762 & 848 & 778 & 705 & 911 & 843 & 824 \\
\hline \multirow{2}{*}{3} & TR1 & $\mathrm{T}$ & 120 & 390 & 500 & 500 & 532 & 858 & 822 & 610 & 943 & 911 & 788 \\
\hline & MP-7 & $\mathrm{C}$ & 510 & 638 & 798 & 798 & 771 & 1031 & 979 & 739 & 1106 & 1064 & 927 \\
\hline
\end{tabular}


Table 3-4 - Failure load results calculated through gradual failure methods using extrapolated Q-s curves (continued)

\begin{tabular}{|c|c|c|c|c|c|c|c|c|c|c|c|c|c|}
\hline \multirow{3}{*}{ Site } & \multirow{3}{*}{ Pile } & \multicolumn{3}{|c|}{ Design } & \multicolumn{9}{|c|}{ Gradual Failure \& Extrapolation Methods (kN) } \\
\hline & & \multirow{2}{*}{$\mathbf{L} \mathbf{T}^{1}$} & \multirow{2}{*}{$\begin{array}{l}\mathrm{DL}^{2} \\
(\mathrm{kN})\end{array}$} & \multirow{2}{*}{$\begin{array}{c}\text { MTL }^{3} \\
(\mathbf{k N})\end{array}$} & \multicolumn{3}{|c|}{ Fuller and Hoy \& } & \multicolumn{3}{|c|}{ De Beer \& } & \multicolumn{3}{|c|}{ Hansen \& } \\
\hline & & & & & Chin & Dec $^{7}$ & VDV $^{6}$ & Chin & Dec $^{7}$ & VDV $^{6}$ & Chin & Dec $^{7}$ & VDV $^{6}$ \\
\hline 4 & LT1 & $\mathrm{T}$ & 710 & 1420 & 2280 & 2250 & 2119 & 2689 & 2607 & 2066 & 2856 & 2773 & 2272 \\
\hline \multirow{2}{*}{5} & LT1 & $\mathrm{C}$ & 1100 & 2200 & 7010 & 7160 & 6667 & 8636 & 8774 & 6886 & 9062 & 9191 & 7114 \\
\hline & LT2 & $\mathrm{C}$ & 900 & 1800 & 3430 & 3430 & 4688 & 3880 & 3880 & 4524 & 4166 & 4166 & 4976 \\
\hline 7 & TP9 & $\mathrm{T}$ & 230 & 384 & 574 & 594 & 510 & 648 & 777 & 456 & 778 & 846 & 618 \\
\hline \multirow{2}{*}{8} & LTS & $\mathrm{T}$ & 1000 & 2000 & 3430 & 3420 & 2963 & 3807 & 4020 & 2838 & 4219 & 4295 & 3156 \\
\hline & LTN & $\mathrm{T}$ & 1000 & 2000 & 3260 & 3240 & 3016 & 3804 & 3857 & 3032 & 4060 & 4092 & 3230 \\
\hline \multirow{4}{*}{20} & 2T & $\mathrm{T}$ & 200 & 532 & 732 & 722 & 879 & 1171 & 1145 & 1090 & 1270 & 1243 & 1236 \\
\hline & $3 \mathrm{~T}$ & $\mathrm{~T}$ & 116 & 406 & 406 & 406 & 406 & 441 & 473 & 393 & 504 & 507 & 582 \\
\hline & $6 \mathrm{~T}$ & $\mathrm{~T}$ & 200 & 532 & 772 & 762 & 967 & 1231 & 1245 & 1175 & 1341 & 1348 & 1392 \\
\hline & $15 \mathrm{~T}$ & $\mathrm{~T}$ & 200 & 532 & 882 & 882 & 1076 & 1520 & 1522 & 1332 & 1653 & 1655 & 1563 \\
\hline \multirow{2}{*}{22} & LT3 & $\mathrm{C}$ & 360 & 720 & 1960 & 1950 & 2499 & 2377 & 2335 & 2487 & 2539 & 2505 & 2728 \\
\hline & LT4 & $\mathrm{C}$ & 360 & 720 & 1050 & 1040 & 863 & 1108 & 1130 & 789 & 1189 & 1201 & 945 \\
\hline 30 & LT1 & $\mathrm{C}$ & 133 & 267 & 267 & 267 & 267 & 154 & 154 & 154 & 265 & 265 & 265 \\
\hline \multirow{14}{*}{32} & C-E-2 & $\mathrm{C}$ & 1219 & 3060 & 8390 & 8350 & 8317 & 10148 & 10077 & 8368 & 10680 & 10578 & 8869 \\
\hline & LR-E-2 & $\mathrm{T}$ & 1196 & 1531 & 5361 & 5371 & 7120 & 8007 & 8099 & 8049 & 8441 & 8524 & 8427 \\
\hline & R-E-2 & $\mathrm{T}$ & 1196 & 1531 & 3201 & 3171 & 4330 & 4526 & 4523 & 4738 & 4793 & 4786 & 5100 \\
\hline & C-W-1 & $\mathrm{C}$ & 1201 & 3003 & 3933 & 3933 & 3510 & 4370 & 4370 & 3504 & 4648 & 4648 & 3681 \\
\hline & LR-W-1 & $\mathrm{T}$ & 1201 & 1501 & 3271 & 3271 & 3425 & 4432 & 4469 & 3559 & 4763 & 4767 & 3945 \\
\hline & R-W-1 & $\mathrm{T}$ & 1201 & 1501 & 2941 & 2921 & 3045 & 4173 & 4144 & 3262 & 4390 & 4361 & 3523 \\
\hline & P1-31 & $\mathrm{T}$ & 1200 & 1560 & 2320 & 2260 & 2179 & 2590 & 2501 & 2155 & 2746 & 2649 & 2295 \\
\hline & P1-34 & $\mathrm{T}$ & 1200 & 1560 & 2030 & 2000 & 1858 & 2229 & 2139 & 1832 & 2396 & 2324 & 1982 \\
\hline & P2-2 & $\mathrm{T}$ & 1200 & 1560 & 2960 & 2960 & 3430 & 3524 & 3563 & 3456 & 3748 & 3774 & 3755 \\
\hline & P2-7 & $\mathrm{T}$ & 1200 & 1560 & 2070 & 2030 & 2212 & 2352 & 2323 & 2228 & 2490 & 2459 & 2401 \\
\hline & P2-8 & $\mathrm{T}$ & 1200 & 1560 & 2130 & 2120 & 1909 & 2362 & 2282 & 1761 & 2502 & 2448 & 2026 \\
\hline & P2-11 & $\mathrm{T}$ & 1200 & 1560 & 2300 & 2270 & 2684 & 2549 & 2473 & 2697 & 2704 & 2623 & 2863 \\
\hline & P3-3 & $\mathrm{T}$ & 1200 & 1560 & 2250 & 2200 & 2153 & 2546 & 2553 & 2147 & 2703 & 2708 & 2306 \\
\hline & P3-10 & $\mathrm{T}$ & 1200 & 1560 & 2480 & 2450 & 2222 & 2828 & 2739 & 2166 & 2998 & 2915 & 2370 \\
\hline
\end{tabular}


Table 3-4 - Failure load results calculated through gradual failure methods using extrapolated Q-s curves (continued)

\begin{tabular}{|c|c|c|c|c|c|c|c|c|c|c|c|c|c|}
\hline \multirow{3}{*}{ Site } & \multirow{3}{*}{ Pile } & \multicolumn{3}{|c|}{ Design } & \multicolumn{9}{|c|}{ Gradual Failure \& Extrapolation Methods (kN) } \\
\hline & & \multirow{2}{*}{$\mathbf{L} \mathbf{T}^{\mathbf{1}}$} & \multirow{2}{*}{$\begin{array}{l}\mathrm{DL}^{2} \\
(\mathrm{kN})\end{array}$} & \multirow{2}{*}{$\begin{array}{c}\text { MTL }^{3} \\
(\mathbf{k N})\end{array}$} & \multicolumn{3}{|c|}{ Fuller and Hoy \& } & \multicolumn{3}{|c|}{ De Beer \& } & \multicolumn{3}{|c|}{ Hansen \& } \\
\hline & & & & & Chin & Dec $^{7}$ & VDV $^{6}$ & Chin & Dec $^{7}$ & VDV $^{6}$ & Chin & Dec $^{7}$ & VDV $^{6}$ \\
\hline \multirow{2}{*}{32} & P3-18 & $\mathrm{T}$ & 1200 & 1560 & 4650 & 4640 & 5332 & 5955 & 5970 & 5650 & 6255 & 6289 & 5887 \\
\hline & P3-24 & $\mathrm{T}$ & 1200 & 1560 & 3640 & 3630 & 3567 & 4751 & 4667 & 3693 & 4996 & 4933 & 3967 \\
\hline 36 & LT1 & $\mathrm{C}$ & 500 & 875 & 1005 & 995 & 1039 & 1220 & 1252 & 1050 & 1309 & 1333 & 1230 \\
\hline \multirow{4}{*}{53} & TP1 & $\mathrm{C}$ & 874 & 2185 & 5445 & 5455 & 6255 & 6744 & 6819 & 6475 & 7102 & 7199 & 6858 \\
\hline & TP3 & $\mathrm{T}$ & 477 & 1431 & 2911 & 2851 & 4773 & 3586 & 3398 & 4951 & 3769 & 3606 & 5198 \\
\hline & C1 & $\mathrm{T}$ & 630 & 725 & 1525 & 1535 & 1218 & 2076 & 2092 & 1227 & 2233 & 2252 & 1430 \\
\hline & $\mathrm{C2}$ & $\mathrm{T}$ & 630 & 725 & 1515 & 1495 & 1583 & 2292 & 2146 & 1592 & 2441 & 2346 & 1934 \\
\hline 54 & TP1 & $\mathrm{C}$ & 225 & 450 & 580 & 570 & 626 & 716 & 672 & 652 & 762 & 721 & 734 \\
\hline
\end{tabular}

${ }^{1}$ LT: load type in either tension (T) or compression (C)

${ }^{2} \mathrm{DL}$ : design load

${ }^{3}$ MTL: maximum test load

${ }^{4}$ Plunging failure by Decourt's method

${ }^{5}$ Skin frictional resistance estimated by Decourt's method

${ }^{6}$ VDV: Van Der Veen's method

${ }^{7}$ Dec: Decourt's method 


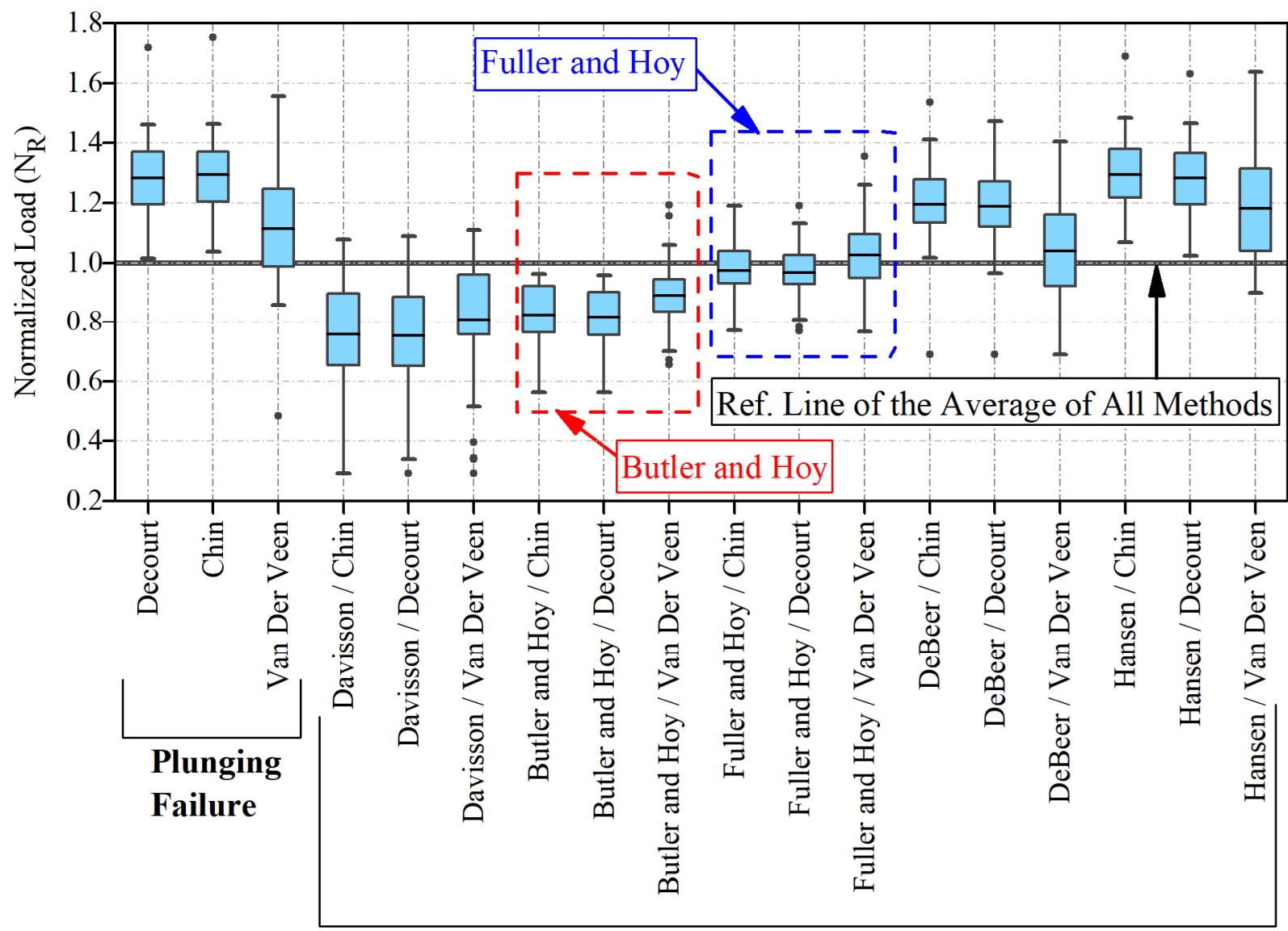

Gradual Failure \& Extrapolation Methods Combination

Figure 3-13 - Boxplot of load variability for all studied micropiles

\subsection{SUMMARY}

A database of micropile load tests was provided by Keller Foundations Ltd, where the tests were carried out in 14 Type A, 6 Type B, 8 CGF, and 12 Type D micropiles. SPT results were also provided for each test. SPT N-values were limited to 60 , due to the reliability of this in-situ test in boulder and cobble rich soils, such as Ontario soils.

Load tests from the database did not achieve the true geotechnical failure. A reasonable solution to analyze them in terms of the ULS was to combine a gradual failure method with an extrapolation method. Through a statistical analysis, the possible combinations of different extrapolation and gradual failure methods were compared among themselves. It was determined that Fuller and Hoy's method is the best method to analyze the database. This method can be combined with any extrapolation method. Thus, for the further analyses, Fuller and Hoy's method was combined with Chin's method to provide the failure load of the micropiles in the database. 


\section{BOND STRENGTH EVALUATION}

\subsection{INTRODUCTION}

The contributions of the micropile tip and of the cased length to the total ultimate capacity of the micropile is required in order to analyze the isolated contribution of the bond length. The micropile tip resistance is estimated using both the Elastic Length method (ELM) and Decourt's Extrapolation method (DEM). The cased length resistance is predicted with the ELM, which is discussed in this chapter. Thus, from the failure load defined in the previous chapter, the values of bond strength (only along the bond length) are calculated. These results are compared with the available values in the literature and suitable parameters for micropiles in Ontario are suggested.

\subsection{Elastic Length Method}

\subsubsection{Concept of the Method}

Bruce et al. (1992) and Bruce et al. (1993) introduced the concept of the Elastic Ratio, ER. This parameter is calculated through Equation 4-1. Gómez et al. (2003) and Cadden et al. (2004) further developed this concept by introducting the elastic length, $L_{e}$, shown in Equation 4-2.

$$
\begin{gathered}
E R=\frac{S_{e}}{\Delta Q} \\
L_{e}=\frac{S_{e} \sum E A}{\Delta Q}
\end{gathered}
$$

where $\Delta Q$ is the applied load, $S_{e}$ is the elastic settlement, shown schematically in Figure 4-2 for the $4^{\text {th }}$ loading cycle, and $\sum E A$ is the combined axial stiffness of the micropile.

Equation 4-2 can be compared with a rod under axial loading. Equation 4-3 computes the elastic deformation $\delta$ of a rod under an axial loading $P$ (Beer, 2011).

$$
\delta=\frac{P L}{E A}
$$

where $L$ is the rod length and $E A$ is the rod axial stiffness.

It is clear the similarity between Equation 4-2 and Equation 4-3. FHWA (2005) has also proposed a modification to compute the elastic deformation. Since the micropile has usually two sections 
with different stiffness values (cased length and bond length), it was proposed to calculate the contribution of each individual length $j$ and sum them to generate the total elastic deformation, $S_{e}$, as shown in Equation 4-4.

$$
S_{e}=\sum_{j=1}^{n} \frac{\Delta Q_{j} L_{j}}{E_{j} A_{j}}
$$

where $\Delta Q_{j}$ is the applied load along the length $j, L_{j}$ is the length $j, E_{j} A_{j}$ is the axial stiffness along the length $j$.

\subsubsection{Prediction of the Elastic Settlement}

The CFEM (CGS, 2006) recommends several different approaches for settlement prediction. One of them was described by Vesic (1970) and futher developed by Vesic (1977). These studies separate the settlement of a loaded single pile, $S$, in elastic deformation of the pile shaft, $S_{e}$, settlement of the pile due to skin frictional load mobilization, $S_{s k}$, and settlement of the pile due to tip mobilization, $S_{t p}$. Equation 4-5 shows this situation.

$$
S=S_{e}+S_{s k}+S_{t p}
$$

For prediction of $S_{e}$, Vesic (1970) proposes the following:

$$
S_{e}=\left(Q_{t p}+\xi Q_{s k}\right) \frac{L}{E A}
$$

where $Q_{t p}$ is the load mobilized at the pile toe, $Q_{s k}$ is the load mobilized along the shaft, $\xi$ is a coefficient which is associated with the load-transfer distribution, $L$ is the pile length, and $E A$ is the pile axial stiffness.

Vesic (1970) had first suggested the value of $\xi$ equal to 0.6. Vesic (1977), nonetheless, refined its values according to the type of load-transfer distribution, illustrated in Figure 4-1.

\subsubsection{Modification of the Elastic Length Method}

Equation 4-3, which was used to generate Equation 4-4, is valid for columns under constant load along its length. Therefore, the coefficient $\xi$ suggested by Vesic (1977) is introduced to account for the load-transfer distribution. Thus, the mobilized length $\left(L_{m}\right)$ is not actually equal to $L_{e}$. $L_{m}$ is shown in Equation 4-7. 


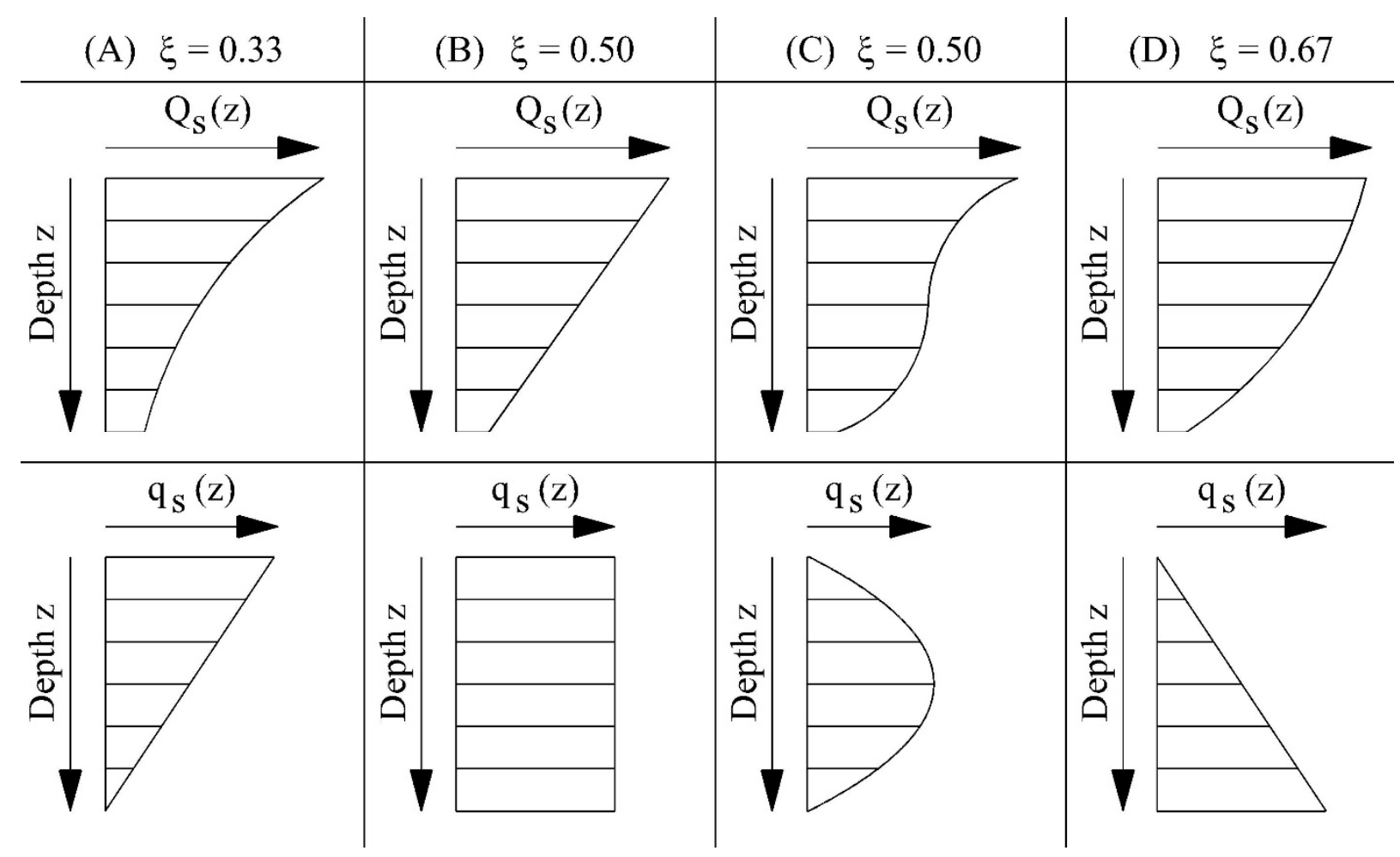

Figure 4-1 - Values of $\xi$ for load-transfer distributions (A) to (D) after Vesic (1977)

$$
L_{m}=\sum_{j=1}^{n} \frac{S_{e, j} E_{j} A_{j}}{\xi_{j} \Delta Q_{j}}
$$

where $\xi_{j}$ is the coefficient $\xi$ of the length $j$ and $S_{e, j}$ is the elastic deformation experience by the length $j$.

Equation 4-7 can be used to estimate the mobilized length for each load cycle. The measured elastic rebound is equal to the elastic settlement, $S_{e}$, and the applied load, $\Delta Q$, is equal to the maximum load of the cycle minus the Alignment Load of the system. Figure 4-2 illustrates these values in the $3^{\text {rd }}$ loading cycle of a Q-s curve.

Bruce et al. (1993) has suggested that the increasing values of $E R$ observed throughout the test indicated that debonding was developing along the micropile. Gómez et al. (2003) has contradicted Bruce et al. (1993) in this matter. They believed that ER could indeed vary during testing due to post-peak reduction of the bond strength or locked-in stresses generation between the micropile and the ground interface. It is believed, however, that ER will naturally vary during testing due to continuous mobilization of the micropile length ( $L_{m}$ increasing gradually) and the change in the curve shape of the load-trasnfer distribution (progressive change in $\xi$ ). 


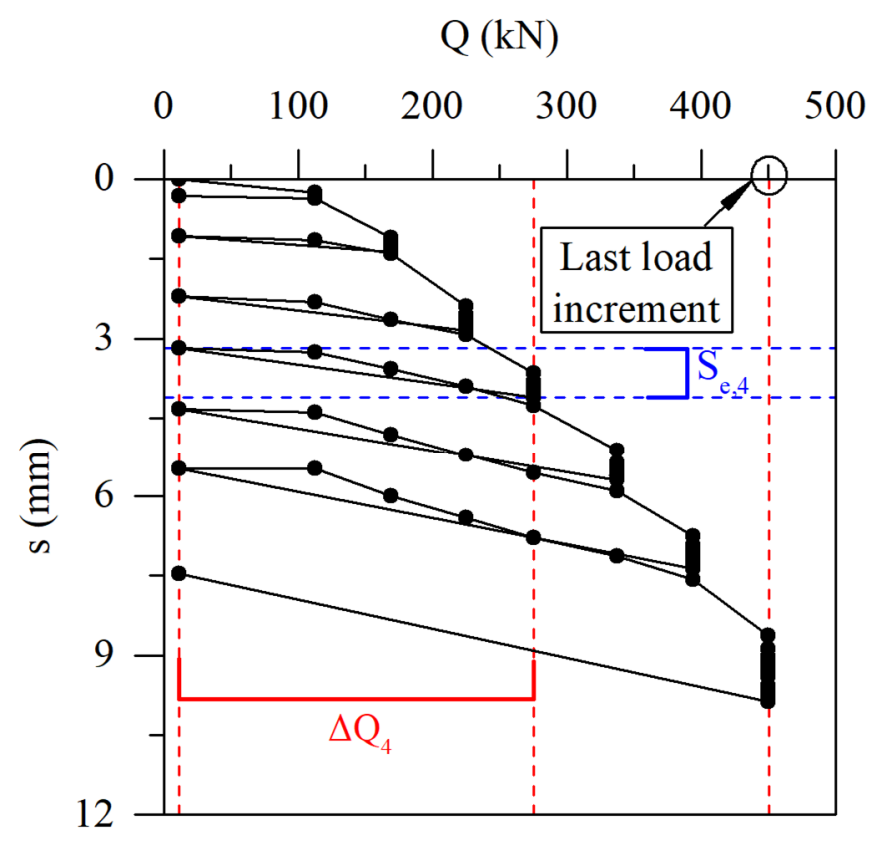

Figure 4-2 - Illustration of $\Delta Q$ and $S_{e}$ interpreted for the $4^{\text {th }}$ loading cycle

Gómez et al (2007) and Post-Tensioning Institute (2014) have also implemented $\xi$ in their equations for $L_{m}$. However, both limited $\xi$ equal to 0.50 (case B from Figure 4-1) and only considered $\xi$ along the bond length. For the case of Post-Tensioning Institute (2014), it is understable this assumption, since the guidelines are for anchors. For micropiles, nonetheless, it is believed that $\xi$ can indeed go higher than 0.50 and the cased length is not necessarily unbonded.

\subsection{Methodology And Results of Bond Stress Prediction}

An instrumented load test can provide the distribution of the axial load along the micropile depth. This information makes it possible to verify the mobilized loading along both cased length and bond length at each loading stage. Ramirez (2006) and Kan et al. (2013) have conducted instrumented load testing in micropiles. Ramirez (2006) performed tests in 8 micropiles, but only 3 of them were exclusive embedded in soils. 1 Type A, 1 Type D, and 1 CGF micropiles were evaluated and it was found that negligible loading was mobilized along the cased length. Kan et al. (2013) analyzed 2 Type A micropiles without casing. It was noticed that both of them did not achieve failure and the distribution curve is equivalent to case A from Figure 4-1.

\subsubsection{Load-Transfer Distribution}

Figure 4-3 shows the evolution of the stress distribution from a first stage 01 to a debonding stage 05 along a cased length or a bond length. From the findings of Kan et al. (2013), it can be stated that the initial loading stages of a loading test are similar to stage 01 from Figure 4-3 for both cased 
length and bond length. When loading is increased, the deeper strata is further mobilized, leading the previous concave shape of the load-transfer distribution to a linear shape (case 02 from Figure 4-3), generating a uniform shape of the stress distribution. With even further load application, deeper strata continue to be mobilized, generating the case 03 from Figure 4-3. Next, the soil in the vicinity of the upper portions of the pile might experience strain softening and contribution of this region is decreased, while mobilization in the deeper strata is still increasing (stage 04 from Figure 4-3). The final stage 05 from Figure 4-3 is believed to be under debonding of the upper strata. During plunging failure, it is believed that the cased length might be in the stage 05 . However, in terms of gradual failure methods, this might not the case because the considered failure is not necessarily in the plunging state.

\subsubsection{Loading Sequence of a Load Test}

Stuedlein et al. (2008) suggests that the progression of the loading stages during testing follows a linear pattern. However, after implementing $\xi$ along the cased length and the bond length, not considered by Stuedlein et al. (2008), the linear shape can be adjusted using the proposed stages (1 to 5) from Figure 4-3. Figure 4-4 illustrates the proposed loading sequence of a load test from an initial loading I to a debonded state $X$ along the casing. Table 4-1 provides the $\xi$ achieved in each case of Figure 4-4 for the cased length $\left(\xi_{c a s}\right)$ and for the bond length $\left(\xi_{\text {bond }}\right)$. Clearly, a fully debonded cased length will have its $\xi_{\text {cas }}$ equal to 1, which is equivalent to the scenario of a column under constant load (Equation 4-3), an ideal bearing pile case without any skin resistance.

The actual mobilization evolution may be only known with instrumented load tests, which are rarely done in micropiles. Thus, Figure 4-4 proposes an assumption only. For instance, the sequence proposed considers that the tip is only mobilized after the shape of the load-distribution curve for both cased length and bond length achieves the convex configuration (stage 4 from Figure 4-3). This is not necessarily true (it may be generated since case IV from Figure 4-4). Nevertheless, this assumption is adopted for simplicity. In addition, there might be several cases between each case. 


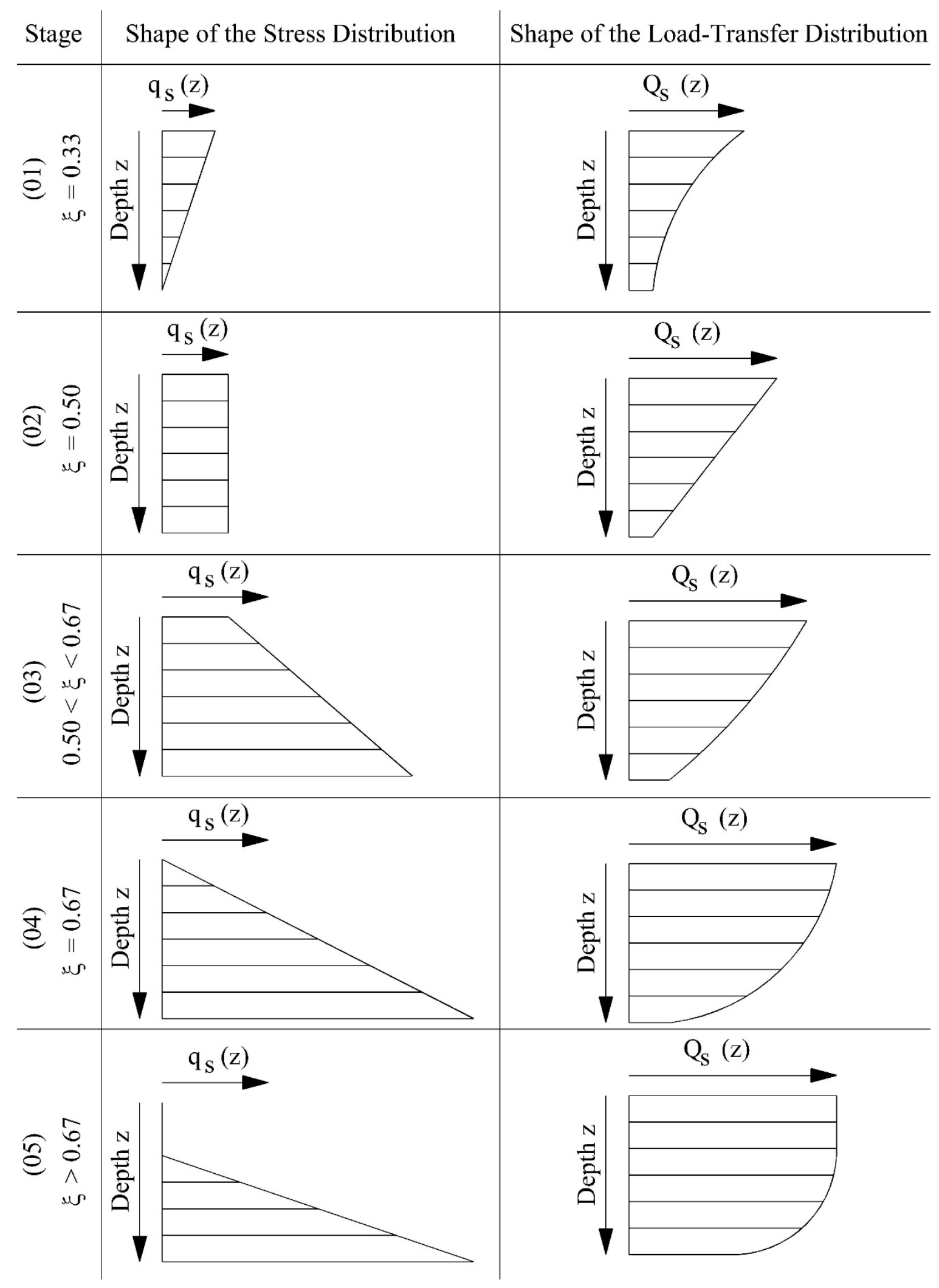

Figure 4-3 - Evolution of stress and load-transfer distributions along the cased length or the bond length 


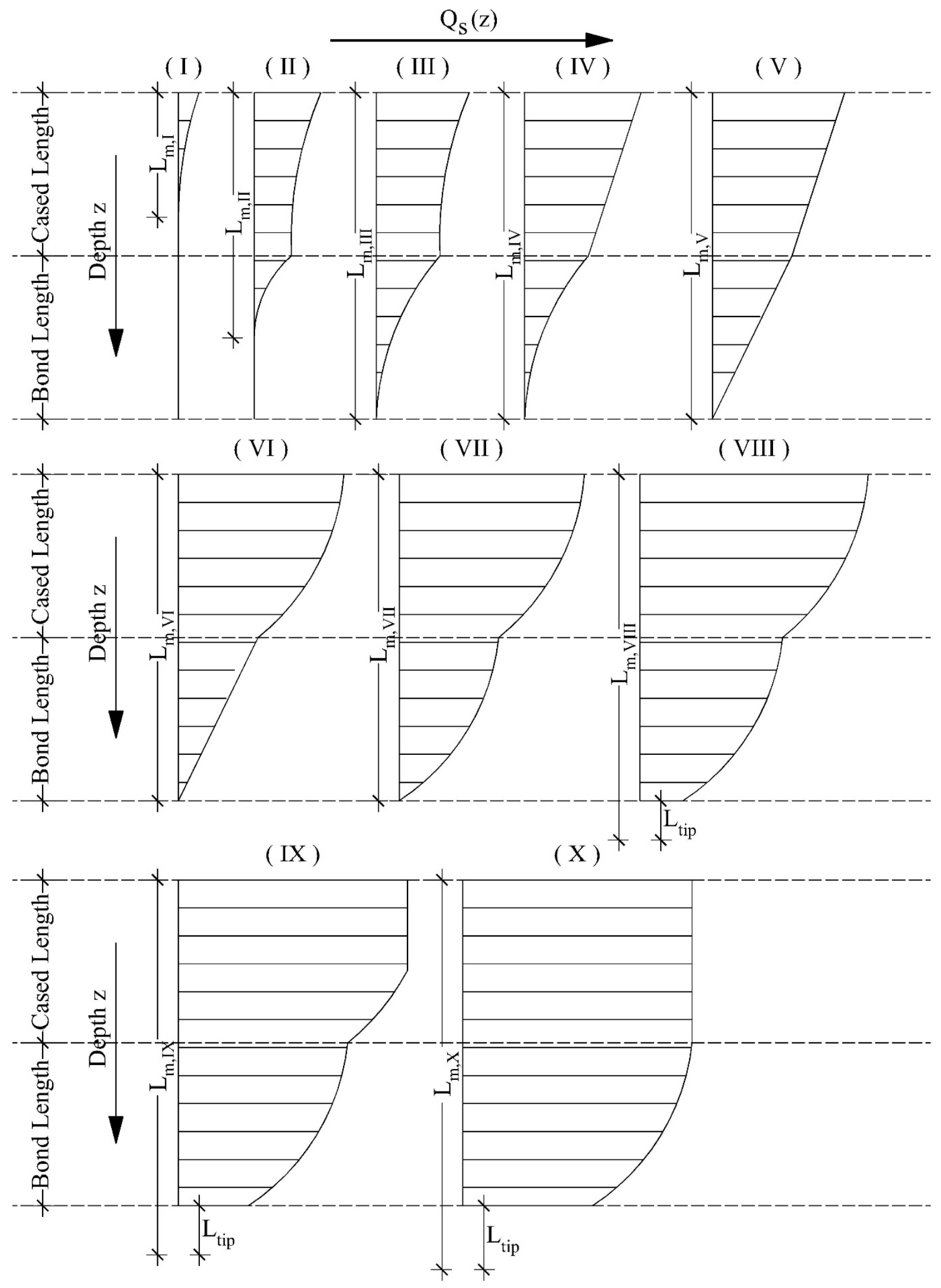

Figure 4-4 - Sequences of load mobilization along the micropile depth 
Table 4-1 - Parameters of load mobilization along the micropile depth

\begin{tabular}{|c|c|c|c|c|c|c|}
\hline \multirow{2}{*}{$\begin{array}{c}\text { Case } \\
\text { Figure 4-4 }\end{array}$} & \multicolumn{3}{|c|}{ Casing Length } & \multicolumn{3}{c|}{ Bond Length } \\
\cline { 2 - 7 } & $\begin{array}{c}\text { Stage } \\
\text { Figure 4-3 }\end{array}$ & $\boldsymbol{\xi}_{\text {cas }}$ & Notes & $\begin{array}{c}\text { Stage } \\
\text { Figure 4-3 }\end{array}$ & $\boldsymbol{\xi}_{\text {bond }}$ & Notes \\
\hline I & 01 & 0.33 & - & - & - & - \\
\hline II & 01 & 0.33 & - & 01 & 0.33 & - \\
\hline III & 01 & 0.33 & - & 01 & 0.33 & - \\
\hline IV & 02 & 0.50 & - & 01 & 0.33 & - \\
\hline V & 02 & 0.50 & - & 02 & 0.50 & - \\
\hline VI & 04 & 0.67 & - & 02 & 0.50 & - \\
\hline VII & 04 & 0.67 & - & 04 & 0.67 & - \\
\hline VIII & 04 & 0.67 & - & 04 & 0.67 & Tip mobilized \\
\hline IX & 05 & $>0.67$ & Debonding starts & 04 & 0.67 & Tip mobilized \\
\hline X & 05 & 1.00 & Fully debonded & 04 & 0.67 & Tip mobilized \\
\hline
\end{tabular}

\subsubsection{Axial Resistance of the Cased length}

From Figure 4-4, it is clear that the skin resistance is gradually mobilized during a load test. It is reasonable to assume that $R_{\text {cas,Max }}$ (the maximum load resisted by the cased length) happens during the first few load increments because the cased length is situated above the bond length (hence, it is the first region to be mobilized), and also it has much lower capacity compared to the bond length (Ramirez, 2006).

The highest value of skin frictional resistance along a length of a pile might be between stages 03 and 04 from Figure 4-3. Vesic (1970) has originally proposed the value of 0.60 for $\xi$. This value would be a reasonable assumption for the case of maximum resistance by skin friction along the cased length. Nonetheless, this study used this method mainly to predict the capacity along the cased length which will be subtracted from the ultimate capacity to generate the ultimate bond strength (see item 4.3.5). Thus, in an effort to account for the worst-case scenario of the bond strength and following the proposed evolution of load mobilization in Figure 4-4, it is assumed that a $\xi_{c a s, M a x}$ equal to 0.67 will generate $R_{\text {cas,Max }}$.

Furthermore, the minimum load resisted by the cased length $\left(R_{\text {cas,Min }}\right)$ will occur when the cased length is first fully mobilized (between cases I and II from Figure 4-4). This scenario can be adopted from Kan et al. (2013), and it will occur with $\xi_{c a s, M i n}$ equal to 0.33 .

During the first full mobilization of the cased length, Equations 4-1 and 4-7 can be used and $L_{m}$ can be taken as equal to the cased length, $L_{c a s}, E_{j} A_{j}$ as $(E A)_{c a s}$, the axial stiffness of the cased length, and $E R$ as $E R_{c a s, i}$, the elastic ratio of the cased lengh during a load cycle $i$. It is generated then Equation 4-8. Hence, it is suggested to find the load resisted by the cased length during a 
cycle of load $i, R_{\text {cas }, i}$, by the mobilization line of the cased length (Figure 4-5a) using the following process:

1) Plot $E R$ vs Q (similar to Figure 4-5a) and find the mobilization line of the cased length;

2) calculate $E R_{\text {cas }, \text { Min }}$ using Equation $4-8$ and $\xi_{\text {cas }, i}$ equal to 0.33 ( $\left.\xi_{\text {cas }, \text { Min }}\right)$;

3) calculate $E R_{\text {cas,Max }}$ using Equation 4-8 and $\xi_{\text {cas }, i}$ equal to 0.67 ( $\xi_{\text {cas }, \text { Max }}$ );

4) find $R_{c a s, \text { Max }}$ and $R_{c a s, M i n}$ from $E R_{c a s, \text { Max }}$ and $E R_{c a s, \text { Min }}$, similar to Figure 4-5b;

$5)$ compute the subsequent which is in between $R_{\text {cas,Min }}$ and $R_{c a s, M a x} . R_{c a s, i}$ value depends on $\xi_{c a s, i}$ (coefficient $\xi$ for the casing in the load cycle $i$ ).

$$
E R_{c a s, i}=\frac{L_{c a s} \xi_{c a s, i}}{(E A)_{c a s}}
$$

Figure 4-5 presents one example of this situation. In the example of Figure 4-5b, ER $R_{\text {cas,Min }}$ is equal to $0.003 \mathrm{~mm} / \mathrm{kN}$ and $E R_{\text {cas,Max }}$ is equal to $0.0061 \mathrm{~mm} / \mathrm{kN}$. $R_{\text {cas,Min }}$ is estimated to be approximately $220 \mathrm{kN}$ and $R_{\text {cas,Max }}$ is approximately $445 \mathrm{kN}$, according to $E R_{c a s, \text { Min }}$ and $E R_{\text {cas }, \text { Max }}$ values. Values of $R_{\text {cas }, i}$ will be between these two values.

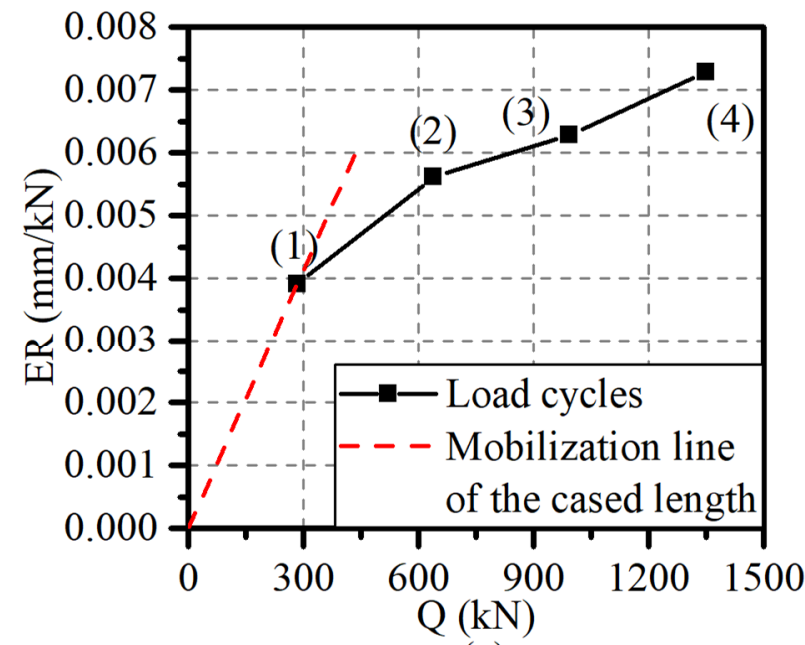

(a)

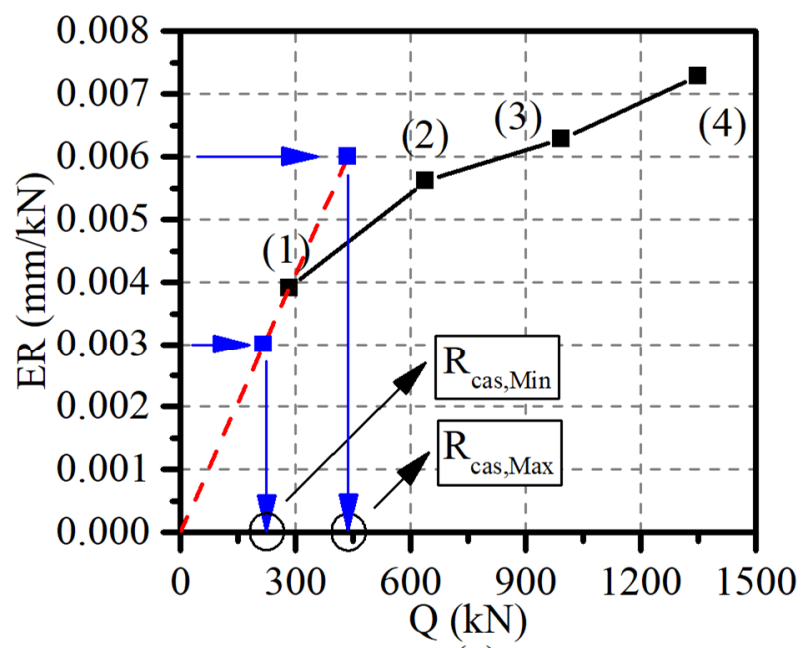

(a)

Figure 4-5 - Estimating $R_{c a s, i}$ range from (a) determining the mobilization line of the cased length and (b) estimating $R_{c a s, M i n}$ and $R_{c a s, M a x}$ from $E R_{c a s, M i n}$ and $E R_{c a s, \text { Max }}$

It is worth noticing that after debonding has started to happen along the cased length (case IX from Figure 4-4), $R_{\text {cas }, i}$ will likely decrease. Thus, the above mobilization line of the cased length is applicable for a value of $\xi_{\text {cas, } i}$ up to $\xi_{\text {cas,Max }}$, which is 0.67 . 


\subsubsection{Bond and Tip Mobilization}

After estimating the contribution from the cased length to the total applied load, it is necessary to compute the contributions from both tip and bond length to the total micropile resistance. Before the full mobilization of $L_{\text {cas }}$, Equation 4-9 can be used, since there is no contribution from the other components (tip and bond length). After its full mobilization, Equation 4-10 should be used instead. Equation 4-10 was developed from the sequence of load mobilization from Figure 4-4 (see Appendix). It is applicable when there is no tip mobilization (cases II to VII from Figure 4-4). Nonetheless, Equation 4-10 is still applied to identify whether the tip is mobilized or not and verify if the load cycle is under the case VIII from Figure 4-4. In order to verify these conditions, the following steps can be applied to calculate the mobilized length of each load cycle $i, L_{m, i}$ :

1) Equation 4-1 should be used to calculate $E R_{i}$ for each load cycle $i$; and

2) compare $E R_{i}$ with $E R_{\text {cas }, i}$ :

a. If $E R_{i} \leq E R_{\text {cas }, i}$, use Equation 4-9 to compute $L_{m, i}$,

$$
L_{m, i}=\frac{E R_{i}(E A)_{c a s}}{\xi_{c a s, i}}
$$

b. otherwise, Equation 4-10 should be used.

$$
L_{m, i}=L_{c a s}+\frac{(E A)_{b o n d}}{\xi_{b o n d, i}\left(Q_{i}-R_{c a s, i}\right)}\left[S_{e, i}-\frac{\left(Q_{i}-R_{c a s, i}\right) E R_{c a s, i}}{\xi_{c a s, i}}-R_{c a s, i} E R_{c a s, i}\right]
$$

where $Q_{i}$ is the total applied load during cycle $i,(E A)_{\text {bond }}$ is the axial micropile stiffness of the bond length, $\xi_{\text {bond, } i}$ and $\xi_{c a s, i}$ are, respectively, the coefficient $\xi$ for the cased length and bond length during a cycle $i$, and $S_{e, i}$ is the elastic rebound of each load cycle $i$.

Equations 4-9 and 4-10 requires $\xi_{c a s, i}$ and $\xi_{\text {bond, } i}$ for each load cycle $i$. Then, it is suggested to use values for both $\xi$ between 0.33 and 0.67 . In addition, the sequence of loading from Figure 4-4 should be followed. For instance, if a test is conducted under tensile load, or if the tip resistance of a test under compressive load was not identified in DEM, the tip resistance is equal to zero. In these cases, the maximum value of $L_{m, i}$ is $L_{c a s}+L_{b o n d}$. By trial and error and from the first cycle to the last cycle $n$, values of $\xi_{c a s, i}$ and $\xi_{\text {bond }, i}$ are incrementally adjusted according to these boundary conditions.

A plot between $L_{m, i}$ and $Q_{i}$ for all load cycles $i$ can then be done. An example is shown at Figure 4-6. The tip resistance, $R_{\text {tip }}$, is identified at Figure 4-6a, if the total length of micropile was $15 \mathrm{~m}$. 
However, if this total length was $16.5 \mathrm{~m}$ (such as in Figure 4-6b), identifying the tip resistance would not be possible and thus would be taken as zero.

The tip mobilization is highly dependent on the adopted $\xi_{b o n d, i}$ and $\xi_{c a s, i}$. Therefore, the equation provided by the line of the "Lower Bound Limit for the Shaft Frictional Resistance" from DEM is also used to assist in establishing the values of $\xi_{\text {bond }, i}$ and $\xi_{c a s, i}$. Values achieved by DEM for tip and skin frictional resistance of each load cycle $i$ are compared with values obtained by the ELM. Then, $\xi_{\text {bond }, i}$ and $\xi_{c a s, i}$ are adjusted accordingly.
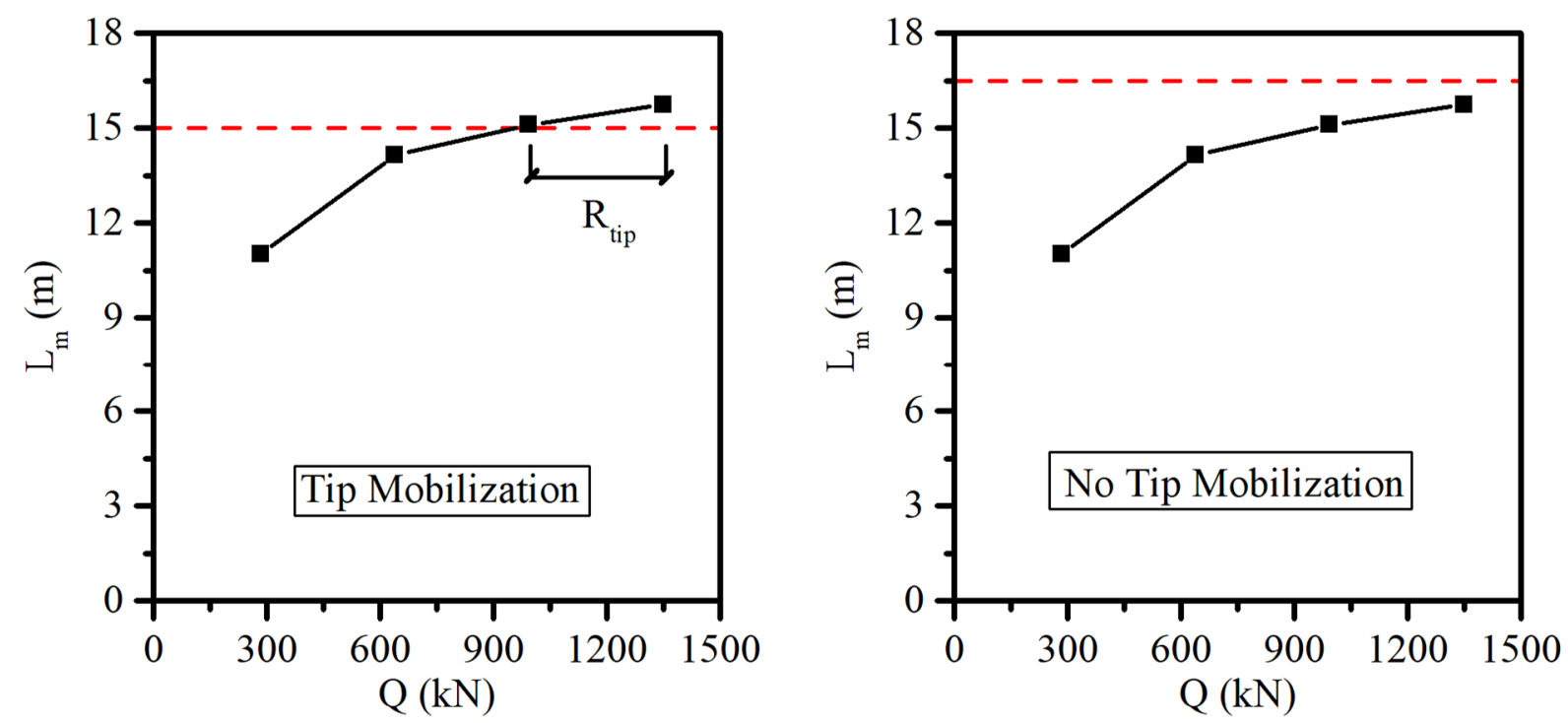

Figure 4-6 - Plot of $L_{m}$ vs Q (a) to estimate $R_{\text {tip }}$ and (b) assume no $R_{\text {tip }}$

\subsubsection{Steps for Analysis}

From the discussion above, it can be summarized the following steps of analysis for bond stress prediction:

1) calculate $E R_{i}$ for all load cycles $i$ using Equation 4-1;

2) plot a graph of $E R_{i}$ vs $Q_{i}$ for all load cycles $i$ (similar to Figure 4-5a);

3) compute $E R_{\text {cas,Max }}$ and $E R_{\text {cas,Min }}$ from Equation 4-8;

4) find $R_{\text {cas,Max }}$ and $R_{c a s, M i n}$ by the mobilization line of the cased length of $E R_{i}$ vs $Q_{i}$ (similar to Figure 4-5b);

5) compute $R_{\text {cas, } i}$ for each load cycle $i$ along the mobilization line of the cased length with adopted $\xi_{c a s, i}$ and $\xi_{\text {bond, } i}$ between 0.33 and 0.67 in an incremental manner, following the evolution of loading in Figure 4-4;

6) calculate $L_{m, i}$ for each load cycle $i$ using either Equation 4-9, if $E R_{i} \leq E R_{c a s}$, otherwise Equation 4-10;

7) estimate the tip resistance $R_{t i p, i}$ for each load cycle $i$ (similar to Figure 4-6a); 
8) compare the estimated tip resistance with the predicted tip resistance by DEM. If necessary, change values of $\xi_{\text {cas }, i}$ and $\xi_{\text {bond }, i}$; and

9) calculate the average bond strength along the bond length, $\overline{q_{s}}$, by using Equation 4-11.

$$
\overline{q_{s}}=\frac{R}{\pi D L_{b o n d}}=\frac{R_{F H}-R_{c a s, \text { Max }}-R_{t i p, F H}}{\pi D L_{b o n d}}
$$

where $R_{F H}$ is the failure load determined by Fuller and Hoy's method, $R_{t i p, F H}$ is the tip resistance during Fuller and Hoy's failure load (estimated with DEM in Figure 4-7), $L_{b o n d}$ is the bond length, and $D$ is the bond length diameter.

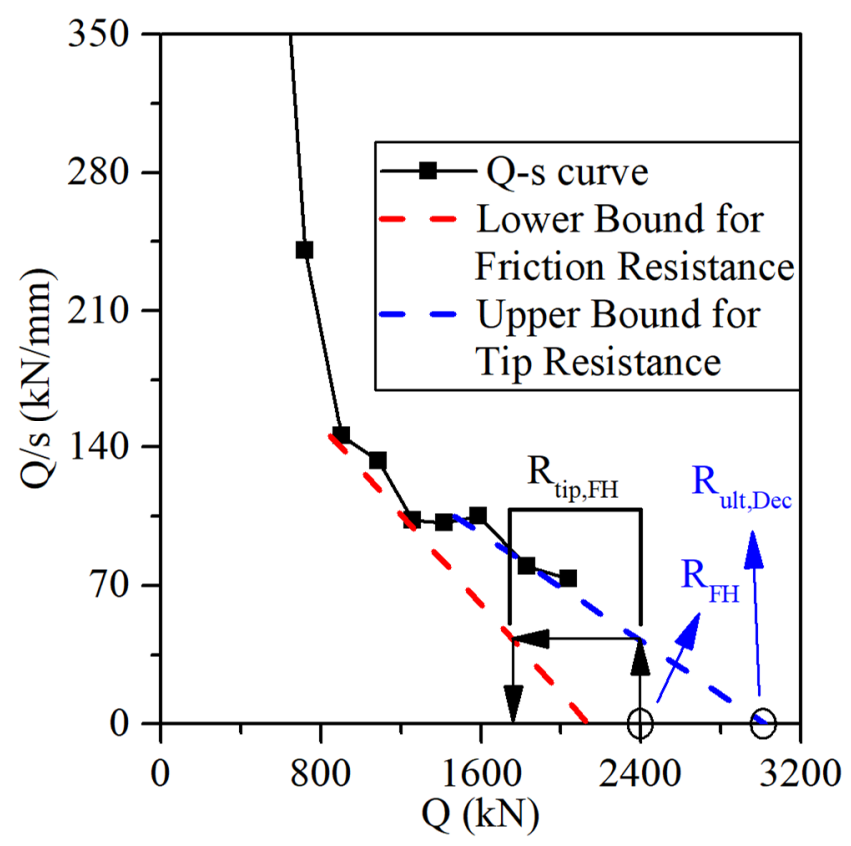

Figure 4-7 - Estimation of $R_{t i p, F H}$ by DEM

\subsubsection{Discussions and Results}

Table 4-2 provides a compassion between the results of the ELM and the skin frictional resistance by DEM at the last load cycle $n$. Combining these two methods in analysis assists in identifying the transition point of DEM (by verifying the values of $\xi_{b o n d, i}$ and $\xi_{c a s, i}$ ) and in determining suitable values of $\xi_{\text {bond,i } i}$ and $\xi_{c a s, i}$ with reasonable estimation of the tip resistance.

Among the compression tests that did not have their skin frictional resistance identified by DEM, the achieved values of $\xi$ for the ELM ranged from 0.33 to 0.67 (validating the assumption in Figure 4-4). Also, the micropiles that had their skin frictional resistance identified by DEM, experienced $\xi$ varying from 0.60 to 0.67 . Several micropiles had their values of $\xi$ equal to 0.33 , showing that 
they are indeed far from failure, such as in Kan et al. (2013). Overall, the values of $\xi$ concentrated between 0.33 and 0.50 for both cased length and bond length. Micropiles that were unbonded according to Table $3-1$ had their $\xi_{c a s, n}$ equal to 1 .

Micropiles from Sites 08 and 30 did not have their respective parameters properly determined due to a high difference between the final load and the alignment load. Also, they were loaded with only one cycle. Hence, mainly the contribution of $R_{\text {bond,n }}$ for the site 30 , and $\xi_{\text {cas }, n}$ and $\xi_{\text {bond,n }}$ for the site 08 obtained much different results than the other sites. Although these sites might be outliers, the ELM mainly contributed for the estimation of $R_{c a s, M a x}$ which is not as high as $R_{F H}$. Thus, in order to not decrease even further the quantities of cases, they were not treated as outliers for the further analyses.

On the one hand, it was proposed a simple approach for determining an approximation of the contributions from the cased length and the micropile tip. On the other hand, this method has three major problems: it is only an approximation of the micropile behaviour due to lack of parameters directly associated with the soil type; the estimation of the casing resistance is dependent on the quantity of load cycles of the test; and it also depends on structural parameters of the micropile which are difficult to predict because of the grout confinement provided by the casing. These may have affected the results. FHWA (2000) suggests a grout modulus of elasticity of $31 \mathrm{GPa}$ for the cased length and $23 \mathrm{GPa}$ for the bond length. This study thus adopted these values.

Figures 4-8 to 4-11 plots achieved values of $\overline{q_{s}}$ against the average uncorrected SPT N value $\left(\mathrm{N}_{\mathrm{f}}\right)$ of the bond length layer. Bond strength values for type A micropiles for the $25^{\text {th }}$ and $75^{\text {th }}$ percentiles from 194 to $567 \mathrm{kPa}$ for sands with $\mathrm{N}_{\mathrm{f}}$ ranging from 40 to 50 , and 34 to $257 \mathrm{kPa}$ for fine soils with $\mathrm{N}_{\mathrm{f}}$ varying from 13 to 43 . For Type B micropiles in sands or in silts, the range was similar to FHWA (2000). CGF micropiles does not even agree with Type D micropile parameters. Their bond strength values for micropiles in sands were situated between 535 and $802 \mathrm{kPa}$ for the $25^{\text {th }}$ and $75^{\text {th }}$ percentiles with $\mathrm{N}_{\mathrm{f}}$ ranging from 31 to 43 , and between 175 and $350 \mathrm{kPa}$ for the $25^{\text {th }}$ and $75^{\text {th }}$ percentiles with $\mathrm{N}_{\mathrm{f}}$ from 10 to 43 for micropiles in silts. Type D micropiles is more on par with FHWA (2000). 
Table 4-2 - Comparison between results of ELM and DEM

\begin{tabular}{|c|c|c|c|c|c|c|c|c|c|c|c|}
\hline \multirow{3}{*}{ Site } & \multirow{3}{*}{ Pile } & \multirow{3}{*}{$\frac{R_{F H}{ }^{1}}{Q_{n}}$} & \multicolumn{8}{|c|}{ ELM } & \multirow{3}{*}{$\begin{array}{c}\text { DEM } \\
R_{s k, n}{ }^{3} \\
(\mathbf{k N})\end{array}$} \\
\hline & & & \multicolumn{2}{|c|}{ Obtained $\xi$} & \multicolumn{6}{|c|}{ Load $(\mathrm{kN})$} & \\
\hline & & & $\xi_{c a s, n}$ & $\xi_{\text {bond }, n}$ & $\mathbf{L T}^{2}$ & $R_{t i p, n}$ & $\mathbf{A L}$ & $R_{c a s, i}$ & $\boldsymbol{R}_{\text {bond }, n}$ & $R_{s k, n}$ & \\
\hline \multirow{3}{*}{2} & TP2 & 1.92 & 0.33 & 0.33 & $\mathrm{C}$ & - & 48 & 119 & 136 & 303 & 309 \\
\hline & TP3 & 1.30 & 0.67 & 0.67 & $\mathrm{C}$ & 167 & 48 & 44 & 45 & 136 & 142 \\
\hline & TA* & 1.33 & 1.00 & 0.50 & $\mathrm{~T}$ & N/A & 48 & 0 & 552 & 600 & 574 \\
\hline \multirow{2}{*}{3} & TR1 & 1.28 & 1.00 & 0.33 & $\mathrm{~T}$ & N/A & 12 & 0 & 378 & 390 & 379 \\
\hline & MP-7 & 1.25 & 0.48 & 0.48 & $\mathrm{C}$ & - & 51 & 26 & 560 & 638 & 631 \\
\hline 4 & LT1 & 1.61 & 0.37 & 0.37 & $T$ & N/A & 71 & 52 & 1297 & 1420 & 1333 \\
\hline \multirow{2}{*}{5} & LT1 & 3.19 & 1.00 & 0.67 & $\mathrm{C}$ & - & 110 & 0 & 2090 & 2200 & 2265 \\
\hline & LT2 & 1.91 & 1.00 & 0.55 & $\mathrm{C}$ & - & 90 & 0 & 1710 & 1800 & 1800 \\
\hline 7 & TP9* & 1.49 & 0.33 & 0.33 & $\mathrm{~T}$ & N/A & 23 & 35 & 327 & 384 & 394 \\
\hline \multirow{2}{*}{8} & LTS* & 1.72 & 0.74 & 0.74 & $\mathrm{~T}$ & N/A & 300 & 45 & 1655 & 2000 & 2024 \\
\hline & LTN* & 1.63 & 1.00 & 0.74 & $\mathrm{~T}$ & N/A & 300 & 0 & 1700 & 2000 & 1998 \\
\hline \multirow{4}{*}{20} & $2 T^{*}$ & 1.38 & 1.00 & 0.50 & $\mathrm{~T}$ & N/A & 33 & 0 & 499 & 532 & 513 \\
\hline & $3 T^{*}$ & 1.00 & 1.00 & 0.50 & $\mathrm{~T}$ & N/A & 28 & 0 & 378 & 406 & 393 \\
\hline & $6 T^{*}$ & 1.45 & 1.00 & 0.50 & $\mathrm{~T}$ & N/A & 33 & 0 & 499 & 532 & 527 \\
\hline & $15 \mathrm{~T}^{*}$ & 1.66 & 1.00 & 0.67 & $\mathrm{~T}$ & N/A & 33 & 0 & 499 & 532 & 500 \\
\hline \multirow{2}{*}{22} & LT3 & 2.72 & 0.58 & 0.58 & $\mathrm{C}$ & - & 36 & 0 & 684 & 720 & 702 \\
\hline & LT4 & 1.46 & 0.33 & 0.33 & $\mathrm{C}$ & - & 36 & 0 & 684 & 720 & 717 \\
\hline 30 & LT1* & 1.00 & 0.67 & 0.67 & $\mathrm{C}$ & 229 & 13 & 25 & 0 & 38 & 111 \\
\hline \multirow{16}{*}{32} & C-E-2 & 2.74 & 0.35 & 0.35 & $\mathrm{C}$ & - & 122 & 148 & 2790 & 3060 & 2816 \\
\hline & LR-E-2 & 3.50 & 0.33 & 0.33 & $\mathrm{~T}$ & N/A & 60 & 0 & 1471 & 1531 & 1372 \\
\hline & R-E-2 & 2.09 & 0.41 & 0.41 & $\mathrm{~T}$ & N/A & 60 & 0 & 1471 & 1531 & 1378 \\
\hline & C-W-1 & 1.31 & 0.62 & 0.62 & $\mathrm{C}$ & 152 & 120 & 230 & 2501 & 2851 & 2811 \\
\hline & LR-W-1 & 2.18 & 0.33 & 0.33 & $\mathrm{~T}$ & N/A & 60 & 238 & 1203 & 1501 & 1410 \\
\hline & R-W-1 & 1.96 & 0.64 & 0.64 & $\mathrm{~T}$ & N/A & 60 & 0 & 1441 & 1501 & 1406 \\
\hline & P1-31* & 1.49 & 0.33 & 0.33 & $\mathrm{~T}$ & N/A & 120 & 251 & 1189 & 1560 & 1492 \\
\hline & P1-34* & 1.30 & 0.33 & 0.33 & $\mathrm{~T}$ & N/A & 120 & 174 & 1266 & 1560 & 1526 \\
\hline & P2-2* & 1.90 & 0.33 & 0.33 & $\mathrm{~T}$ & N/A & 120 & 343 & 1097 & 1560 & 1553 \\
\hline & P2-7* & 1.33 & 0.33 & 0.33 & $\mathrm{~T}$ & N/A & 120 & 199 & 1241 & 1560 & 1521 \\
\hline & P2-8* & 1.37 & 0.33 & 0.33 & $\mathrm{~T}$ & N/A & 120 & 451 & 989 & 1560 & 1551 \\
\hline & P2-11* & 1.47 & 0.33 & 0.33 & $\mathrm{~T}$ & N/A & 180 & 503 & 877 & 1560 & 1532 \\
\hline & P3-3* & 1.44 & 0.33 & 0.33 & $\mathrm{~T}$ & N/A & 120 & 259 & 1181 & 1560 & 1499 \\
\hline & P3-10* & 1.59 & 0.33 & 0.33 & $\mathrm{~T}$ & N/A & 120 & 442 & 998 & 1560 & 1536 \\
\hline & P3-18* & 2.98 & 0.38 & 0.38 & $\mathrm{~T}$ & N/A & 120 & 234 & 1206 & 1560 & 1545 \\
\hline & P3-24* & 2.33 & 0.54 & 0.54 & $\mathrm{~T}$ & N/A & 120 & 248 & 1192 & 1560 & 1551 \\
\hline 36 & LT1 & 1.15 & 0.60 & 0.60 & $\mathrm{C}$ & 191 & 125 & 76 & 483 & 684 & 637 \\
\hline \multirow{4}{*}{53} & TP1 & 2.49 & 0.36 & 0.36 & C & - & 173 & 118 & 1894 & 2185 & 2171 \\
\hline & TP3 & 2.03 & 0.33 & 0.33 & $\mathrm{~T}$ & 115 & 70 & 1246 & 1431 & N/A & 1328 \\
\hline & C1* & 2.10 & 0.33 & 0.33 & $\mathrm{~T}$ & 32 & 652 & 41 & 725 & N/A & 739 \\
\hline & $\mathrm{C}^{*}$ * & 2.09 & 0.33 & 0.33 & $\mathrm{~T}$ & 32 & 478 & 215 & 725 & N/A & 716 \\
\hline 54 & TP1 & 1.29 & 0.45 & 0.45 & $\mathrm{C}$ & 89 & 7 & 355 & 450 & - & 445 \\
\hline
\end{tabular}


${ }^{1} \frac{\boldsymbol{R}_{F H}}{\boldsymbol{Q}_{n}}$ : failure load by Fuller and Hoy's method divided by the last load increment (extrapolation ratio)

${ }^{2}$ Load Type: either tension (T) or compression (C)

${ }^{3}$ Dec.'s $R_{s k, n}$ : is the skin frictional resistance estimated through Decourt's method *Micropiles with only one loading cycle

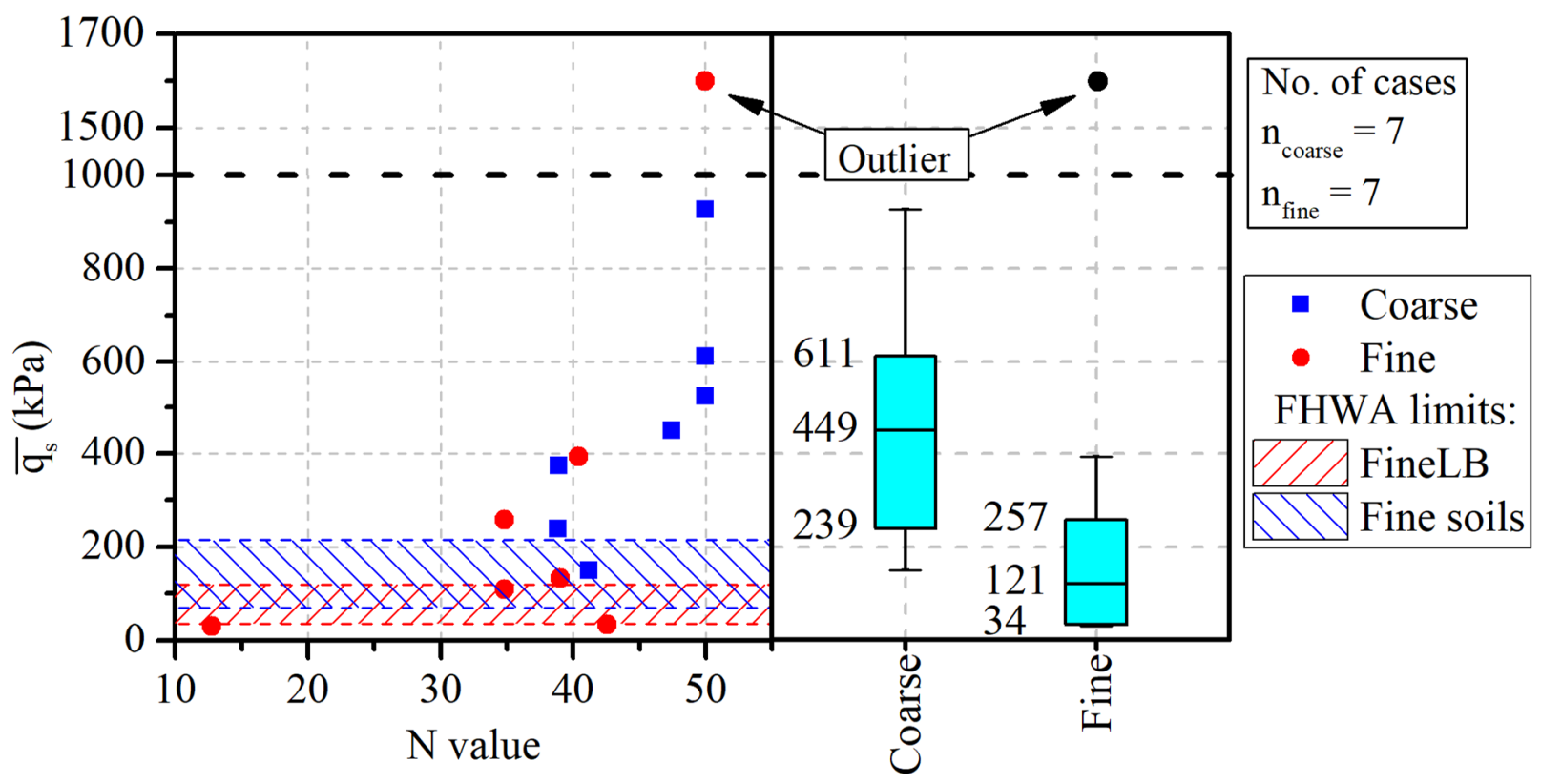

Figure 4-8 - Plot between $\overline{q_{s}}$ and $\mathrm{N}_{\mathrm{f}}$ value for Type A micropiles $(\mathrm{n}=14)$

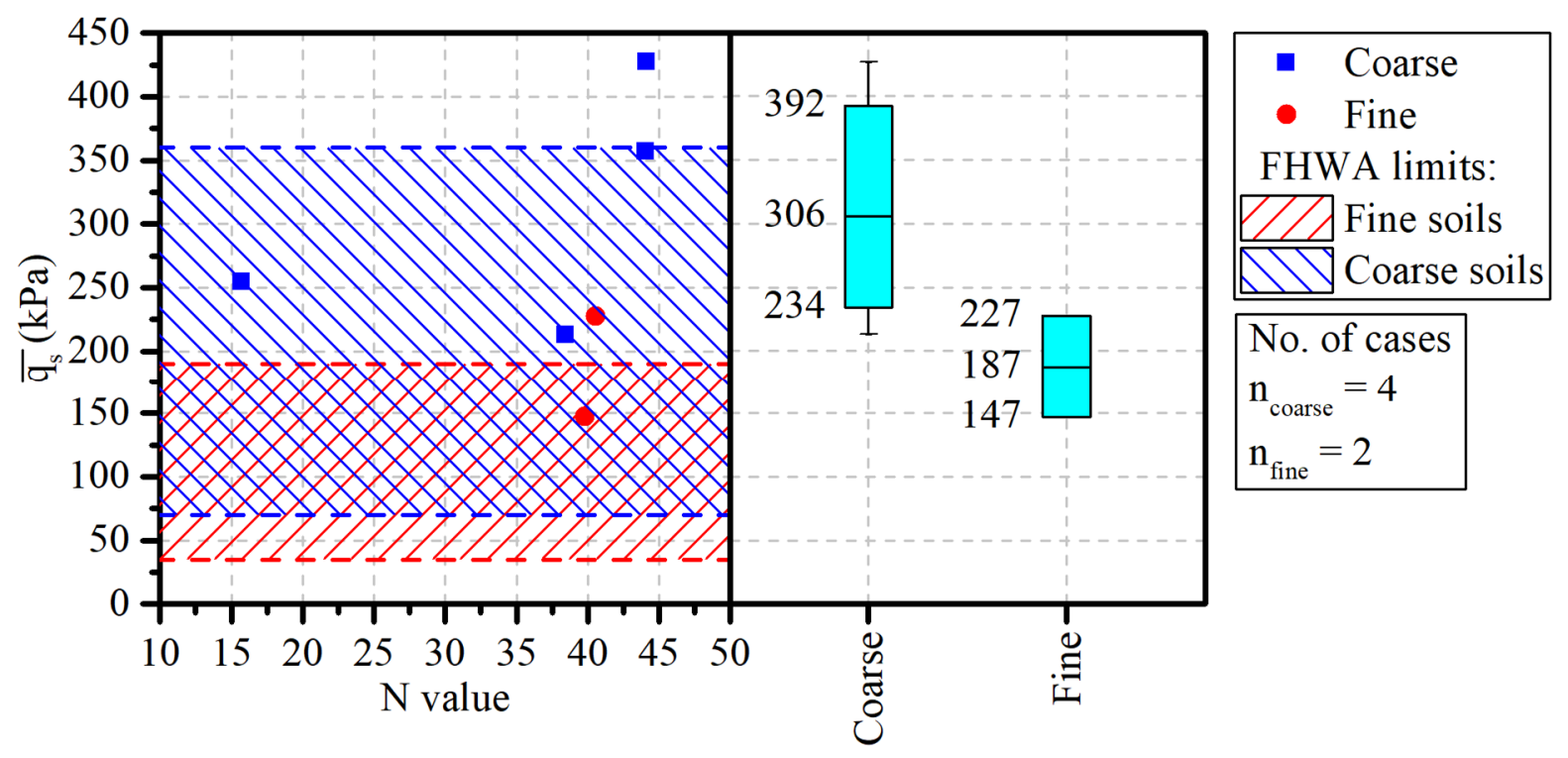

Figure 4-9 - Plot between $\overline{q_{s}}$ and $\mathrm{N}_{\mathrm{f}}$ value for Type B micropiles $(\mathrm{n}=6)$ 


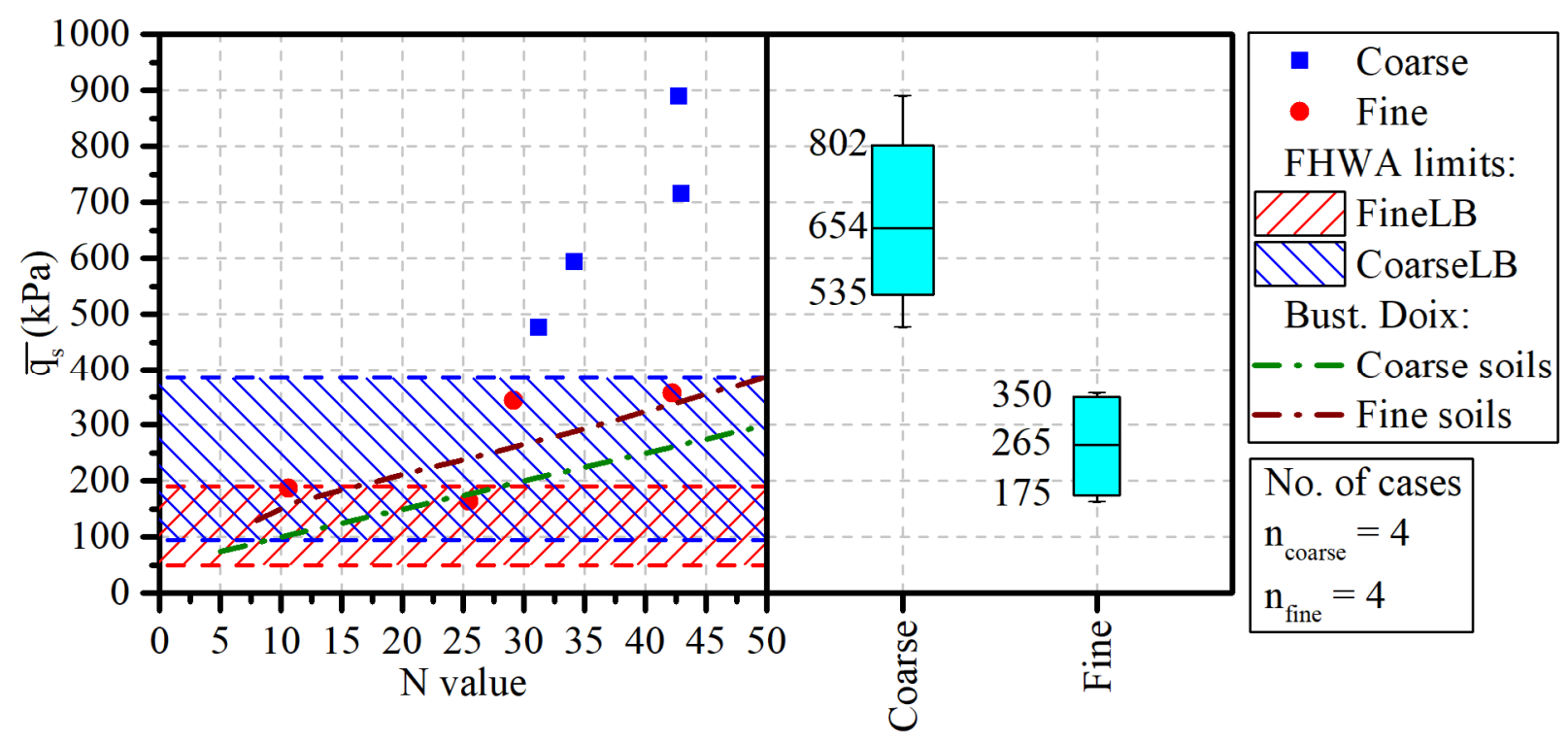

Figure 4-10 - Plot between $\overline{q_{s}}$ and $\mathrm{N}_{\mathrm{f}}$ value for CGF micropiles $(\mathrm{n}=8)$

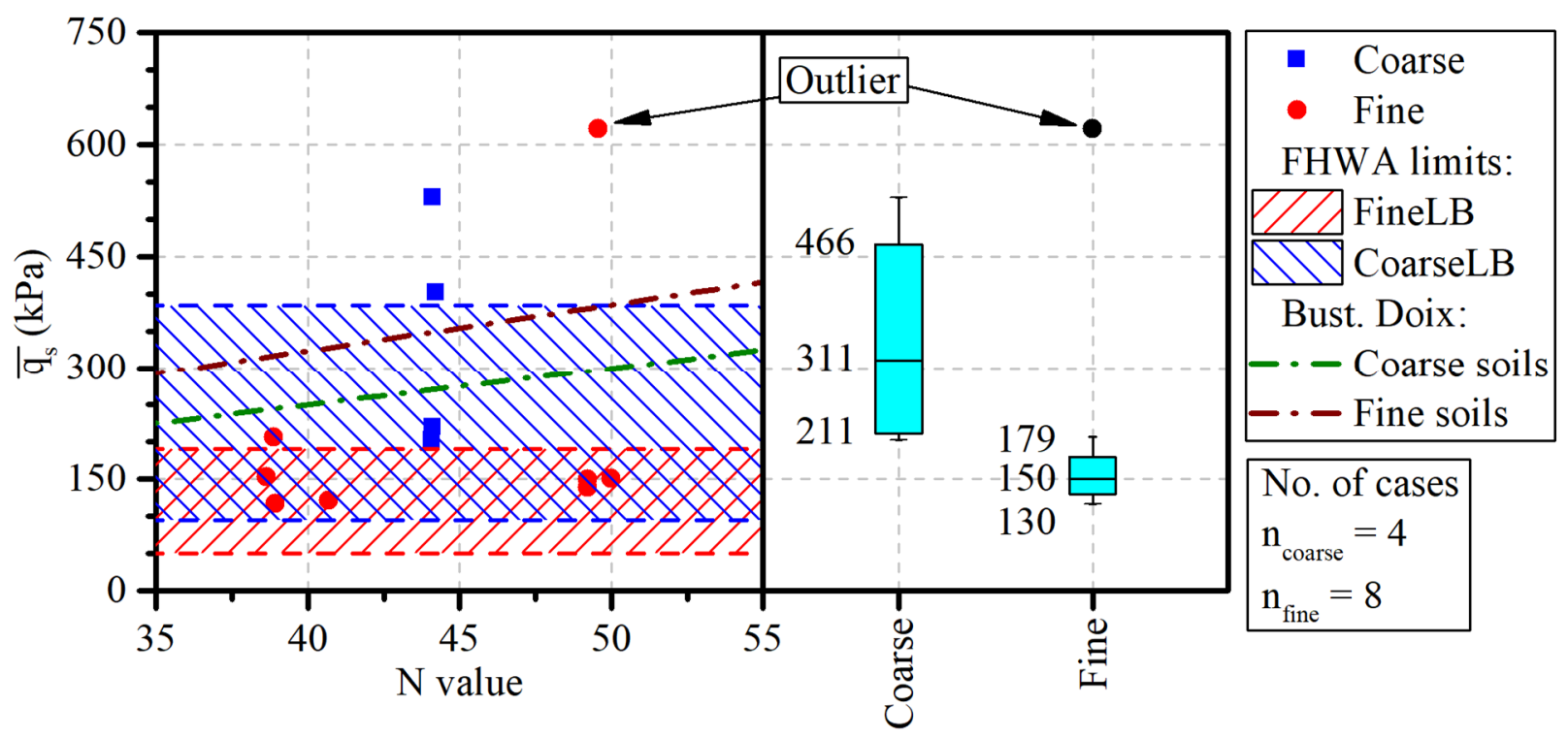

Figure 4-11 - Plot between $\overline{q_{s}}$ and $\mathrm{N}_{\mathrm{f}}$ value for Type D micropiles $(\mathrm{n}=12)$

The $25^{\text {th }}$ and $75^{\text {th }}$ percentiles obtained for micropiles in coarse and fine soils are therefore indicated to predict values of bond strength (Figures 4-8 to 4-11). This recommendation forms the "Suggested Parameters" case in the reliability analysis of Chapter 5 . The $25^{\text {th }}$ percentile represents the minimum bound of bond strength, while the $75^{\text {th }}$ represents the maximum bound.

Figures 4-12 to 4-15 present the achieved values of the parameters for $\alpha$ and $\beta$ method against the equivalent slenderness ratio of a micropile, $L / D_{\text {eq }}$, where $L$ is the micropile depth and $D_{\text {eq }}$ is given in Equation 4-12. For micropiles which had their cased length unbonded, the cased length was not considered in the calculation of $\mathrm{L}$. In order to apply this method, both the bulk unit weight and 
undrained cohesion had to be estimated (none of these parameters were present in the borehole reports). Thus, values of bulk unit weight suggested by Kulhawy and Mayne (1990) were used to estimate the effective stress of the soil. Additionally, Equation 4-13 provides the adopted correlations between the undrained cohesion, $C_{u}$, and the uncorrected $\mathrm{N}_{\mathrm{f}}$ value as suggested by Kulhawy and Mayne (1990) and Hara et al. (as cited in Kulhawy and Mayne, 1990). Commonly, the atmospheric pressure, $p_{a}$, is taken as $100 \mathrm{kPa}$.

$$
D_{e q}=\frac{D_{\text {cas }} L_{\text {cas }}+D_{\text {bond }} L_{\text {bond }}}{L_{\text {cas }}+L_{\text {bond }}}
$$

where $D_{\text {cas }}$ is the diameter of the casing, $L_{c a s}$ is the cased length, $D_{\text {bond }}$ is the diameter of the bond length, and $L_{\text {bond }}$ is the bond length.

$$
\begin{gathered}
C_{u}=\frac{C_{u, 1}+C_{u, 2}}{2} \\
C_{u, 1} / p_{a}=0.06 * N \\
C_{u, 2} / p_{a}=0.29 * N^{0.72}
\end{gathered}
$$

Results of $\alpha$, in Figure 4-12a, are not much different from those obtained for drilled shafts. However, no conclusion can be drawn, due to the low number of samples for this case. Values of $\beta$ in Figure $4-12 b$ considerably varied from the usual values for bored piles. CGS (2006) recommends $\beta$ values from 0.2 to 0.6 , and clearly $\beta$ results in Figure $4-12 \mathrm{~b}$ are usually higher than that. This is consistent with the increase of $\beta$ reported by Jeon and Kulhawy (2001). Overall, the increase of $\beta$ for the other micropiles types, Figures 4-13 to 4-15, were also similar to Jeon and Kulhawy (2001). In addition, the decrease in $\beta$ when the slenderness ratio increases observed by Jeon and Kulhawy (2001) was observed for Type B, and CGF micropiles. Type A and Type D micropiles, nevertheless, did not obtain a regular pattern. 


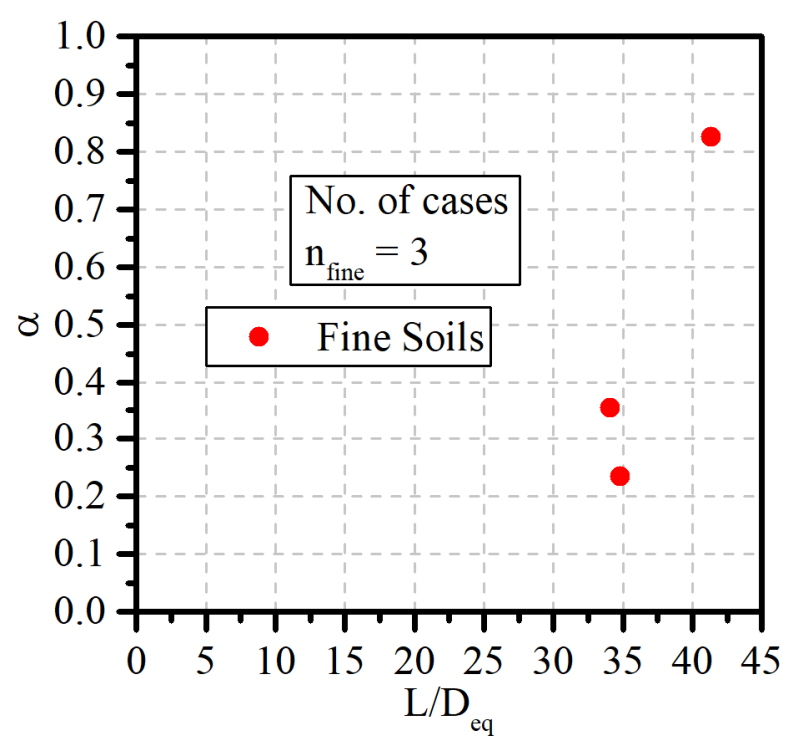

(a)

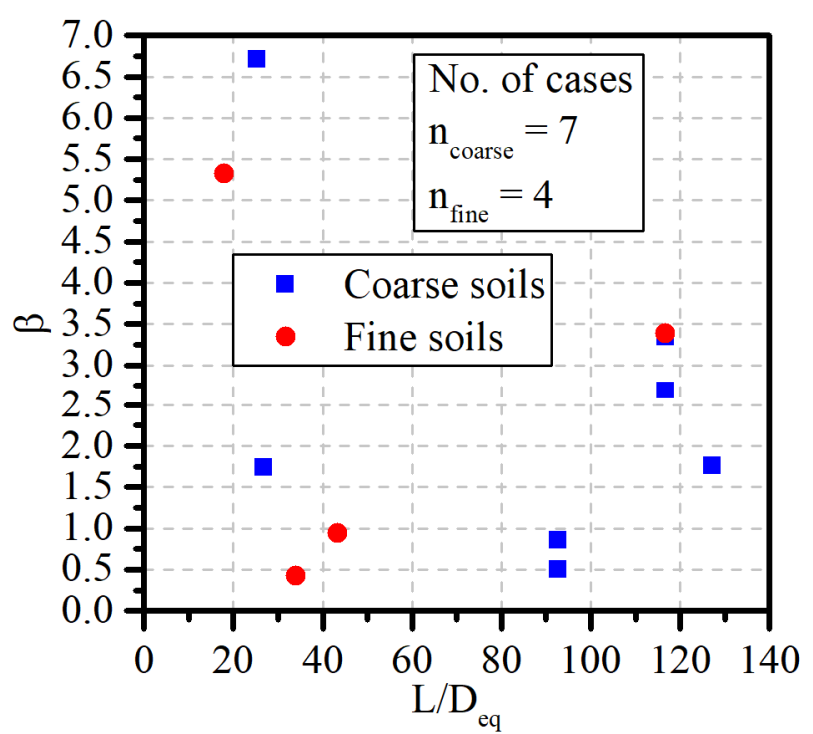

(b)

Figure 4-12 - Plot of (a) $\alpha$ vs L/D $\mathrm{D}_{\text {eq }}$ and (b) $\beta$ vs $\mathrm{L} / \mathrm{D}_{\text {eq }}$ for Type A micropiles

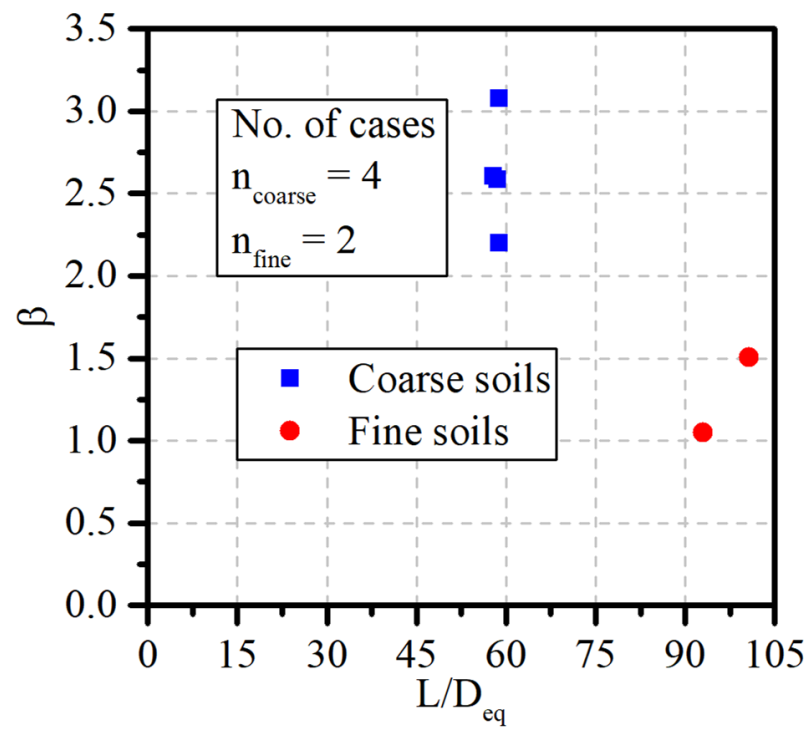

Figure 4-13 - Plot of $\beta$ vs L/D $\mathrm{D}_{\text {eq }}$ for Type B micropiles 


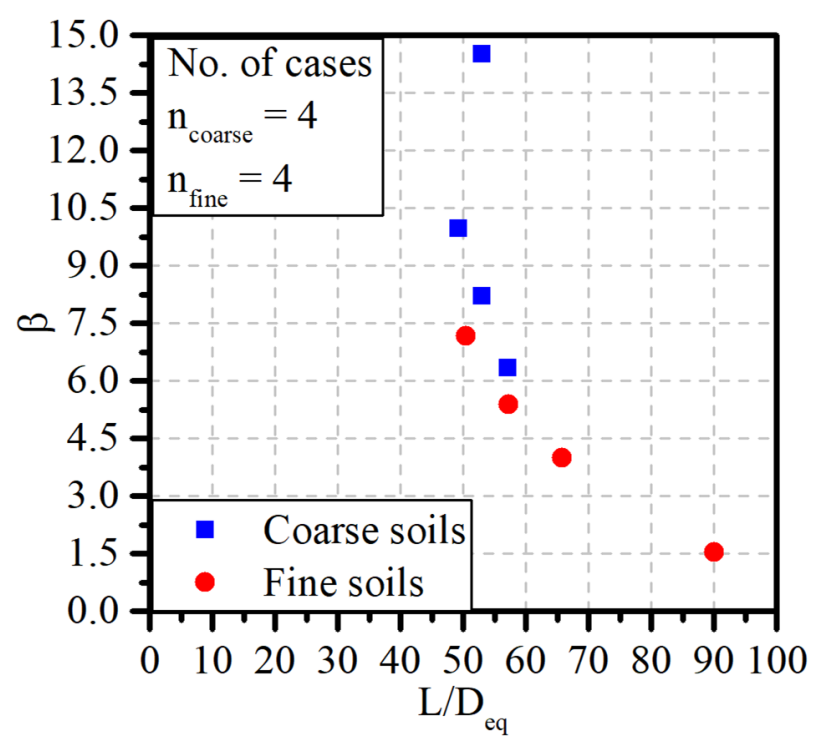

Figure 4-14 - Plot of $\beta$ vs L/Deq for CGF micropiles

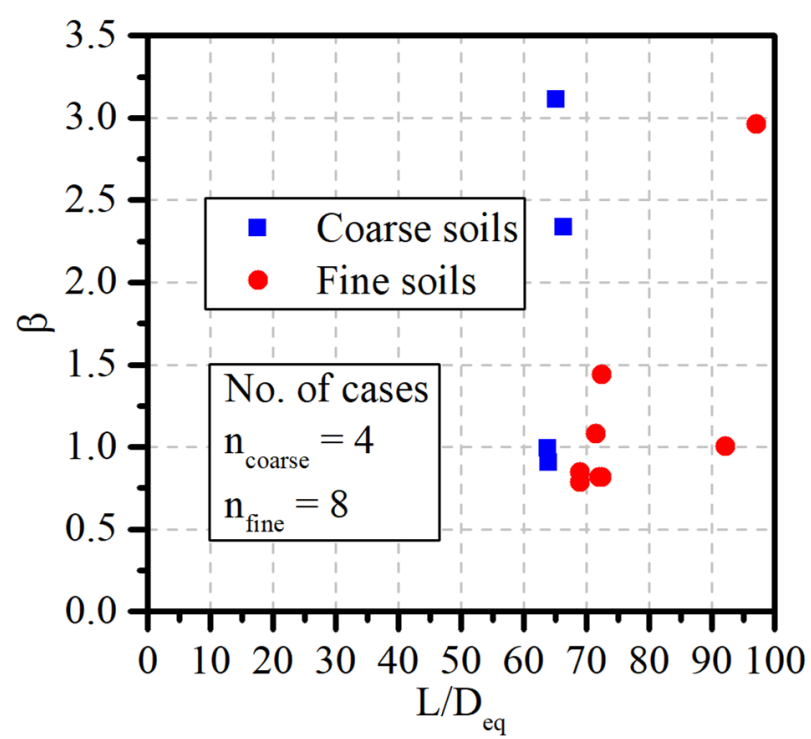

Figure 4-15 - Plot of $\beta$ vs L/Deq for Type D micropiles 


\section{RELIABILITY-BASED DESIGN METHODOLOGY}

\subsection{INTRODUCTION}

Walpole et al. (2012) defines statistical methods as those which contribute to the process of making scientific judgements with the presence of uncertainties and variation. The Load and Resistance Factored Design methodology (LRFD) treats engineering problems considering the uncertain behaviour of the system. To develop the LRFD, reliability analysis was employed in past successful case histories to both evaluate the safety of the deterministic approaches, and to define equivalent parameters for the LRFD with the same level of safety. Currently, the trend is to enhance the LRFD parameters to adjust different components of a system (i.e foundation and structure) to the same level of safety. In some cases, parameters need to go towards a safer system, whereas in other parameters can be adjusted to a more economical design. This section first discusses some probability definitions, which serves as background, followed by in-depth concepts of reliability analysis, and then a reliability analysis of the database is conducted and results of the achieved reliability index and recalibrated resistance factors are provided.

\subsection{Design Methodologies}

\subsubsection{Allowable Stress Design}

The Allowable Stress Design (ASD) has been utilized in civil engineering since the early 1800s (Paikowsky et al., 2004). The allowable load, $Q_{a}$, is calculated through the application of a Factor of Safety, $F S$, to the ultimate resistance, $R_{u l t}=R_{k}$, and this expression should be greater or equal to the applied load, $Q$, as shown in Equation 5-1.

$$
Q \leq Q_{a}=\frac{R_{k}}{F S}
$$

The main problem of this method is that all sources with different levels of uncertainties are treated with a single coefficient: FS. Thus, engineers had to heavily use subjective judgement and experience to overcome this problem (Paikowsky et al., 2004).

\subsubsection{Load and Resistance Factored Design}

The LRFD was developed to mitigate the drawback of the ASD. This methodology is probability based, considering each source of uncertainty $l$ separately with its own level of uncertainty. This is done through individual load factors $\gamma_{u, l}$ for each applied load $a, Q_{a, k}$. In addition, the foundation 
has its own ultimate geotechnical resistance factor $\phi_{g u}$, to consider its associated uncertainty within the design. Finally, the consequence factor, $\psi$, takes into account the level of consequence of the structure in case of exceeded limit state. Thus, this methodology prescribes the following expression according to the CHBDC (Canadian Standards Association, 2016b):

$$
\psi \phi_{g u} R_{k} \geq \sum_{i} \gamma_{u, l} Q_{a, k}
$$

This study does not consider the parameter $\psi$ due to being related to the purpose of the structure rather than foundation structure itself. The LRFD is indicated in several design codes in North America, such as the NBCC (National Research Council of Canada, 2015), the CHBDC (Canadian Standards Association, 2016b), the AASHTO LRFD Bridge Design Specifications (AASHTO, 2012), and the Micropile Design and Construction Guidelines (FHWA, 2000).

\subsection{Limit State Function and Probability of Failure}

The Ultimate Limit State (ULS) of a system can be defined by the limit state function $L S$ shown in Equation 5-3, where $R$ is a random variable representing the foundation resistance and $Q$ is the random variable of the applied load. When $L S<0$, the system is in a failure state. Thus, Equation 5-4 gives the probability of failure $P_{f}$ of the system.

$$
\begin{array}{cc}
L S=R-Q & \text { Eq. } 5-3 \\
P(L S=R-Q<0)=P(R<Q)=P_{f} & \text { Eq. } 5-4
\end{array}
$$

The bias of a random variable is defined as the relationship between the random variable and its nominal value (Wang and Cao, 2015). The biases of $\mathrm{R}, X_{R}$, and $\mathrm{Q}, X_{Q}$, are given in Equation 5-5 and 5-6, respectively. $X_{R}$ is equal to the ratio of the resistance of the bond length, from Equation 4-11, to the ultimate geotechnical axial capacity of a micropile from Equation 2-1 (for FHWA design method), from Equation 2-1 with $q_{s}$ being equal to the Suggested Parameters in Chapter 4, or from Equation 2-2 (for Bustamante and Doix (1985) applied to CGF micropiles only). It is important to note that the bias is still a random variable. Combining Equation 5-2 with Equations 5-5 and 5-6, LS transforms to Equation 5-7. Note that $\psi=1$ due to not considering the importance of the project in this study.

$$
X_{R}=\frac{R}{R_{k}}=\frac{R_{F H}-R_{c a s, M a x}-R_{t i p, F H}}{R_{u l t}}
$$




$$
\begin{gathered}
X_{Q}=\frac{Q}{Q_{k}} \\
L S=X_{R} \frac{\sum \gamma_{u} Q_{k}}{\phi_{g u}}-X_{Q} Q_{k}
\end{gathered}
$$

Taking $g$, the equivalent limit state function, as $g=\frac{L S}{Q_{k}}$ then:

$$
g=X_{R} \frac{\gamma_{u}}{\phi_{g u}}-X_{Q}
$$

To properly account for different sources of applied loads, such as live and dead loads, the final equation for $\mathrm{g}$ is shown in Equation 5-9, as suggested by Reddy and Stuedlein (2017).

$$
g=\frac{X_{R}}{\phi_{g u}} \frac{\gamma_{u, D} X_{Q, D}+\gamma_{u, L} X_{Q, L} \rho}{X_{Q, D}+X_{Q, L} \rho}-\frac{X_{Q, D}+X_{Q, L} \rho}{\rho+1} \geq 0
$$

where $\gamma_{u, D}$ is the load factor of the dead load, $\gamma_{u, L}$ is the load factor of the live load, $X_{Q, D}$ is the random variable of the dead load bias, $X_{Q, L}$ is the random variable of the live load bias, and $\rho$ is the ratio between live load to dead load. The value of $\rho$ varies from 0.2 to 0.5 for highway bridges, according to Allen (as cited in Reddy and Stuedlein, 2017).

Since this study deals with ranges of values for $R_{u l t}$, it was selected the most probable $R_{u l t}$ value to represent $R_{k}$ in Equation 5-5. This was done by considering that the range of the FHWA design method is lognormally distributed which is a common consideration in geotechnical studies (Christian, 2008). Additionally, the Three-Sigma rule was applied to the normal distribution of $\ln \left(R_{\text {ult }}\right)$ which, according to Dai and Wang (as cited in Duncan, 2000), considers that $99.73 \%$ of values in a normal distribution lies between three standard deviations from the average. With the distribution defined, the median was taken to represent the most likely value of $R_{u l t}$ and then taken as equal to $R_{k}$. The median represented in Figures 4-8 to 4-11 for the Suggested Parameters were also taken to represent $R_{k}$ for this design method.

To analyze the equivalent limit state function $g$, it is thus necessary to characterize the random variables $X_{R}, X_{Q, D}$, and $X_{Q, L}$ in terms of their probability. Therefore, probability distributions and their respective parameters should be defined. This is discussed in the following sections of this chapter. 


\subsection{Probability Distributions}

Probability distributions are defined rules that can describe a random event in terms of probability of occurrence (Ang and Tang, 2007). For continuous random variables, the mathematical definition comes as probability distribution function (PDF) and associated cumulative distribution function (CDF). Three different distributions are discussed: the Normal, the Lognormal, and the 3-Parameter Lognormal distributions.

\subsubsection{Normal Distribution}

The Normal distribution is the widest used distribution (Ang and Tang, 2007). Equation 5-10 shows the PDF for this distribution, where $\mu$ and $\sigma$ are the parameters of the distribution. In the case of the Normal distribution, $\mu$ is equal to the mean of $\mathrm{X}, \bar{x}$, and $\sigma$ is equal to the standard deviation of $\mathrm{X}, s_{X}$.

$$
f_{X}(x)=\frac{1}{\sigma \sqrt{2 \pi}} \exp \left[-\frac{1}{2}\left(\frac{x-\mu}{\sigma}\right)^{2}\right], \quad-\infty<x<+\infty
$$

\subsubsection{Lognormal Distribution}

The Lognormal distribution is a transformation of the Normal distribution. It is defined when the natural logarithm of a random variable $X$ is normally distributed (Ang and Tang, 2007). Equation 5-11 shows its PDF. Parameters $\lambda$ and $\zeta$ are given by Equations 5-11a and 5-11b.

$$
f_{X}(x)=\frac{1}{\zeta x \sqrt{2 \pi}} \exp \left[-\frac{1}{2}\left(\frac{\ln x-\lambda}{\zeta}\right)^{2}\right], \quad x \geq 0
$$

where,

$$
\begin{aligned}
& \lambda=\ln \left(\frac{\bar{x}}{\sqrt{1+\frac{s_{X}^{2}}{\bar{x}^{2}}}}\right) \\
& \zeta^{2}=\ln \left(1+\frac{s_{X}^{2}}{\bar{x}^{2}}\right)
\end{aligned}
$$




\subsubsection{3-Parameter Lognormal Distribution}

The 3-Parameter Lognormal Distribution is similar to the Lognormal distribution. The difference is that the natural logarithm of a random variable $\mathrm{X}$ minus a threshold $\gamma$ is normally distributed, instead of only the natural logarithm of X (Aristizabal, 2012). Thus, the shape of the PDF is similar to the PDF of a lognormal distribution (it is only shifted by the value of $\gamma$ ). Equation 5-12 gives the PDF of a 3-Parameter Lognormal distribution. The parameters $\lambda$ and $\zeta$ are given by the same expressions in Equations 5-11a and 5-11b. Figure 5-1 shows one example of a PDF and a CDF of a 3-Parameter Lognormal Distribution.

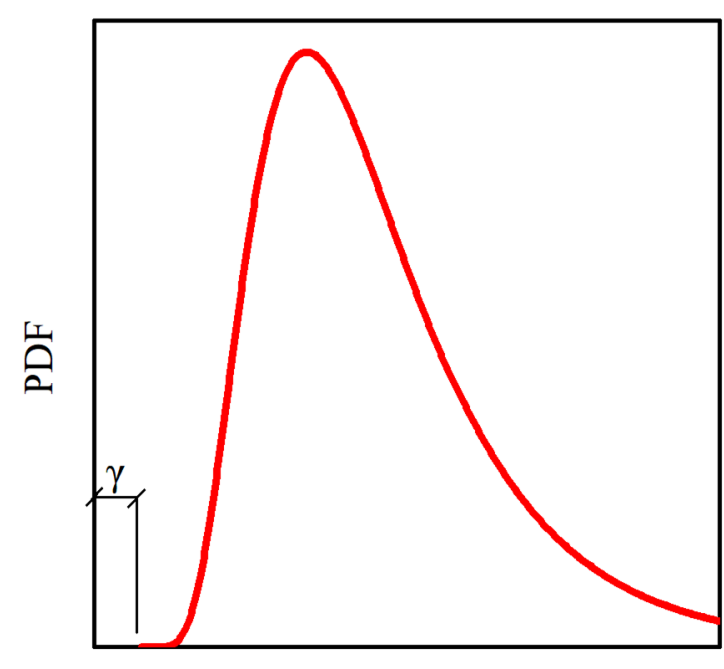

(a)

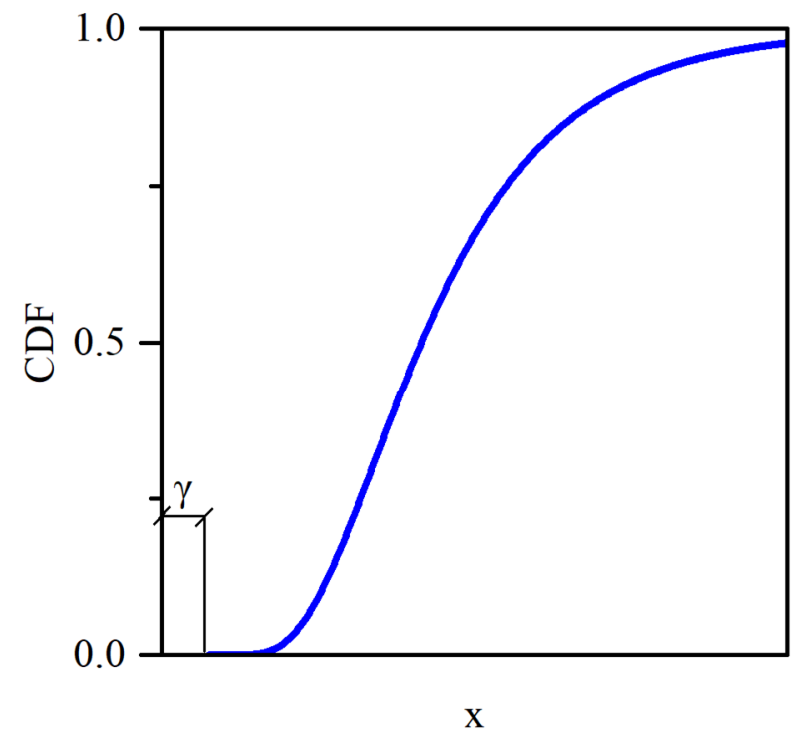

(b)

Figure 5-1 - (a) PDF and (b) CDF of a 3-Parameter Lognormal distribution

$$
f_{X}(x)=\frac{1}{\zeta(x-\gamma) \sqrt{2 \pi}} \exp \left[-\frac{1}{2}\left(\frac{\ln (x-\gamma)-\lambda}{\zeta}\right)^{2}\right], \quad x>\gamma \geq 0
$$

\subsection{Assessment of the Probability Distribution Function of an Event}

The probability distribution function (PDF) to model a random phenomenon is rarely known (Ang and Tang, 2007). Hence, to assign a probability distribution model to a certain event, it is necessary to assess its fit. This may be done through many different methods, such as visual inference. It is discussed two empirical methodologies: Goodness-of-fit Tests and Probability Paper Plots (PPP). A best fit for $X_{R}$ is provided at the end for the considered cases. 


\subsubsection{Goodness-of-fit Tests}

Goodness-of-fit tests (GoF tests) are statistical tests to verify the assumption of a particular PDF (Ang and Tang, 2007). In this study, 3 GoF tests are considered and discussed below: the Kolmogorov-Smirnov (K-S) test, the Chi-Square $\left(\chi^{2}\right)$ test, and the Shapiro-Wilk (S-W) test. These tests, however, never confirm or denies the assumed distribution. They only provide a parameter $\alpha$ which measures the significance level in which the data distribution is equivalent to the tested distribution.

\subsubsection{Kolmogorov-Smirnov Test}

The K-S test compares the observed cumulative frequency with the CDF of the tested distribution $\left(F_{X}(x)\right)$ (Haldar and Mahadevan, 2000). After sorting the data (with $\mathrm{n}$ observed values of $\mathrm{x}$ ) in an ascending order, Equations 5-13 and 5-14 are calculated to generate $D_{n}$. Then, Equation 5-15 provides the significance level $\alpha$ of the test. The P-value is given in Equation 5-15. The higher the P-value, the better the fit of the tested PDF is. Table 5-1 gives the possible empirical values of $D_{n}^{\alpha}$.

$$
\begin{gathered}
S_{n}=\left\{\begin{array}{c}
0, \text { if } x<x_{1} \\
\frac{k}{n}, \text { if } x_{k} \leq x \leq x_{k+1} \\
1, \text { if } x \geq x_{n}
\end{array}\right. \\
D_{n}=\max \left|F_{X}(x)-S_{n}(x)\right| \\
P\left(D_{n} \leq D_{n}^{\alpha}\right)=1-\alpha
\end{gathered}
$$

\subsubsection{Chi-Square ( $\left.\chi^{2}\right)$ Test}

The Chi-Square test compares the observed frequencies $\left(n_{1}\right.$ to $\left.n_{k}\right)$ with corresponding theoretical frequencies $\left(e_{1}\right.$ to $e_{k}$ ) of the tested distribution, where $\mathrm{k}$ is equal to the number of observations or intervals. Equation 5-16 presents the testing distribution. When it approaches a critical value, $c_{1-\alpha, f}$, which follows a chi-square distribution with $f=k-1$ degrees of freedom, the tested distribution is acceptable with a significance level $\alpha$ (Ang and Tang, 2007). If the condition imposed by Equation 5-16 is not satisfied, the assumed distribution cannot be validated by the $\chi^{2}$ test.

$$
\sum_{i=1}^{k} \frac{\left(n_{i}-e_{i}\right)^{2}}{e_{i}}<c_{1-\alpha, f}
$$


Table 5-1 - Values of $D_{n}^{\alpha}$ for K-S test (Haldar and Mahadevan, 2000)

\begin{tabular}{|c|c|c|c|c|c|}
\hline $\mathbf{N}$ & $\boldsymbol{D}_{\boldsymbol{n}}^{\mathbf{0 . 2 0}}$ & $\boldsymbol{D}_{\boldsymbol{n}}^{\mathbf{0 . 1 5}}$ & $\boldsymbol{D}_{\boldsymbol{n}}^{\mathbf{0 . 1 0}}$ & $\boldsymbol{D}_{\boldsymbol{n}}^{\mathbf{0 . 0 5}}$ & $\boldsymbol{D}_{\boldsymbol{n}}^{\mathbf{0 . 0 1}}$ \\
\hline $\mathbf{5}$ & 0.446 & 0.474 & 0.510 & 0.563 & 0.669 \\
\hline $\mathbf{6}$ & 0.410 & 0.436 & 0.470 & 0.521 & 0.618 \\
\hline $\mathbf{7}$ & 0.381 & 0.405 & 0.438 & 0.486 & 0.577 \\
\hline $\mathbf{8}$ & 0.358 & 0.381 & 0.411 & 0.457 & 0.543 \\
\hline $\mathbf{9}$ & 0.339 & 0.360 & 0.388 & 0.432 & 0.514 \\
\hline $\mathbf{1 0}$ & 0.322 & 0.342 & 0.368 & 0.409 & 0.486 \\
\hline $\mathbf{1 1}$ & 0.307 & 0.326 & 0.352 & 0.391 & 0.468 \\
\hline $\mathbf{1 2}$ & 0.295 & 0.313 & 0.338 & 0.375 & 0.450 \\
\hline $\mathbf{1 3}$ & 0.284 & 0.302 & 0.325 & 0.361 & 0.433 \\
\hline $\mathbf{1 4}$ & 0.274 & 0.292 & 0.314 & 0.349 & 0.418 \\
\hline $\mathbf{1 5}$ & 0.266 & 0.283 & 0.304 & 0.338 & 0.404 \\
\hline $\mathbf{2 0}$ & 0.231 & 0.246 & 0.264 & 0.294 & 0.352 \\
\hline $\mathbf{2 5}$ & 0.210 & 0.220 & 0.240 & 0.264 & 0.320 \\
\hline $\mathbf{3 0}$ & 0.190 & 0.200 & 0.220 & 0.242 & 0.290 \\
\hline $\mathbf{3 5}$ & 0.180 & 0.190 & 0.210 & 0.230 & 0.270 \\
\hline $\mathbf{4 0}$ & 0.170 & 0.180 & 0.190 & 0.210 & 0.250 \\
\hline $\mathbf{4 5}$ & 0.160 & 0.170 & 0.180 & 0.200 & 0.240 \\
\hline $\mathbf{5 0}$ & 0.150 & 0.160 & 0.170 & 0.190 & 0.230 \\
\hline$>\mathbf{5 0}$ & $1.07 / \sqrt{n}$ & $1.14 / \sqrt{n}$ & $1.22 / \sqrt{n}$ & $1.36 / \sqrt{n}$ & $1.63 / \sqrt{n}$ \\
\hline
\end{tabular}

\subsubsection{Shapiro-Wilk Test}

The Shapiro-Wilk test is mathematically more complex. However, it is highly recommended for small sample sizes (smaller than 50 observations). This test is only applicable for normality test. Equations 5-17 and 5-18 show the original statistics $W$ which is related to the significance level of a tested distributions. Values of $W$ closer to 0 rejects the normality assumption, whereas those closer to 1 approaches normality (Razali and Wah, 2011).

$$
\begin{gathered}
W=\frac{\left(\sum_{i=1}^{n} a_{i} x_{i}\right)^{2}}{\sum_{i=1}^{n}\left(x_{i}-\bar{x}\right)^{2}} \\
a_{i}=\left(a_{1}, \ldots, a_{n}\right)=\frac{m^{T} V^{-1}}{\left(m^{T} V^{-1} V^{-1} m\right)^{1 / 2}}
\end{gathered}
$$

where, $\bar{x}$ is the sample mean, $m=\left(m_{1}, \ldots, m_{n}\right)^{T}$ are the expected values of the order statistics of independent identically distributed random variables of a standard normal distribution, $V$ is the covariance matrix of those order statistics. This method was further modified by several different 
studies. It was then implemented in IBM ${ }^{\circledR}$ SPSS Statistics Software. Its further enhanced equations are not discussed in this study.

\subsubsection{Probability Paper Plot}

Probability Paper Plots (PPP) are plots of an observed value and their estimated cumulative distribution function (CDF). For each distribution type there is a different corresponding PPP (Ang and Tang, 2007). The main advantage of the PPP is that it is a simple tool for PDF comparison, since a best distribution fit is determined when a PPP shows a good fit for a line. According to Haldar and Mahadevan (2000), to construct a PPP the following steps should be carried out:

a. sort the data $(\mathrm{X})$ in an ascending order;

b. compute $p_{i}$ which is an empirical distribution function (EDF) that estimates the CDF by using Equation 5-19 for each observation $i$ and total number of observations $n$;

c. transform the EDF to $\mathrm{Z}$ and $\mathrm{X}$ to $\mathrm{Y}$ for each observation using Table 5-2; and

d. plot $Z$ values vs the data $X$.

$$
p_{i}=\frac{i}{n+1}
$$

Figure 5-2 depicts an example of a lognormal PPP. $\mathrm{R}^{2}$, which measures the fit of a curve, serves to compare different PPPs and establish the best one.

\subsubsection{Results of PDF Assessment for the Bias Distribution of the Foundation Resistance}

Distributions of $X_{R}$ were divided into 5 different cases: All micropiles combined in one distribution and other four distributions representing Type A, Type B, CGF, and Type D micropiles separately. Further segregation of this main categories would represent an ideal case. These main cases would be divided in terms of soil types and direction of the applied load (either tensile or compressive loads). However, this study has a very narrow database for a probabilistic study. Thus, this further sub-categorization was not performed and results might have been affected by this grouping of micropiles in different conditions.

Using the three mentioned Goodness-of-Fit tests, several distributions were tested to evaluate the best candidates for modelling the random variable of the resistance bias, $X_{R}$. K-S and $\chi^{2}$ tests were applied to all tested distributions, and S-W test was only applied to distributions derived from the Normal Distribution. S-W test was also the main test used to select the best distributions, since the sample size is small and suitable for this test. Thus, distributions derived from the Normal Distribution were preferred due to S-W limitations. 
Table 5-2 - Transformation equations for PPP

\begin{tabular}{|c|c|c|}
\hline Distribution Type & $\mathbf{Z}$ & $\mathbf{Y}$ \\
\hline Normal & $Z=\Phi^{-1}\left(p_{i}\right)$ & $Y=X_{i}$ \\
\hline Lognormal & $Z=\Phi^{-1}\left(p_{i}\right)$ & $Y=\log \left(X_{i}\right)$ \\
\hline 3-P Lognormal & $Z=\Phi^{-1}\left(p_{i}\right)$ & $Y=\log \left(X_{i}-\gamma\right)$ \\
\hline
\end{tabular}

$\Phi:$ CDF of a standard normal distribution

$\gamma$ : the 3rd parameter of a 3-Parameter Lognormal distribution

$X_{i}$ : the random variable of the observed data.

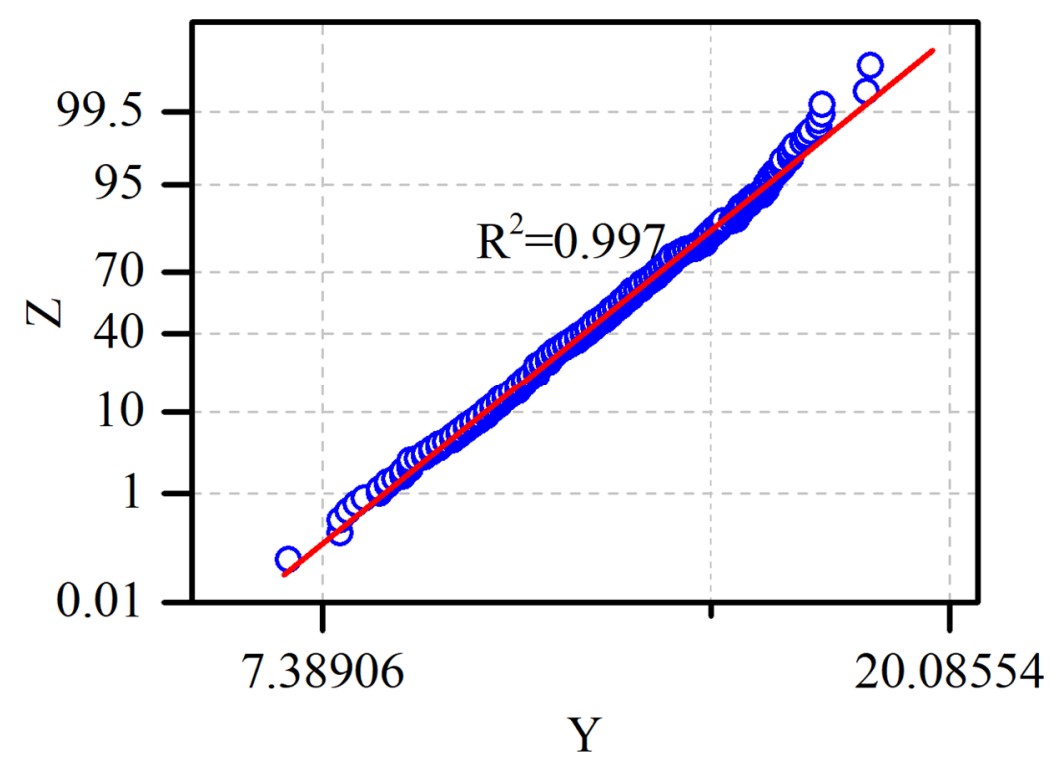

Figure 5-2 - Example of a PPP

Tables 5-3 give results of P-value and PPP $\mathrm{R}^{2}$ of $X_{R}$ considering the FHWA design method, the Suggested Parameters in Chapter 4, and Bustamante and Doix (1985) (B. D. in Table 5-3), respectively. The considered cases for analysis were classified in terms of micropile type and soil type (either coarse or fine) to evaluate the distribution of $X_{R}$. The considered GoF tests were K-S (test 1 in Table 5-3), $\chi^{2}$ (test 2 in Table 5-3), and S-W (test 3 in Table 5-3). The latter test was the main test considered among GoF tests and PPP $\mathrm{R}^{2}$ values to define the best-fit distribution. PPP $\mathrm{R}^{2}$ served mostly to validate the chosen distributions. Preference was given to the 3-Parameter lognormal distribution, due to the case with the highest number of cases (All Micropiles case) being best-fitted by a 3-Parameter Lognormal Distribution. Also, the Lognormal distribution cannot provide values of $X_{R}$ lower than zero, which is reasonable for a pile resistance. The only case that was modelled by a Lognormal distribution was in Type A micropiles embedded in coarse soils (which might be also best-fitted by coarse soils in the All MPs case). This occurred due to the extremely low S-W P-value achieved by one of the design methods in this situation. The selected distributions for each case are summarized in Table 5-4. 
Table 5-3 - P-value for GoF tests and PPP $\mathrm{R}^{2}$ for the considered design methods

\begin{tabular}{|c|c|c|c|c|c|c|c|c|c|c|c|c|c|c|c|c|c|c|c|}
\hline \multicolumn{2}{|c|}{ Case } & \multicolumn{6}{|c|}{ 3-Par. Lognormal } & \multicolumn{6}{|c|}{ Lognormal } & \multicolumn{6}{|c|}{ Normal } \\
\hline \multirow{2}{*}{$\mathrm{Met}^{3}$} & \multirow{2}{*}{$\begin{array}{c}\text { MP } \\
\text { Typ } \\
\end{array}$} & \multicolumn{3}{|c|}{ Coarse } & \multicolumn{3}{|c|}{ Fine } & \multicolumn{3}{|c|}{ Coarse } & \multicolumn{3}{|c|}{ Fine } & \multicolumn{3}{|c|}{ Coarse } & \multicolumn{3}{|c|}{ Fine } \\
\hline & & \multicolumn{2}{|c|}{ GoF test } & \multirow{4}{*}{$\begin{array}{l}\mathrm{R}^{2} \\
\stackrel{\circ}{\circ} \\
\stackrel{8}{8}\end{array}$} & \multicolumn{2}{|c|}{ GoF test } & \multirow{4}{*}{$\frac{\mathrm{R}^{2}}{\mathscr{\varrho}}$} & \multicolumn{2}{|c|}{ GoF test } & \multirow{4}{*}{$\begin{array}{l}\mathrm{R}^{2} \\
\stackrel{0}{\circ} \\
\stackrel{0}{0}\end{array}$} & \multicolumn{2}{|c|}{ GoF test } & \multirow{4}{*}{$\frac{\mathrm{R}^{2}}{\stackrel{n}{\circ}}$} & \multicolumn{2}{|c|}{ GoF test } & & & F test & $\mathrm{R}^{2}$ \\
\hline & & 1 & 0.67 & & 1 & 0.77 & & 1 & 0.65 & & 1 & 0.45 & & 1 & 0.47 & & 1 & 0.08 & \\
\hline & All & 2 & 0.81 & & 2 & 0.50 & & 2 & 0.83 & & 2 & 0.26 & & 2 & 0.14 & $\precsim$ & 2 & 0.02 & $n$ \\
\hline & & 3 & 0.27 & & 3 & 0.83 & & 3 & 0.26 & & 3 & 0.28 & & 3 & 0.03 & & 3 & 0.00 & \\
\hline & & 1 & 0.09 & & 1 & 0.44 & & 1 & 0.76 & & 1 & 0.98 & & 1 & 0.94 & & 1 & 0.66 & \\
\hline & A & 2 & $N / A^{*}$ & ర్t. & 2 & $\mathbf{N} / \mathbf{A}^{*}$ & 5 & 2 & $\mathbf{N} / \mathbf{A}^{*}$ & $\tilde{\sigma}$ & 2 & $N / A^{*}$ & 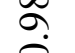 & 2 & N/A* & 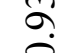 & 2 & $\mathrm{~N} / \mathrm{A}^{*}$ & 2 \\
\hline & & 3 & 0.00 & & 3 & 0.93 & & 3 & 0.28 & & 3 & 0.88 & & 3 & 0.45 & & 3 & 0.05 & \\
\hline & & 1 & $\mathbf{N} / \mathbf{A}^{1}$ & & 1 & $\mathrm{~N} / \mathrm{A}^{2}$ & & 1 & $\mathrm{~N} / \mathrm{A}^{1}$ & & 1 & $N / A^{2}$ & & 1 & $\mathrm{~N} / \mathrm{A}^{1}$ & & 1 & $\mathrm{~N} / \mathrm{A}^{2}$ & \\
\hline 3 & B & 2 & $\mathbf{N} / \mathbf{A}^{1}$ & ڤ. & 2 & $\mathrm{~N} / \mathrm{A}^{2}$ & 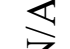 & 2 & $\mathrm{~N} / \mathrm{A}^{1}$ & $\infty$ & 2 & $\mathrm{~N} / \mathrm{A}^{2}$ & 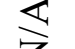 & 2 & $\mathrm{~N} / \mathrm{A}^{1}$ & 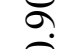 & 2 & $\mathrm{~N} / \mathrm{A}^{2}$ & 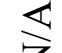 \\
\hline & & 3 & 0.56 & & 3 & $\mathrm{~N} / \mathrm{A}^{2}$ & & 3 & 0.42 & & 3 & $\mathrm{~N} / \mathrm{A}^{2}$ & & 3 & 0.57 & & 3 & $\mathrm{~N} / \mathrm{A}^{2}$ & \\
\hline & & 1 & $\mathbf{N} / \mathbf{A}^{\mathbf{1}}$ & & 1 & $\mathbf{N} / \mathbf{A}^{1}$ & & 1 & $\mathrm{~N} / \mathrm{A}^{1}$ & & 1 & $\mathrm{~N} / \mathrm{A}^{1}$ & & 1 & $\mathrm{~N} / \mathrm{A}^{1}$ & & 1 & $\mathrm{~N} / \mathrm{A}^{1}$ & \\
\hline & CGF & 2 & $\mathbf{N} / \mathbf{A}^{1}$ & $\infty$ & 2 & $\mathbf{N} / \mathbf{A}^{1}$ & gे & 2 & $\mathrm{~N} / \mathrm{A}^{1}$ & $\infty$ & 2 & $\mathrm{~N} / \mathrm{A}^{1}$ & $a$ & 2 & $\mathrm{~N} / \mathrm{A}^{1}$ & $\infty$ & 2 & $\mathrm{~N} / \mathrm{A}^{1}$ & $\infty$ \\
\hline & & 3 & 0.38 & & 3 & $\mathbf{0 . 8 3}$ & & 3 & 0.26 & & 3 & 0.47 & & 3 & 0.40 & & 3 & 0.27 & \\
\hline & & 1 & $\mathbf{N} / \mathbf{A}^{1}$ & & 1 & 0.15 & & 1 & $\mathrm{~N} / \mathrm{A}^{1}$ & & 1 & 0.21 & & 1 & $\mathrm{~N} / \mathrm{A}^{1}$ & & 1 & 0.06 & \\
\hline & D & 2 & $\mathbf{N} / \mathbf{A}^{1}$ & $\infty$ & 2 & $\mathbf{N} / \mathbf{A}^{*}$ & ? & 2 & $\mathrm{~N} / \mathrm{A}^{1}$ & $\widehat{\sigma}$ & 2 & N/A ${ }^{*}$ & $\approx$ & 2 & $\mathrm{~N} / \mathrm{A}^{1}$ & ?. & 2 & N/A ${ }^{*}$ & กุ \\
\hline & & 3 & 0.31 & & 3 & 0.20 & & 3 & 0.37 & & 3 & 0.01 & & 3 & 0.39 & & 3 & 0.00 & \\
\hline & & 1 & 0.79 & & 1 & 0.52 & & 1 & 0.71 & & 1 & 0.35 & & 1 & 0.89 & & 1 & 0.02 & \\
\hline & All & 2 & 0.48 & ริ & 2 & 0.06 & g. & 2 & 0.98 & $\hat{a}$ & 2 & 0.45 & . & 2 & 0.33 & 0 & 2 & 0.00 & $\stackrel{ナ}{\circ}$ \\
\hline r & & 3 & 0.88 & & 3 & 0.18 & & 3 & 0.76 & & 3 & 0.09 & & 3 & 0.38 & & 3 & 0.00 & \\
\hline $\bar{I}$ & & 1 & 0.58 & & 1 & 0.66 & & 1 & 0.49 & & 1 & 0.82 & & 1 & 0.90 & & 1 & 0.29 & \\
\hline$\underset{g}{0}$ & A & 2 & N/A* & 3 & 2 & $\mathbf{N} / \mathbf{A}^{*}$ & $\infty$ & 2 & $\mathbf{N} / \mathbf{A}^{*}$ & $\ddot{0}$ & 2 & N/A & ڤิ & 2 & N/A & 2 & 2 & N/A ${ }^{*}$ & . \\
\hline & & 3 & 0.41 & & 3 & 0.20 & & 3 & 0.35 & & 3 & 0.44 & & 3 & 0.53 & & 3 & 0.01 & \\
\hline$\overline{0}$ & & 1 & $\mathbf{N} / \mathbf{A}^{1}$ & & 1 & $\mathrm{~N} / \mathrm{A}^{2}$ & & 1 & $\mathrm{~N} / \mathrm{A}^{1}$ & & 1 & $\mathrm{~N} / \mathrm{A}^{2}$ & & 1 & $\mathrm{~N} / \mathrm{A}^{1}$ & & 1 & $\mathrm{~N} / \mathrm{A}^{2}$ & \\
\hline$\Xi$ & B & 2 & $\mathbf{N} / \mathbf{A}^{1}$ & $\approx$ & 2 & $\mathrm{~N} / \mathrm{A}^{2}$ & 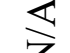 & 2 & $\mathrm{~N} / \mathrm{A}^{1}$ & $\alpha$ & 2 & $\mathrm{~N} / \mathrm{A}^{2}$ & 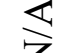 & 2 & $\mathrm{~N} / \mathrm{A}^{1}$ & a & 2 & $\mathrm{~N} / \mathrm{A}^{2}$ & 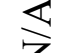 \\
\hline हुँ & & 3 & 0.45 & & 3 & $\mathrm{~N} / \mathrm{A}^{2}$ & & 3 & 0.75 & & 3 & $\mathrm{~N} / \mathrm{A}^{2}$ & & 3 & 0.72 & & 3 & $\mathrm{~N} / \mathrm{A}^{2}$ & \\
\hline o & & 1 & $\mathbf{N} / \mathbf{A}^{1}$ & & 1 & $\mathbf{N} / \mathbf{A}^{1}$ & & 1 & $\mathrm{~N} / \mathrm{A}^{1}$ & & 1 & $\mathrm{~N} / \mathrm{A}^{1}$ & & 1 & $\mathrm{~N} / \mathrm{A}^{1}$ & & 1 & $\mathrm{~N} / \mathrm{A}^{1}$ & \\
\hline$\frac{0}{0}$ & CGF & 2 & $\mathbf{N} / \mathbf{A}^{1}$ & ְ. & 2 & $\mathbf{N} / \mathbf{A}^{1}$ & 0 & 2 & $\mathrm{~N} / \mathrm{A}^{1}$ & ㅇ. & 2 & $\mathrm{~N} / \mathrm{A}^{1}$ & - & 2 & $\mathrm{~N} / \mathrm{A}^{1}$ & ڤ̆ & 2 & $\mathrm{~N} / \mathrm{A}^{1}$ & $\infty$ \\
\hline 足 & & 3 & $\mathbf{0 . 9 7}$ & & 3 & 0.26 & & 3 & 0.99 & & 3 & 0.18 & & 3 & 0.95 & & 3 & 0.32 & \\
\hline & & 1 & $\mathbf{N} / \mathbf{A}^{1}$ & & 1 & $\mathbf{0 . 0 7}$ & & 1 & $\mathrm{~N} / \mathrm{A}^{1}$ & & 1 & 0.21 & & 1 & $\mathrm{~N} / \mathrm{A}^{1}$ & & 1 & 0.16 & \\
\hline & D & 2 & $\mathbf{N} / \mathbf{A}^{1}$ & $\infty$ & 2 & $\mathbf{N} / \mathbf{A}^{*}$ & : & 2 & $\mathrm{~N} / \mathrm{A}^{1}$ & 2 & 2 & N/A ${ }^{*}$ & ㅇ. & 2 & $\mathrm{~N} / \mathrm{A}^{1}$ & 2 & 2 & $\mathrm{~N} / \mathrm{A}^{*}$ & $\tilde{n}$ \\
\hline & & 3 & $\mathbf{0 . 3 1}$ & & 3 & 0.55 & & 3 & 0.37 & & 3 & 0.00 & & 3 & 0.39 & & 3 & 0.00 & \\
\hline & & 1 & $\mathbf{N} / \mathbf{A}^{1}$ & & 1 & $\mathbf{N} / \mathbf{A}^{1}$ & & 1 & $\mathrm{~N} / \mathrm{A}^{1}$ & & 1 & $\mathrm{~N} / \mathrm{A}^{1}$ & & 1 & $\mathrm{~N} / \mathrm{A}^{1}$ & & 1 & $\mathrm{~N} / \mathrm{A}^{1}$ & \\
\hline ? & CGF & 2 & $\mathbf{N} / \mathbf{A}^{1}$ & ติ & 2 & $\mathbf{N} / \mathbf{A}^{1}$ & 6 & 2 & $\mathrm{~N} / \mathrm{A}^{1}$ & $\infty$ & 2 & $\mathrm{~N} / \mathrm{A}^{1}$ & $\approx$ & 2 & $\mathrm{~N} / \mathrm{A}^{1}$ & $\infty$ & 2 & $\mathrm{~N} / \mathrm{A}^{1}$ & $\infty$ \\
\hline & & 3 & $\mathbf{0 . 3 3}$ & & 3 & 0.21 & & 3 & 0.31 & & 3 & 0.11 & & 3 & 0.24 & & 3 & 0.22 & \\
\hline
\end{tabular}


Table 5-4 - Summary of the selected distributions for each case

\begin{tabular}{|c|c|c|}
\hline Case & Soil Type & Selected Distribution \\
\hline \multirow{2}{*}{ All MPs } & Coarse-grained & 3-P Lognormal \\
\cline { 2 - 3 } & Fine-grained & 3-P Lognormal \\
\hline \multirow{2}{*}{$A$} & Coarse-grained & Lognormal \\
\cline { 2 - 3 } & Fine-grained & 3-P Lognormal \\
\hline \multirow{2}{*}{ B } & Coarse-grained & 3-P Lognormal \\
\cline { 2 - 3 } & Coarse-grained & 3-P Lognormal \\
\cline { 2 - 3 } & Fine-grained & 3-P Lognormal \\
\cline { 2 - 3 } D & Coarse-grained & 3-P Lognormal \\
\cline { 2 - 3 } & Fine-grained & 3-P Lognormal \\
\hline
\end{tabular}

\subsection{MAXIMUM LiKELIHOOD ESTIMATOR}

The parameters of a certain PDF can be determined when a random variable $\mathrm{X}$ have observed values $x_{1}, x_{2}, \ldots, x_{n}$ through the Method of Maximum Likelihood. This method states that the parameters which give highest probability to predict $x_{1}, x_{2}, \ldots, x_{n}$ are the best estimation for the model. Thus, the likelihood function, $L(\theta \mid X)$, shown in Equation 5-20, should be maximized in order to determine the distributions parameters (Haldar and Mahadevan, 2000).

$$
L(\theta \mid X)=f_{X}(X \mid \theta)
$$

where $\theta$ is the vector with the values of the parameters.

If each observation is independent from one another, then the multiplicative rule can be applied. Also, maximizing the function $L(\theta \mid X)$ is equivalent to maximizing its natural logarithm, function $l(\theta \mid X)$. This transformation highly decreases the computational effort. Therefore, Equation 5-21 provides the final form of function for independent events that should be maximized.

$$
l(\theta \mid X)=\sum_{i=1}^{n} \ln \left[f_{X}(X \mid \theta)\right]
$$

With the advancement of technology, this method can be easily implemented in analysis through an optimization algorithm. In Microsoft ${ }^{\circledR}$ Excel, for instance, this task can be done by the Solver ${ }^{\circledR}$ add-in. 


\subsection{ReLiABILITY INDEX AND RESISTANCE FACTOR}

It is more common to use the reliability index, $\beta$, instead of the probability of failure, $P_{f}$ (Esposito and Fenton, 2018). Measuring such small values as $P_{f}$ is much harder than measuring values of $\beta$, which usually range from 2 to 4 for geotechnical structures. Equation 5-22 thus gives the expression for $\beta$ (Haldar and Mahadevan, 2000).

$$
\beta=\Phi^{-1}\left(1-P_{f}\right)
$$

Eq. 5-22

where $\Phi$ is the CDF of a standard normal distribution.

If the bias distribution of either resistance $\left(X_{R}\right)$ or applied load $\left(X_{Q}\right)$ do not follow a normal distribution, Equation 5-22 cannot be used. One solution for that is using Rackwitz and Fiessler (1978). This algorithm basically transforms each random variable to an equivalent standard normal random variable, $z$, and aims to minimize the expression on Equation 5-23.

$$
\beta=\min \left(Z^{T} Z\right)^{0.5}
$$

where $Z$ is a standard normal vector with the values of the equivalent random variables. When the expression is minimized, the reliability index is calculated. This can be done through Solver ${ }^{\circledR}$ addin in Microsoft ${ }^{\circledR}$ Excel.

Figure 5-3 illustrates graphically the value of $\beta$ and $P_{f}$. If a load is applied to a foundation with resistance $R$ and normally distributed the distance between the mean of the limit state distribution and the value 0 is equal to the product of $\sigma$ and $\beta$.

The resistance factor, $\phi_{g u}$, is usually lower than one to account for the variability of the foundation. If a $R^{\prime}$ distribution (the green distribution in Figure 5-4) is taken so that the mean of the limit state distribution remains the same, the probability of failure decreases, while the reliability index increases. This is demonstrated in Figure 5-4. 


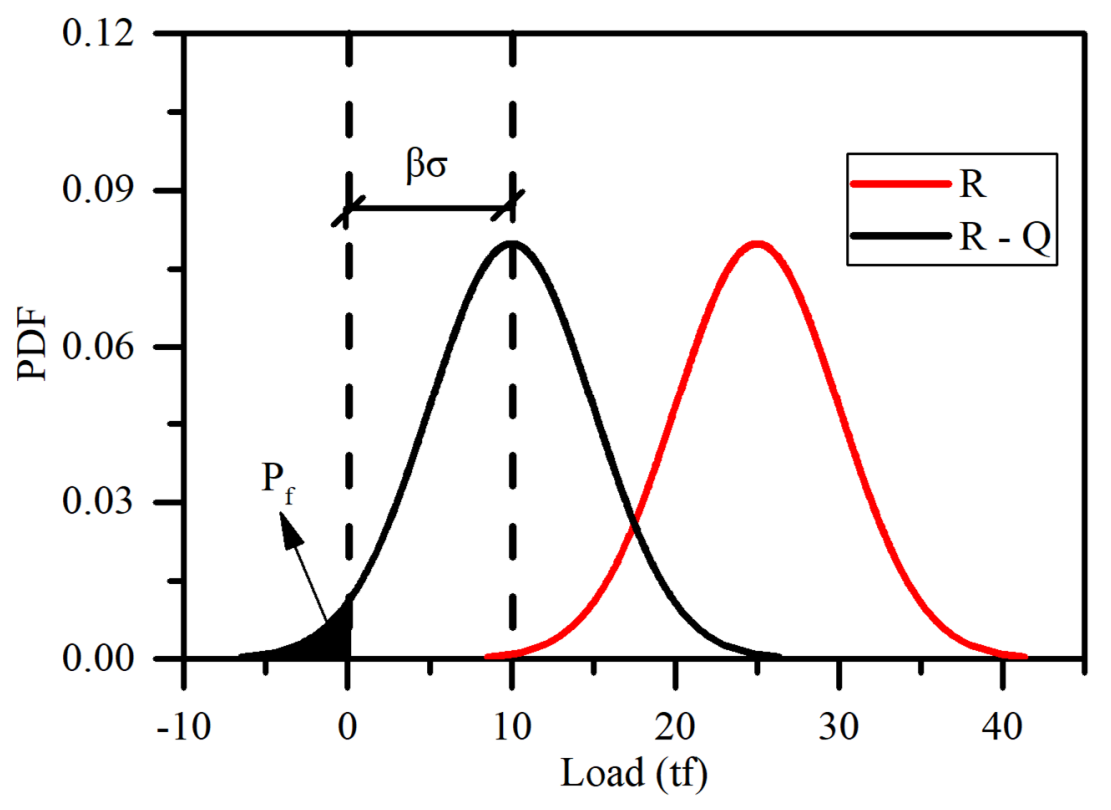

Figure 5-3 - Graphical value of $\beta$ and $P_{f}$

\subsection{Monte Carlo Simulations}

With this method, each component of the system (random variables) in a specific problem is sampled $N$ times, according to its own probability distribution (Haldar and Mahadevan, 2000). Failure is evaluated for each realization and then the probability of failure is calculated by the simplest form: number of failed realizations $\left(N_{\text {fail }}\right)$ divided by the total number of realizations $N$. According to Haldar and Mahadevan (2000), this technique has 6 basic steps:

1) define the problem in terms of its system components (random variables);

2) quantify the PDF type and parameters for each random variable;

3) generate $N$ values of each random variables following their own PDF;

4) evaluate deterministically the failure of each set of realization;

5) calculate the probabilistic results for the $N$ realizations; and

6) determine the accuracy and efficiency of the simulation (Eq. 5-24). 


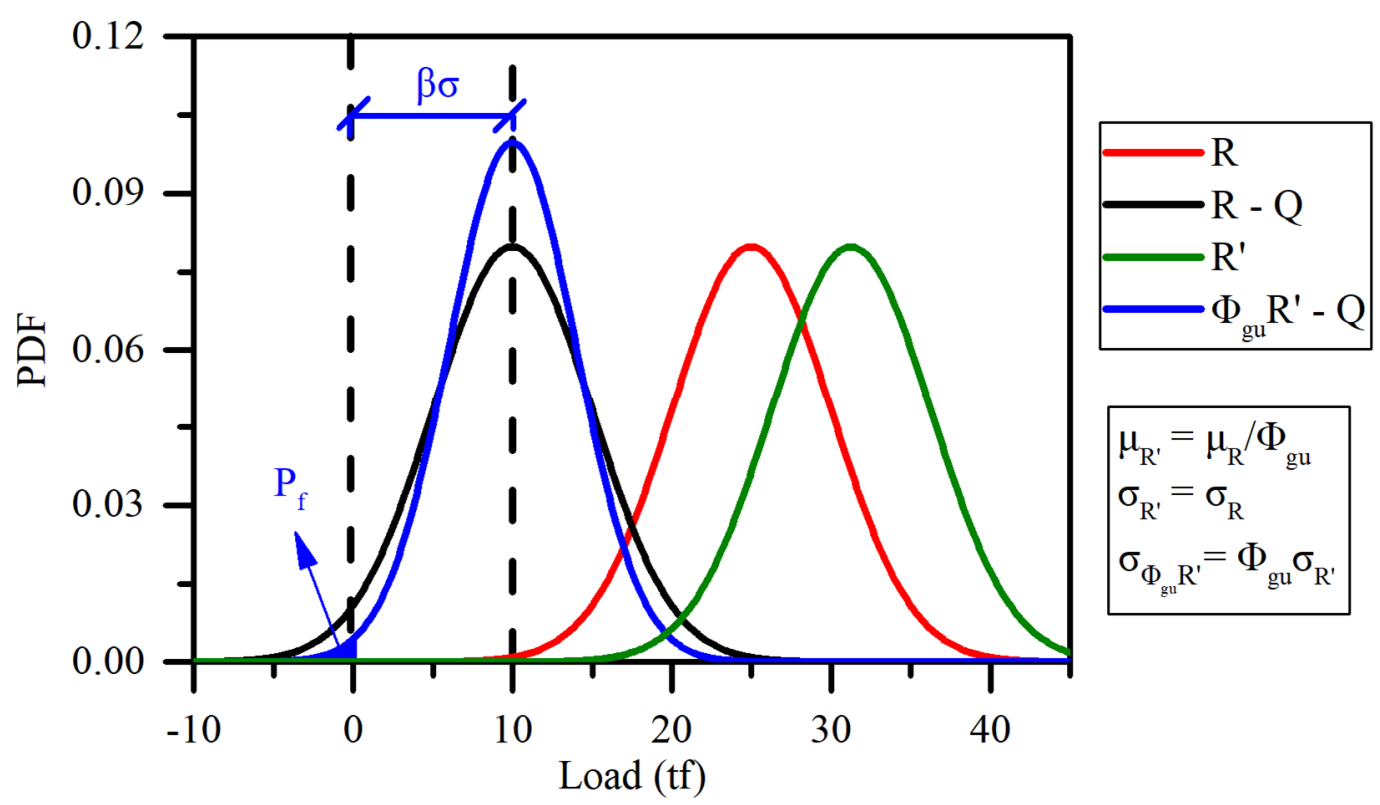

Figure 5-4 - Representation of changes when $\phi_{g u}$ is inserted

For a reliability analysis of foundation elements under axial loading, the following can be taken from the definition above:

1) define the limit state function (Eq. 5-21) according to the parameters of the considered code/standard (see item 5.9);

2) determine the distribution types and parameters for the following random variables: $X_{R}$ (from database), $X_{Q, D}$, and $X_{Q, L}$ (from code/standards - see item 5.9);

3) randomly generate values for $X_{R}, X_{Q, D}$, and $X_{Q, L}$, following their respective probability distribution;

4) a realization fails when $g<0$ (Eq. 5-21);

5) calculate $P_{f}=\frac{N_{\text {fail }}}{N}$; and

6) compute $\operatorname{COV}\left(P_{f}\right)$ from Eq. 5-24 (Haldar and Mahadevan, 2000).

$$
\operatorname{Cov}\left(P_{f}\right)=\frac{\sqrt{\frac{\left(1-P_{f}\right) P_{f}}{N}}}{P_{f}}
$$

Table 5-5 shows the values of $\operatorname{COV}\left(P_{f}\right)$ assuming a probability of failure of 2.3262E-04 (see item 5.9) and $95 \%$ confidence interval. Thus, it is chosen for this study $N$ equal to $10,000,000$ simulations to provide both an acceptable range of $P_{f}$ and a low computational cost. 
Table 5-5 - Variation of $P_{f}$ due to number of simulations $N$

\begin{tabular}{|c|c|c|c|}
\hline $\boldsymbol{N}$ & $\mathbf{C O V}$ & Lower Bound of $\boldsymbol{P}_{\boldsymbol{f}}$ & Upper Bound of $\boldsymbol{P}_{\boldsymbol{f}}$ \\
\hline $\mathbf{1 , 0 0 0 , 0 0 0}$ & 0.06556 & $2.0273 \mathrm{E}-04$ & $2.6251 \mathrm{E}-04$ \\
\hline $\mathbf{1 0 , 0 0 0 , 0 0 0}$ & 0.02073 & $2.2317 \mathrm{E}-04$ & $2.4207 \mathrm{E}-04$ \\
\hline $\mathbf{5 0 , 0 0 0 , 0 0 0}$ & 0.00927 & $2.2839 \mathrm{E}-03$ & $2.3685 \mathrm{E}-04$ \\
\hline
\end{tabular}

With advancement of technology, this method can be easily implemented in computer algorithms. In this study, this analysis was written in a Microsoft $\AA$ Excel application through Visual Basic for Applications (VBA) language.

\subsection{Codes ANd Standards Parameters And ReQuirements}

The ASD methodology prescribed similar FS worldwide. The required reliability index was first back calculated from the usual FS values. Thus, it is expected that the value of $\beta$ was also similar. Nevertheless, since the computation of $\beta$ considers the variability of the system components, a change between two different codes is expected, especially in the case of structures embedded in soils.

Table 5-6 summarizes the required parameters: the resistance factor $\phi$, the load factors $\gamma_{u, D}$ and $\gamma_{u, L}$, and also the target reliability index $\beta_{\text {tar }}$ with correspondent $P_{f}$ by the CHBDC, the NBCC, and the AASHTO. It was considered a Normal Traffic situation with a typical degree of understanding assumption as per the CHBDC for all codes. Values of $\phi$ were taken for deep foundations from the CHBDC and NBCC. From the AASHTO, nonetheless, $\phi$ was taken specifically for micropiles. Additionally, due to the combination of different directions of applied load (tensile and compressive loads), the considered resistance factor $\phi_{c o n}$ was taken as the minimum value $\phi$ between compressive loads, $\phi_{C}$, and tensile loads, $\phi_{T}$.

Table 5-6 - Required parameters for reliability analysis according to different codes

\begin{tabular}{|c|c|c|c|c|}
\hline \multicolumn{2}{|c|}{ Parameter } & $\begin{array}{c}\text { CHBDC (CSA, 2016a } \\
\text { and 2016b) }\end{array}$ & NBCC (NRCC, 2015) & $\begin{array}{c}\text { AASHTO (AASHTO, } \\
\text { 2012) }\end{array}$ \\
\hline \multirow{4}{*}{$\begin{array}{c}\text { Limit } \\
\text { State } \\
\text { Equation }\end{array}$} & $\boldsymbol{\phi}_{\boldsymbol{C}}$ & 0.40 & 0.40 & 0.55 \\
\cline { 2 - 5 } & $\boldsymbol{\phi}_{\boldsymbol{T}}$ & 0.30 & 0.30 & 0.55 \\
\cline { 2 - 5 } & $\boldsymbol{\phi}_{\boldsymbol{c o n}}$ & 0.30 & 0.30 & 0.55 \\
\cline { 2 - 5 } & $\boldsymbol{\gamma}_{\boldsymbol{u}, \boldsymbol{D}}$ & 1.20 & 1.25 & 1.25 \\
\cline { 2 - 5 } & $\boldsymbol{\gamma}_{\boldsymbol{u}, \boldsymbol{L}}$ & 1.70 & 1.50 & 1.75 \\
\hline $\begin{array}{c}\text { Target } \\
\text { Reliability }\end{array}$ & $\boldsymbol{\beta}_{\boldsymbol{t a r}}$ & 3.50 & $3.00^{*}$ & 3.50 \\
\cline { 2 - 5 } & $\boldsymbol{P}_{\boldsymbol{f}}$ & $2.3262 \mathrm{E}-04$ & $1.3499 \mathrm{E}-03$ & $2.3262 \mathrm{E}-04$ \\
\hline
\end{tabular}

*The NBCC does not directly indicate a target reliability index, but indicates possible values depending on the assumed FS. FS $=2.5$ leads to $\beta=3.0$, approximately. 
Other studies have brought the concept of redundancy for deep foundations. It is considered a redundant foundation when a pile cap contains more than 5 piles in a single pile cap (Paikowsky et al., 2004). This concept was first introduced by Barker et al. (1991) which suggested a target reliability index ranging from 2.5 to 3.0 for single piles and 2.0 to 2.5 for group piles. Paikowsky et al. (2004) later formalized this concept and proposed a targer reliability index of 3.0 for pile caps with up to 4 piles and 2.33 for pile caps with 5 or more piles.

In addition to the probability characteristics of the foundation resistance, it is needed the probability distribution function to model the applied load. The CHBDC in its Commentary Section indicates that both dead and live loads follow a lognormal distribution (Canadian Standards Association, 2016a). As indicated by Paikowsky et al. (2004), the AASHTO has also adopted a lognormal distribution and parameters are indicated in Nowak (1999). The NBCC does not provide a requirement in terms of applied load modelling. Therefore, it is assumed the parameters from Nowak (1999) for the NBCC in this study. Table 5-7 summarizes the parameters for each code.

Table 5-7 - Parameters for modelling the applied loads by Nowak (1999) and (Canadian Standards Association, 2016a)

\begin{tabular}{|c|c|c|c|c|c|c|}
\hline \multirow{2}{*}{ Code } & \multicolumn{3}{|c|}{ Dead Load Bias $\left(\boldsymbol{X}_{\boldsymbol{Q}, \boldsymbol{D}}\right)$} & \multicolumn{3}{c|}{ Live Load Bias $\left(\boldsymbol{X}_{\boldsymbol{Q}, \boldsymbol{L}}\right)$} \\
\cline { 2 - 7 } & Mean & COV & PDF Type & Mean & COV & PDF Type \\
\hline CHBDC & 1.05 & 0.10 & Lognormal & 1.35 & 0.035 & Lognormal \\
\hline AASHTO & 1.05 & 0.10 & Lognormal & 1.15 & 0.20 & Lognormal \\
\hline NBCC & 1.05 & 0.10 & Lognormal & 1.15 & 0.20 & Lognormal \\
\hline
\end{tabular}

\subsection{Reliability Analysis of Design Methods for MiCropiles}

\subsubsection{Reliability Index of Design Methods}

Parameters for all cases and scenarios were estimated by the Maximum Likelihood Estimator methodology. Values are shown in Table 5-8 for all considered methods: FHWA design method, the Suggested Parameters in Chapter 4, and Bustamante and Doix (1985).

Then, $\beta$ was calculated using Rackwitz and Fiessler (1978) to provide the current reliability state of micropiles. As before, the analyzed cases were separated between coarse- and fine-grained soils. Results are shown for the FHWA design method in Figure 5-5 according to the requirements of the AASHTO, in Figure 5-6 according to the requirements of the CHBDC, and in Figure 5-7 according to the requirements of the NBCC. For the Suggested Parameters in Chapter 4, results of $\beta$ are shown in Figure 5-8 according to the requirements of the AASHTO, in Figure 5-9 according to the requirements of the $\mathrm{CHBDC}$, and in Figure 5-10 according to the requirements of the NBCC. 
Figure 5-11 shows results for Bustamante and Doix (1985) with requirements of the AASHTO, the CHBDC, and the NBCC.

Table 5-8 - Values of the parameters for each probability distribution

\begin{tabular}{|c|c|c|c|c|c|c|c|}
\hline \multirow{2}{*}{ Case } & \multirow{2}{*}{ Par. } & \multicolumn{2}{|c|}{ FHWA } & \multicolumn{2}{c|}{ Sug. Par. Chap. 4 } & \multicolumn{2}{c|}{ Bust. Doix } \\
\cline { 2 - 8 } & & Coarse & Fine & Coarse & Fine & Coarse & Fine \\
\hline \multirow{3}{*}{ All } & $\lambda$ & 0.78589 & 0.06775 & 0.30747 & -0.01192 & - & - \\
\cline { 2 - 8 } & $\zeta$ & 0.66691 & 1.02396 & 0.32215 & 1.04303 & - & - \\
\cline { 2 - 8 } & $\gamma$ & 0.19246 & 0.28937 & -0.25993 & 0.16799 & - & - \\
\hline \multirow{4}{*}{$\mathrm{A}$} & $\lambda$ & 1.25729 & 0.17523 & 0.24773 & -0.63373 & - & - \\
\cline { 2 - 8 } & $\zeta$ & 0.55831 & 5.38730 & 0.50724 & 5.51686 & - & - \\
\cline { 2 - 8 } & $\gamma$ & - & 0.39116 & - & 0.27533 & - & - \\
\hline \multirow{4}{*}{$\mathrm{B}$} & $\lambda$ & 2.76262 & - & -3.35517 & - & - & - \\
\cline { 2 - 8 } & $\zeta$ & 0.01915 & - & 4.06710 & - & - & - \\
\cline { 2 - 8 } & $\gamma$ & -14.16863 & - & 0.69600 & - & - & - \\
\hline \multirow{4}{*}{ CGF } & $\lambda$ & 3.65932 & -1.71625 & -0.57690 & -1.71238 & -2.69021 & 2.53362 \\
\cline { 2 - 8 } & $\zeta$ & 0.01817 & 1.79152 & 0.40637 & 2.12119 & 1.82056 & 0.01290 \\
\cline { 2 - 8 } & $\gamma$ & -34.97724 & 1.20000 & 0.41389 & 0.61000 & 1.59000 & -11.87713 \\
\hline \multirow{3}{*}{$\mathrm{D}$} & $\lambda$ & -3.18062 & -2.13354 & -2.66532 & -2.65036 & - & - \\
\cline { 2 - 8 } & $\zeta$ & 4.26297 & 3.09753 & 2.96597 & 3.73295 & - & - \\
\cline { 2 - 8 } & $\gamma$ & 0.85500 & 0.66040 & 0.64900 & 0.77970 & - & - \\
\hline
\end{tabular}

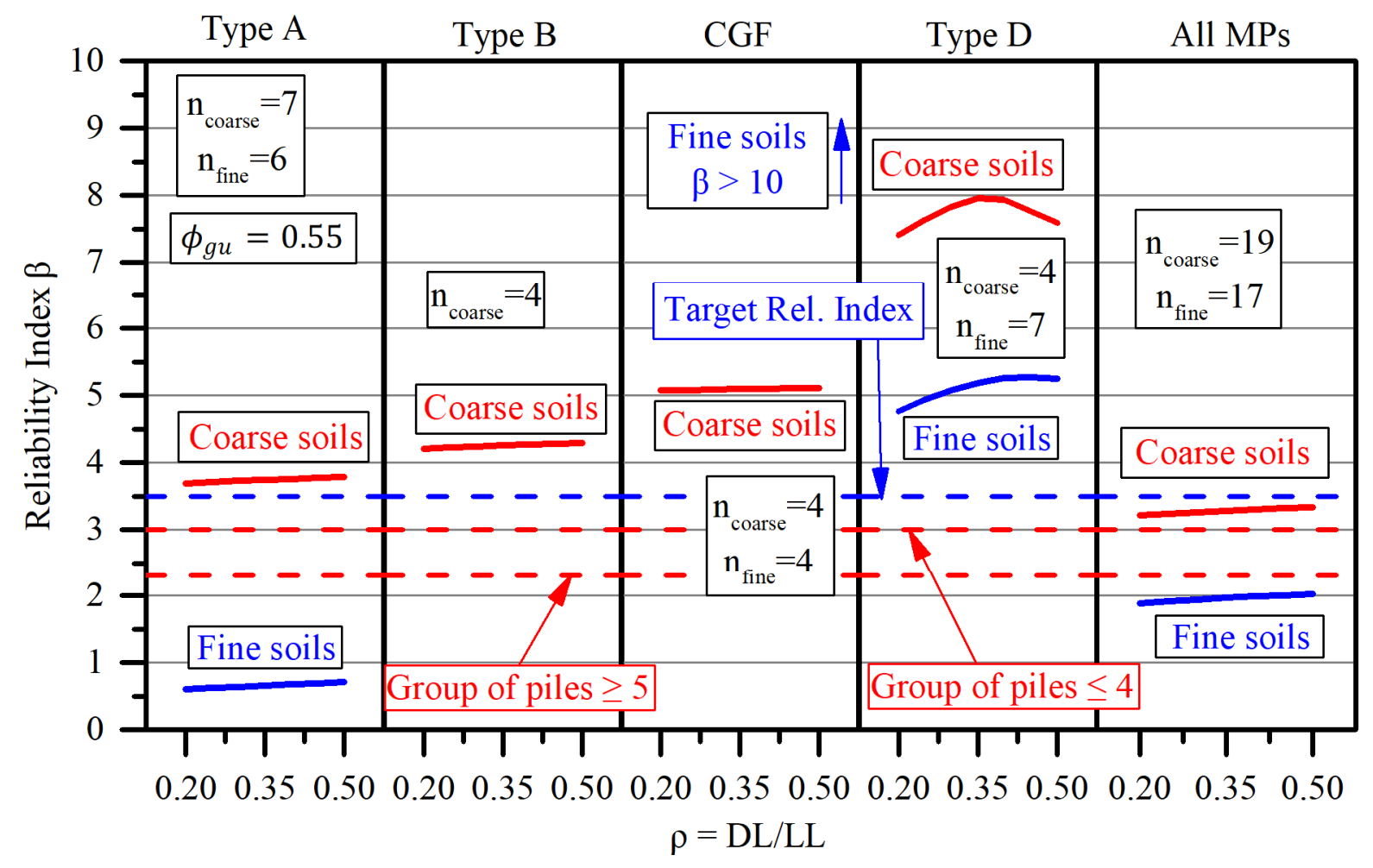

Figure 5-5 - $\beta$ achieved by the FHWA design method according to the AASHTO requirements 


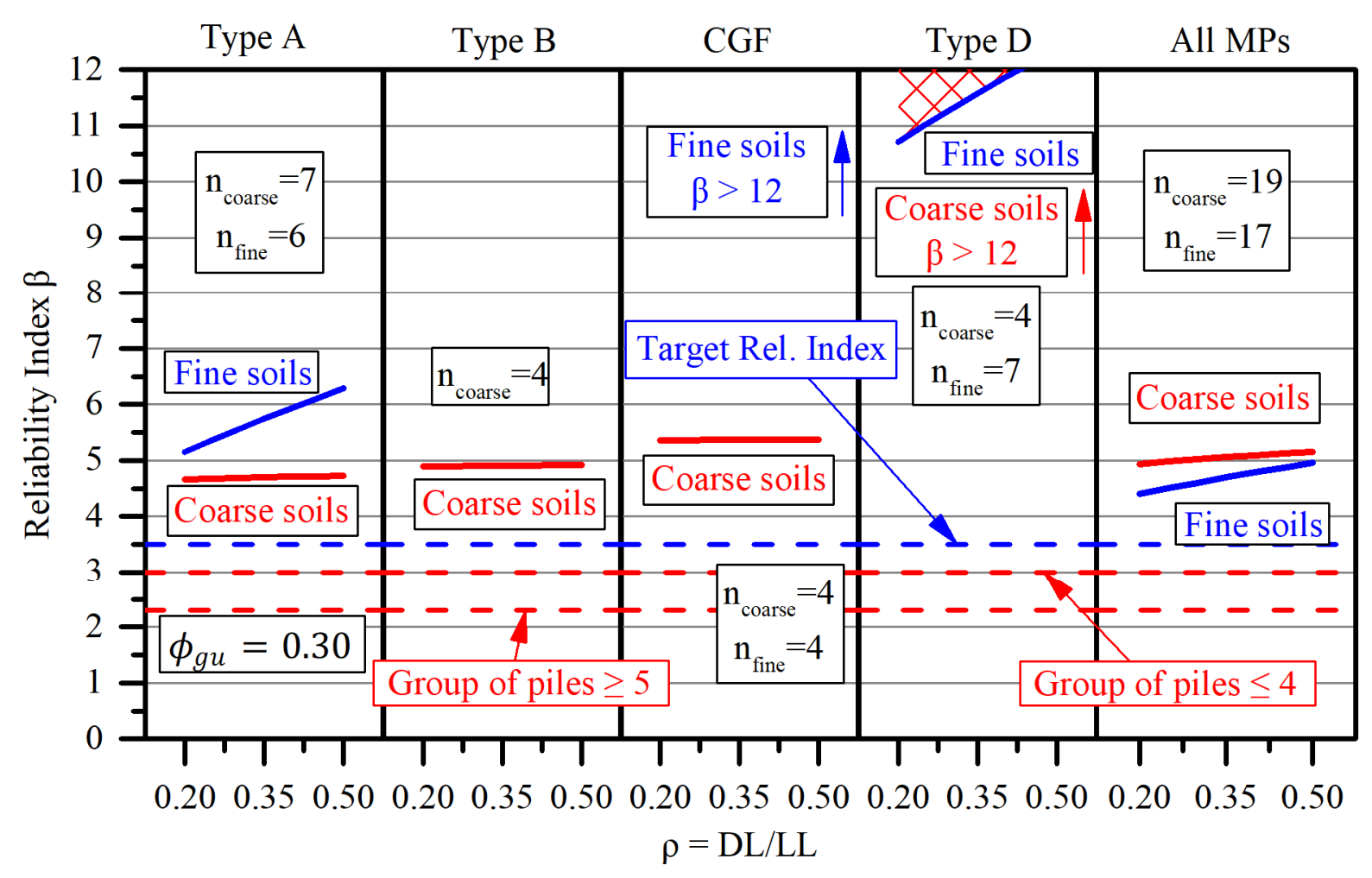

Figure 5-6 - $\beta$ achieved by the FHWA design method according to the CHBDC requirements

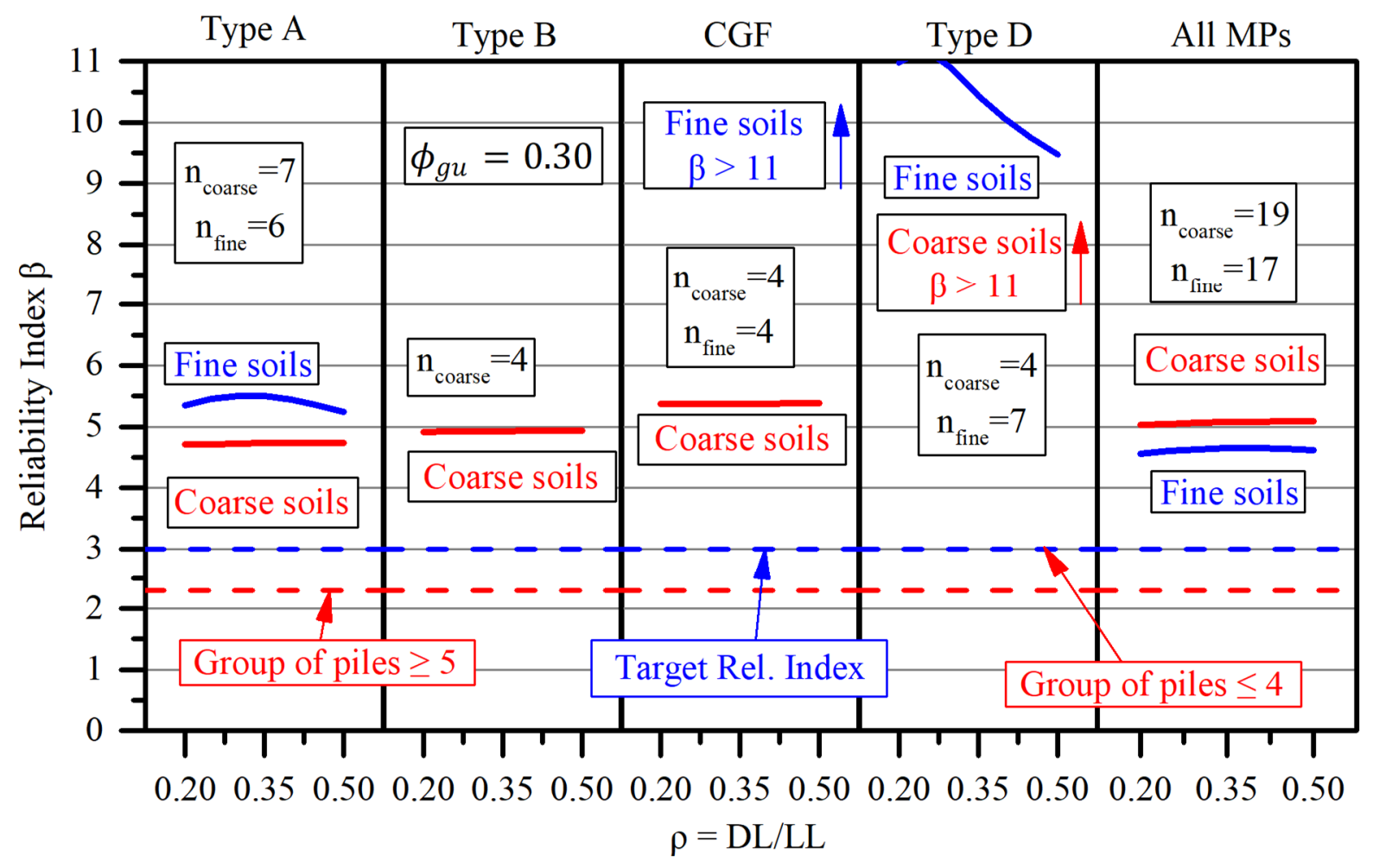

Figure 5-7 - $\beta$ achieved by the FHWA design method according to the NBCC requirements 


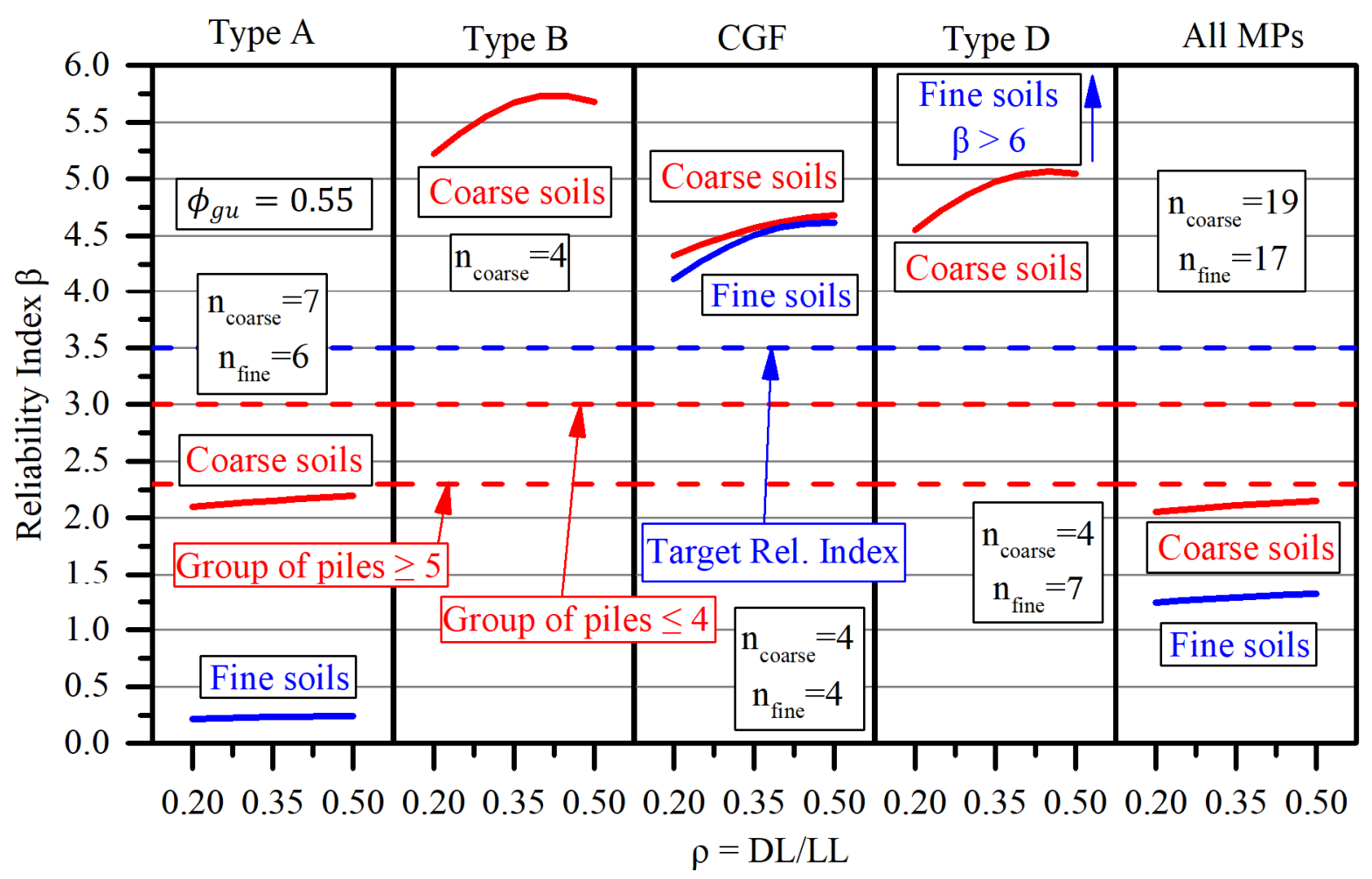

Figure 5-8 - $\beta$ achieved by the Suggested Parameters according to the AASHTO requirements

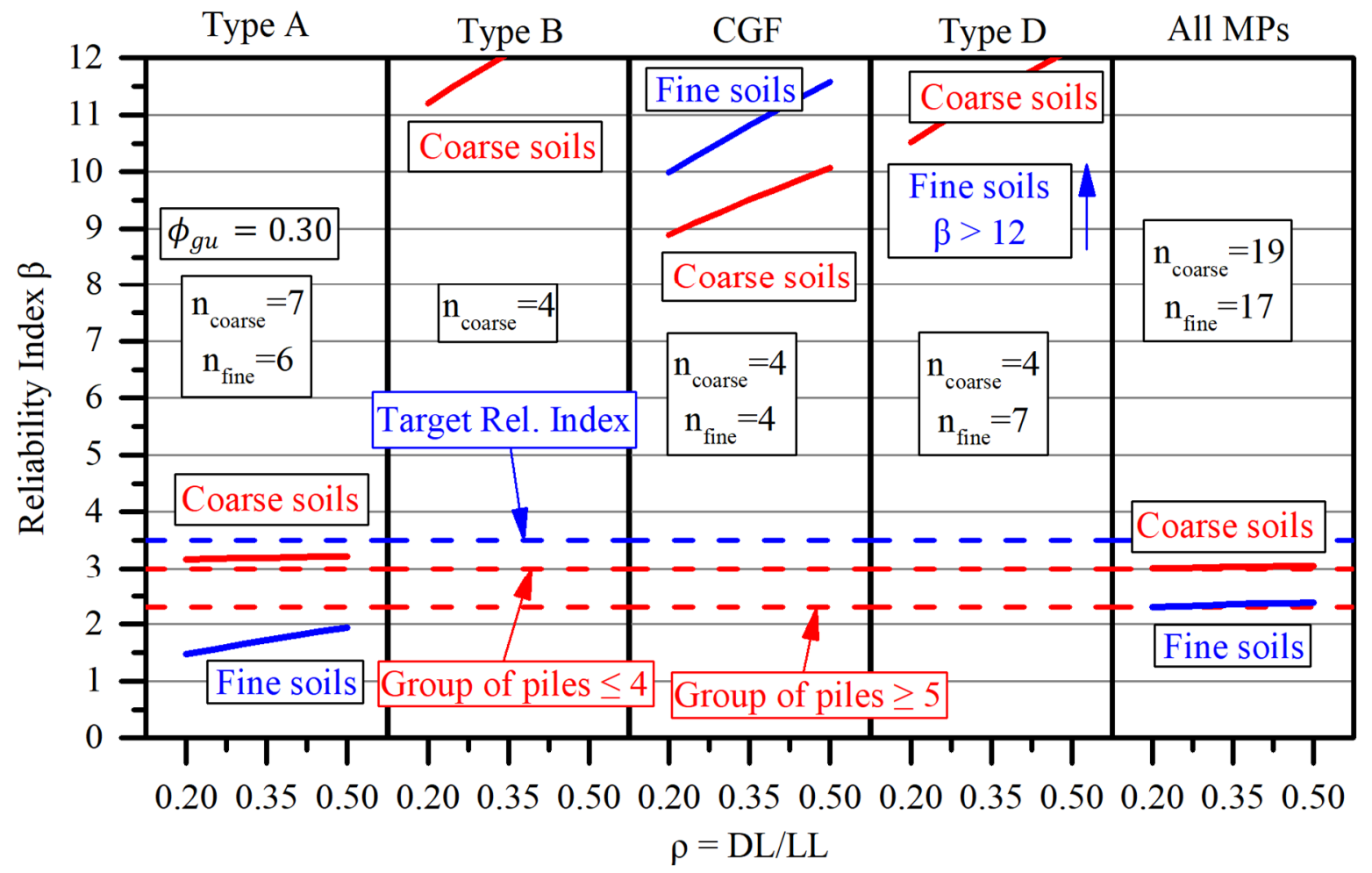

Figure 5-9 - $\beta$ achieved by the Suggested Parameters according to the CHBDC requirements 


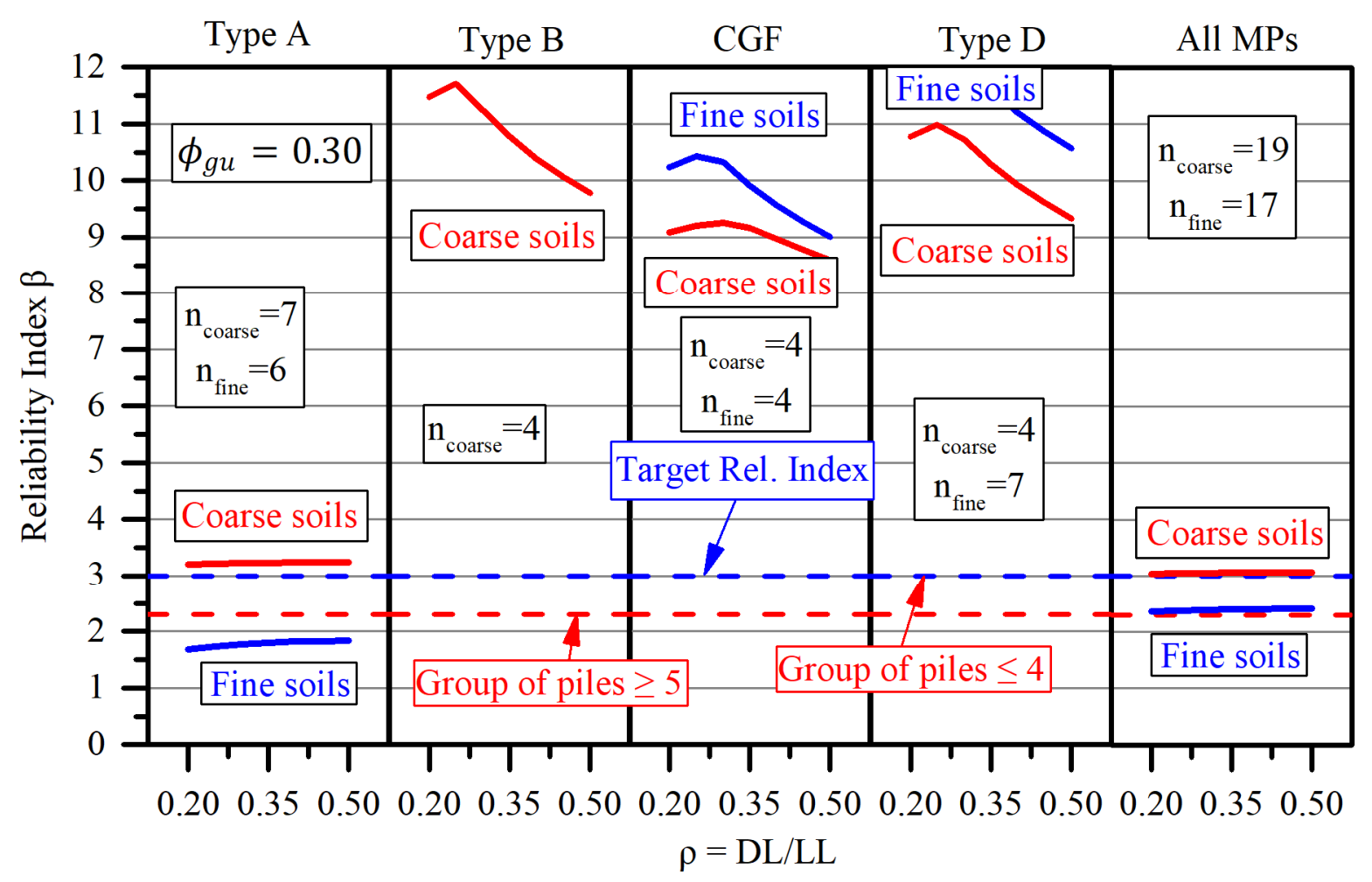

Figure 5-10 - $\beta$ achieved by the Suggested Parameters according to the NBCC requirements

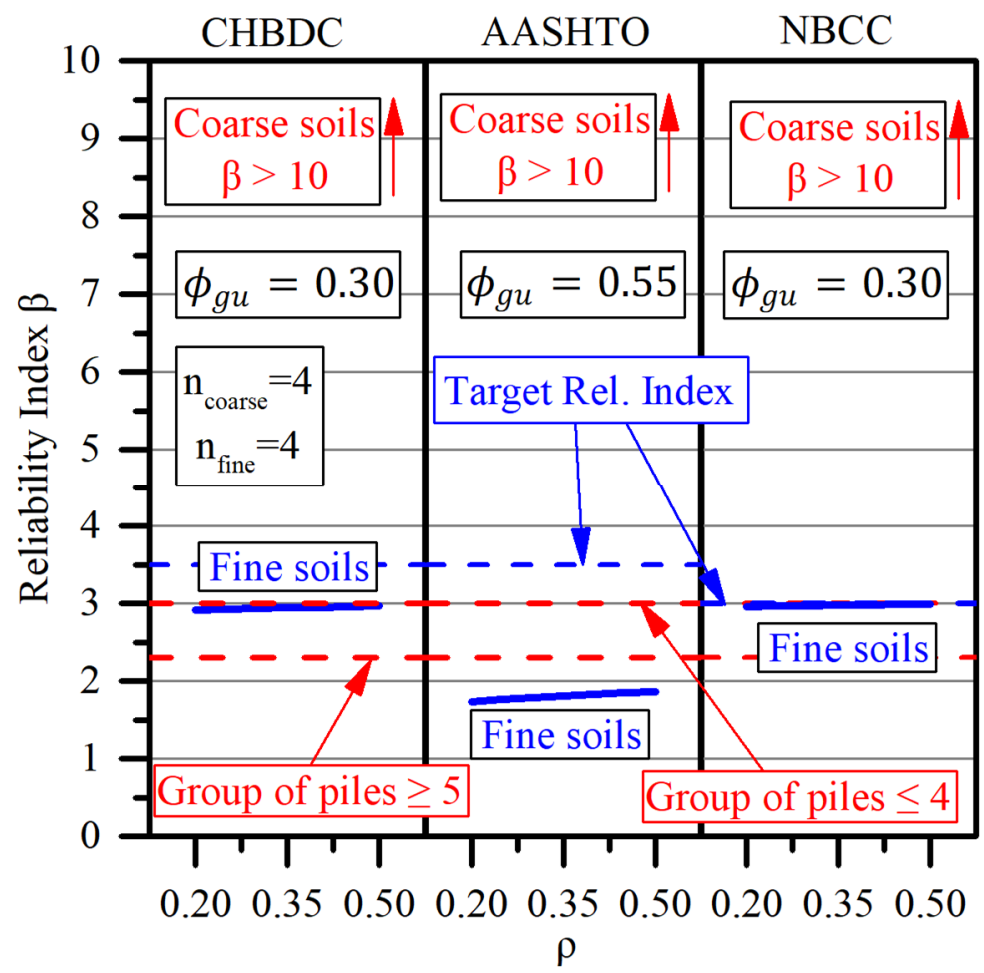

Figure 5-11 - $\beta$ achieved by Bustamante and Doix (1985) 
Clearly, $\phi_{g u}$ of each code should be recalibrated so that the target resistance factor is achieved. In the FHWA design method, Type A in fine-grained soils was the only case that the achieved $\beta$ fell short of $\beta_{\text {tar }}$ of the AASHTO. Type B, CGF micropiles, Type D, and the 'All Micropiles' cases can have an increased $\phi_{g u}$. Bustamante and Doix (1985) obtained high values of $\beta$ in coarsegrained soils. Additionally, the Suggested Parameters in Chapter 4 can be used after recalibration of $\phi_{g u}$. Bustamante and Doix (1985) have to decrease $\phi_{g u}$ for fine-grained soils.

\subsubsection{Recalibration of the Resistance Factor}

In order to achieve the target reliability index, values of $\phi_{g u}$ have to be recalibrated for all discussed methods: the FHWA, Bustamante and Doix (1985), and the Suggested Parameters in Chapter 4. The recalibration was done with an algorithm written in VBA through Monte Carlo Simulations. Table 5-9 provides the results of recalibrated $\phi_{g u}$. It was used for simulations $\rho$ equal to 0.33 since it is the most common value adopted in $\phi_{g u}$ recalibration (Fenton et al., 2016).

It is worth noticing that values of $\phi_{g u}$ might have been affected by several situations of this study, such as the combination of different directions of applied load in a single case, the low number of cases available, and the extrapolation of the Q-s curve that was required to analyze in terms of the ULS. For instance, it is commonly believed that a good estimation of a distribution variation is done with at least 100 events. However, this study has cases with a number of samples as low as 4. 
Table 5-9 - Recalibrated $\phi_{g u}$ for each case

\begin{tabular}{|c|c|c|c|c|c|}
\hline Case & Des. Method & Soil Type & CHBDC & AASHTO & NBCC \\
\hline \multirow{4}{*}{$\begin{array}{c}\text { All } \\
\text { MPs }\end{array}$} & \multirow{2}{*}{ FHWA } & Coarse & 0.50 & 0.47 & 0.50 \\
\hline & & Fine & 0.35 & 0.37 & 0.39 \\
\hline & \multirow{2}{*}{$\begin{array}{l}\text { Suggested } \\
\text { Parameters }\end{array}$} & Coarse & 0.21 & 0.22 & 0.31 \\
\hline & & Fine & 0.22 & 0.23 & 0.24 \\
\hline \multirow{4}{*}{$\mathbf{A}$} & \multirow{2}{*}{ FHWA } & Coarse & 0.58 & 0.58 & 0.62 \\
\hline & & Fine & 0.37 & 0.38 & 0.38 \\
\hline & \multirow{2}{*}{$\begin{array}{l}\text { Suggested } \\
\text { Parameters }\end{array}$} & Coarse & 0.25 & 0.27 & 0.33 \\
\hline & & Fine & 0.25 & 0.27 & 0.27 \\
\hline \multirow{2}{*}{ B } & FHWA & Coarse & 0.80 & 0.75 & 0.80 \\
\hline & Sug. Par. & Coarse & 0.64 & 0.67 & 0.67 \\
\hline \multirow{6}{*}{ CGF } & \multirow{2}{*}{ FHWA } & Coarse & 1.72 & 1.71 & 1.79 \\
\hline & & Fine & 1.14 & 1.19 & 1.19 \\
\hline & \multirow{2}{*}{$\begin{array}{l}\text { Suggested } \\
\text { Parameters }\end{array}$} & Coarse & 0.60 & 0.63 & 0.65 \\
\hline & & Fine & 0.58 & 0.60 & 0.61 \\
\hline & \multirow{2}{*}{$\begin{array}{c}\text { Bust. } \\
\text { and Doix }\end{array}$} & Coarse & 1.48 & 1.54 & 1.54 \\
\hline & & Fine & 0.19 & 0.21 & 0.29 \\
\hline \multirow{4}{*}{ D } & \multirow{2}{*}{ FHWA } & Coarse & 0.82 & 0.79 & 0.82 \\
\hline & & Fine & 0.62 & 0.64 & 0.64 \\
\hline & \multirow{2}{*}{$\begin{array}{l}\text { Suggested } \\
\text { Parameters }\end{array}$} & Coarse & 0.60 & 0.63 & 0.63 \\
\hline & & Fine & 0.72 & 0.75 & 0.75 \\
\hline
\end{tabular}




\section{CONCLUSIONS AND FUTURE RESEARCH}

\subsection{SUMMARY}

A comprehensive study was conducted in this research on the reliability-based design of ultimate limit state of micropiles in Ontario soils. First, a statistical analysis was conducted on different methods to identify the failure load of micropiles. This analysis was able to provide the best method to analyze non-failed tests of micropiles which is not only a safe method by not relying on a prediction of the plunging failure, but also it is not conservative to the point of not establishing an ultimate state, such as the maximum test load. In addition, an improved method was applied to predict the load contributions of the cased length and the tip to the total resistance. Values of bond strength were obtained with this method and compared with parameters provided by FHWA (2000) and Bustamante and Doix (1985). Suitable ranges of bond strength were provided for micropiles in Ontario soils. Ultimately, a reliability analysis was conducted to evaluate both the Suggested Parameters for micropile design, and parameters from FHWA (2000) and Bustamante and Doix (1985) in terms of the achieved reliability index. Also, the resistance factor for each one of these methods was recalibrated to comply with the requirements from three different codes: the AASHTO, the CHBDC, and the NBCC.

\subsection{CONCLusions}

Several Gradual Failure methods were combined with three different Extrapolation methods. The Fuller and Hoy method in the combination with any of Decourt's Extrapolation method, Chin's method, or Van Der Veen's method were found to be the best method to evaluate the pile axial capacity from a non-failure load test.

Different from Bruce et al. (1993) and Gómez et al. (2003) which suggested that variation of ER was a consequence of debonding of the cased length or due to strain softening after achieving a peak strength, the ER seems to vary due to progressive loading throughout testing which gradually increases the value of the coefficient $\xi$ associated with the load-transfer distribution.

Additionally, a method was proposed for estimating the load contribution of the cased length and the pile toe. The mobilized line of the cased length is a reasonable approach for the cased length contribution. The combination of the Decourt's method and the Elastic Length method, improved herein, can estimate reasonably the contribution from the mobilized pile tip. The task of determining a suitable $\xi$ value and finding the transition point of the Decourt's Extrapolation method is much simpler by using the combination of these two methods.

From the findings of the Elastic Length method, the tip starts to be mobilized when $\xi$ for both cased length and bond length achieves a value between 0.60 to 0.67 for load tests under 
compressive loads. Also, the resistance of the cased length might achieve its maximum value with $\xi_{\text {cas }}$ between 0.60 to 0.67 .

Suitable values of $q_{s}$ were proposed for Type A, Type B, CGF, and Type D micropiles. They are summarized as follows:

Table 6-1 - Suggested values of $q_{s}$ for each micropile type

\begin{tabular}{|c|c|c|c|c|c|c|}
\hline \multirow{2}{*}{$\begin{array}{c}\text { Micropile } \\
\text { Type }\end{array}$} & \multirow{2}{*}{$\begin{array}{c}\text { Soil } \\
\text { Type }\end{array}$} & Minimum & Median & Maximum & $\begin{array}{c}\text { Average } \\
\text { SPT N } \\
\text { Range }\end{array}$ & $\begin{array}{c}\text { Recommended } \\
\boldsymbol{\phi}_{\boldsymbol{g} \boldsymbol{u}}\end{array}$ \\
\cline { 3 - 7 } Type A & Fine & 34 & 110 & 257 & $13-43$ & 0.25 \\
\cline { 2 - 7 } & Coarse & 194 & 411 & 567 & $40-50$ & 0.25 \\
\hline \multirow{2}{*}{ Type B } & Coarse & 234 & 306 & 392 & $16-44$ & 0.64 \\
\hline \multirow{2}{*}{ CGF } & Fine & 175 & 265 & 350 & $10-43$ & 0.58 \\
\cline { 2 - 7 } & Coarse & 535 & 654 & 802 & $31-43$ & 0.60 \\
\hline \multirow{2}{*}{ Type D } & Fine & 130 & 150 & 179 & $38-50$ & 0.72 \\
\cline { 2 - 7 } & Coarse & 211 & 311 & 466 & 44 & 0.60 \\
\hline
\end{tabular}

Values of $q_{s}$ can be extremely high from Table 6-1. However, the resistance factors in Table 5-12 for the parameters above are lower than the resistance factors for the FHWA design method. In this manner, the resultant factored resistance provided by the Suggested Parameters is not only higher than the ones generated by the FHWA, but they are also reasonable. Values of $\beta$ for the $\beta$ method (see item 2.3.4) were obtained and seem to be related to the slenderness ratio, as raised by Jeon and Kulhawy (2001), but a direct relationship was not obtained.

The majority of the PDFs of the bias distribution for the micropile resistance followed a 3Parameter Lognormal distribution. For the FHWA method, Type A micropile in fine-grained soils fell short the target reliability index using the AASHTO requirements. Also, evaluating all micropiles in a single scenario provided lower reliability indexes than the target using the AASHTO. All the other cases achieved or exceeded the target reliability index. Type A, Type B, CGF, and Type D micropiles had the resistance factor recalibrated to achieve the prescribed reliability index of each code.

\subsection{StUdy Limitations}

This study had a significant amount of limitations. The number of load tests are limited to 40 reliable load tests in this study. For statistical and reliability analyses, nevertheless, this quantity of tests is deemed low, especially because micropiles are group of piles with different features (pressure- or post-grouting and different drilling techniques) grouped together. This forced grouping of micropiles with different load directions (tensile and compressive loads) in order to achieve a minimum quantity of samples for each scenario. More micropile load tests should be 
collected in the future to increase the number of load cases in each soil type. In addition, the improved Elastic Length method is an approximation of the true behaviour. Its drawbacks were discussed in Chapter 4. Since extrapolation was required, the considered level of failure in this study is much higher than the current practice. Extrapolation also brings uncertainties to the analysis. Ultimately, parameters related to the shape of the load-distribution curve had to be assumed because of the lack of instrumentation.

\subsection{Future RESEARCH}

This research focused primarily on the ULS of micropiles. Design of foundation structures, however, also considers the Serviceability Limit State (SLS) which focuses on analyzing conditions of the generated deformation (settlement) in a foundation. Plasticity analysis can be conducted to generate load-displacement functions (t-z curves) with this same database. For this, methods such as Misra et al. (2004) can be used. This study would serve as an important source, since there is a lack of SLS analysis available for micropiles. Results from the t-z curves could be compared with the Elastic Length method, improved in this study, to verify their accuracy.

Obtaining a larger database is suggested to increase the number of cases reported in this study. Therefore, the analyses herein can be further improved in the future, generating better estimations of the intervals of bond stress. Also, if a database with failed tests is available, the validity of the combination of Fuller and Hoy's method and Extrapolation methods could be verified. In addition, an analysis of a database with instrumented micropile is highly recommended. The assumptions of this research and the Elastic Length method could have their validity verified. Nonetheless, this research serves as an important benchmark by analyzing several different aspects of micropiles and providing valuable recommendations for its design in Ontario soils. 


\section{APPENDIX}

Case II from Figure 4-4 can be used as a model for calculating $L_{m, i}$, though the expression is valid for the remaining cases. Figure A-1 separated the load-transfer distribution of case II in 3 different components: $a, b$, and c. Figure A-1 is drawn linearly for simplicity only, the real shape is given by $\xi_{\text {cas }, i}$ and $\xi_{\text {bond, } i}$.

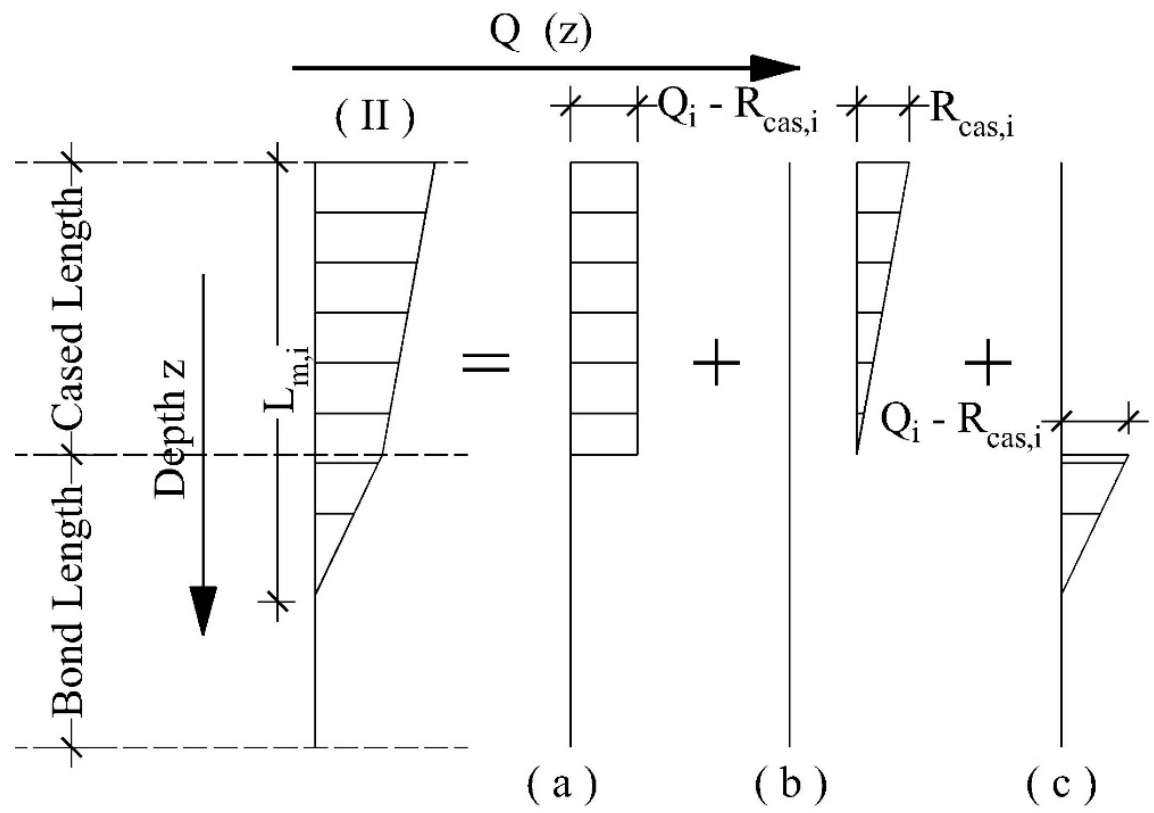

Figure A-1 - Loading components a, b, and c of a load-transfer distribution curve

With the implementation of $\xi$ to Equation 4-4, the following can be defined:

$$
\begin{gathered}
S_{e, i, a}=\frac{\left(Q_{i}-R_{c a s, i}\right) L_{c a s}}{(E A)_{c a s}} \\
S_{e, i, b}=\frac{\xi_{c a s, i} R_{c a s, i} L_{c a s}}{(E A)_{c a s}} \\
S_{e, i, c}=\frac{\xi_{\text {bond }, i}\left(Q_{i}-R_{c a s, i}\right)\left(L_{m, i}-L_{c a s}\right)}{(E A)_{b o n d}}
\end{gathered}
$$

Then:

$$
S_{e, i}=\frac{\left(Q_{i}-R_{c a s, i}\right) L_{c a s}}{(E A)_{c a s}}+\frac{\xi_{c a s, i} R_{c a s, i} L_{c a s}}{(E A)_{c a s}}+\frac{\xi_{b o n d, i}\left(Q_{i}-R_{c a s, i}\right)\left(L_{m, i}-L_{c a s}\right)}{(E A)_{b o n d}} \quad \text { Eq. A-4 }
$$


Thus:

$$
L_{m, i}=L_{c a s}+\frac{(E A)_{b o n d}}{\xi_{\text {bond }, i}\left(Q_{i}-R_{c a s, i}\right)}\left[S_{e, i}-\frac{\left(Q_{i}-R_{c a s, i}\right) E R_{c a s, i}}{\xi_{c a s, i}}-R_{c a s, i} E R_{c a s, i}\right]
$$

Eq. 4-10 


\section{BIBLIOGRAPHY}

Abd Elaziz, A.-Y. and El Naggar, M.-H. (2014). Geotechnical capacity of hollow-bar micropiles in cohesive soils. Canadian Geotechnical Journal, 51, 1123-1138.

Abdlrahem, M.-A. and El Naggar, M.-H. (2016) Full Scale Uplift Load Testing of Micropiles in Cohessionless Soil. Proceedings of the 41st International Conference on Deep Foundations, Seepage Control and Remediation, New York, USA, 217-224.

Almeida, A., Jesswwin, M., Liu, J., Gurpersaud, N. and Bruce, J. (2018). Statistical Evaluation of Design Methods for Micropiles in Ontario Soils. Proceedings of GeoEdmonton 2018: 71st Canadian Geotechnical Conference, Edmonton, AB.

American Association of State Highway and Transportation Officials. (2012). AASHTO LRFD Bridge Design Specifications (6th ed), Washington, USA: AASHTO.

Ang, A. H.-S. and Tang, W. H. (2007). Probability Concepts Engineering (2nd ed.), New York, USA: John Wiley \& Sons Inc.

Aristizabal, R.-J. (2012). Estimating the Parameters of the Three-Parameter Lognormal Distribution. Florida International University FIU Digital Commons. Retrieved from https://pdfs.semanticscholar.org/8740/c7fea3de915f3077884b6fe84b5088e8c44f.pdf

ASTM. (2013a). Standard Test Methods for Deep Foundations Under Static Axial Compressive Load. ASTM International, D1143/D1143M-07(2013)e1, West Conshohocken, USA.

ASTM. (2013b). Standard Test Methods for Deep Foundations Under Static Axial Tensile Load. ASTM International, D3689/D3689M-07(2013)e1, West Conshohocken, USA.

Barker, R.-M., Duncan, J.-M., Rojiani, K.-B., Ooi, P.-S.-K., Tan C.-K. and Kim, S.-G. (1991). Manuals for the Design of Bridge Foundations. NCHRP Report 343, Washington, USA: Transportation Research Board.

Beer, F.-P. (2011). Statics and Mechanics of Materials, Columbus, USA: The McGraw-Hill Companies, Inc. 
Bruce, D.-A., Bjorhovde, R. and Kenny, J.-R. (1993). Fundamental Tests On The Performance Of High Capacity Pin Piles ${ }^{\mathrm{SM}}$. Proceeding of the 18th Annual DFI Conference, Pittsburgh, USA.

Bruce, D.-A., Hall, C.-H. and Triplett, R.-E. (1992). Structural Underpinning By Pinpiles. Proceedng of the 17th DFI Annual Meeting, New Orleans, USA.

Bruce, J., Gurpersaud, N., Han, Z., Montgomery and M., Lee, H. (2018). An appropriate method for constructing deep foundations that must penetrate artesian aquifers. Proceedings of GeoEdmonton 2018: 71st Canadian Geotechnical Conference, Edmonton, AB.

Bruce, J. and Gurpersaud, N. (2009). Grout flushed micropile foundations for a new rail overpass. Proceeding of the 9th International Society for Micropiles Workshop. London, UK.

Bustamante, M. and Doix, B. (1985). Une méthode pour le calcul des tirants et des micropieux injectés. Bull Liaison Lab Ponts Chauss, Ministere de l'equipement, du logement, de l'amenagement du territoire et des transports, Paris, France, 75-92.

Cadden, A., Gómez, J., Bruce, D. and Armour, T. (2004). Micropiles: Recent Advances and Future Trends, Current Practices and Future Trends in Deep Foundations, GSP 125, 140-165.

Canadian Geotechnical Society. (2006). Canadian Foundation Engineering Manual (4th ed), Richmond, BC: CGS.

Canadian Standards Association. (2016a). Commentary on CSA S6-14, Canadian Highway Bridge Design Code. Rexdale, ON: Canadian Standards Association.

Canadian Standards Association. (2016b). CSA S6-14, Canadian Highway Bridge Design Code. Rexdale, ON: Canadian Standards Association.

Chin, F.-K. (1970). Estimation of the Ultimate Load of Piles from Tests Not Carried to Failure. Proceedings of Second Southeast Asian Conference on Soil Engineering. Singapore City, Singapore, 81-92. 
Christian, J.-T. (2001). Discussion of Factor of Safety and Reliability in Geotechnical Engineering. Journal of Geotechnical and Geoenvironmental Engineering, 127(8), 700-721.

Das, B.-M. (2016). Principles of Foundation Engineering (8th ed.), Columbus, USA: McGrawHill handbooks.

Décourt, L. (1997). A ruptura de fundações avaliada com base no conceito de rigidez. Seminário de Engenharia de Fundações Especiais III, São Paulo, Brazil, 215-224.

Décourt, L. (2008). Provas de carga em estacas podem dizer muito mais do que tem dito. Seminário de Engenharia de Fundações Especiais VI, São Paulo, Brazil, 221-245.

Duncan, J.-M. (2000). Factor of Safety and Reliability in Geotechnical Engineering. Journal of Geotechnical and Geoenvironmental Engineering, 126(4), 307-316.

Esposito, G. and Fenton, G.-A. (2018). Review of Reliability Levels Achieved by Geotechnical Design Codes. Proceedings of GeoEdmonton 2018: 71st Canadian Geotechnical Conference, Edmonton, AB: Canadian Geotechnical Society.

Federal Highway Administration. (2000). Micropile Design and Construction Guidelines Implementation Manual. FHWA-SA-97-070, Dallas, USA: United States Department of Transportation.

Federal Highway Administration. (2005). Micropile design and construction. FHWA-NHI-05039, Dallas, USA: United States Department of Transportation.

Fellenius, B.-H. (1980). The analysis of results from routine pile load tests. Ground Engineering, 13(6), 19-31.

Fellenius, B.-H. (2001). What capacity value to choose from the results of static loading test. The Newsletter of the Deep Foundations Institute: Deep Foundation Institute

Fenton, G.-A., Naghibi, F., Dundas, D., Bathurst, R.-J. and Griffiths, D.-V. (2016). Reliabilitybased geotechnical design in 2014 Canadian Highway Bridge Design Code. Canadian Geotechnical Journal, 53, 236-251. 
Fuller, F.-M. and Hoy, H.-E. (1970). Pile load tests including quick-load test method, conventional methods, and interpretations. Highway Research Record, 333, 74-86.

Gómez, J., Cadden, A. and Bruce, D.-A. (2003). Micropiles founded in rock. Development and evolution of bond stresses under repeated loading. Proceedings of the 12th PanAmerican Conference on Soil Mechanics and Geotechnical Engineering, Cambridge, USA, 19111916.

Gómez, J. E., Rodriguez, C.-J., Robinson, H.-D. and Keough, L. (2007). Hollow Core Bar Micropiles - Design Parameters Interpreted From 260 Load Tests. Proceedings of the 32nd Annual Conference on Deep Foundations, Colorado Springs, USA.

Gómez, J. E., Rodriguez, C.-J., Mikitka, J. and Robinson, H.-D. (2008). Hollow Core Bar Micropiles - Design Paramenters Interpreted From 404 Load Tests. Proceedings of the 33rd Annual Conference on Deep Foundations. New York, USA.

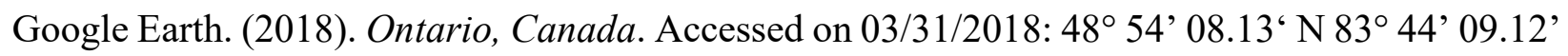
W.

Gurpersaud, N. (2018). Full-scale Pile Load Testing. CGS-SOS Summer 2018 Workshop: Pile Capacity Verification and Testing Methods, Toronto, ON: Canadian Geotechnical Society.

Haldar, A. and Mahadevan, S. (2000). Probability, ReliabilityProbability, Reliability, and Statistical Methods in Engineering Design, New York, USA: John Wiley \& Sons Inc.

Ischebeck, E.-F. (2010). The Design and Execution of Drilled and Flush-Grouted TITAN Micropiles is Governed in European Union (EU) by National Technical Approval Z-34.14209 (DIBT). Proceeding of the 10th International Society for Micropiles Workshop, Washington, USA.

Jeon, S.-S. and Kulhawy, F.-H. (2001). Evaluation of Axial Compression Behavior of Micropiles. Foundations and ground improvement, Blacksburg, USA, 460-471.

Kan, C.-Y., Wong, C.-T. and Leung, M.-K. (2013). Relationship of friction and shear displacement along the depth of shaft-grouted mini-piles and a case study, HKIE Transactions, 20(4), 206-213. 
Kulhawy, F.-H. and Mayne, P.-W. (1990). Manual on Estimating Soil Properties for Foundation Design, EPRI-EL-6800, Palo Alto, USA: Cornell University.

Misra, A., Chen, C.-H., Oberoi, R. and Kleiber, A. (2004). Simplified Analysis Method for Micropile Pullout Behavior. Journal of Geotechnical and Geoenvironmental Engineering, 130(10), 1024-1033.

National Research Council of Canada. (2015). National Building Code of Canada 2015, Ottawa, ON.

Nowak, A.-S. (1999). Calibration of LRFD Bridge Design Code. NCHRP Report 368, Washington, USA: Transportation Research Board.

Paikowsky, S.-G., Birgisson, B., Mcvay, M., Nguyen, T., Kuo, C., Baecher, G., Stenersen, K., O'Malley, K., Chernauskas, L. and O'Neil, M. (2004). Load and Resistance Factor Design (LRFD) for Deep Foundations, NCHRP Report 507. Washington, DC, USA: Transportation Research Board.

Post-Tensioning Institute. (2014). Recommendations for Prestressed Rock and Soil Anchors. PTI DC-35-14, Post-Tensioning Institute, Farming Hills, USA.

Rackwitz, R. and Fiessler, B. (1978). Structural reliability under combined random load sequences. Computer \& Structures, 9(5), 489-494.

Ramirez, D. (2006). What We Have Learned About Micropile Behaviour From Field Instrumentation. Proceeding of the 7th ISM Workshop, Schrobenhausen, Germany.

Razali, N.-M. and Wah, Y.-B. (2011). Power comparisons of Shapiro-Wilk , KolmogorovSmirnov, Lilliefors and Anderson-Darling tests. Journal of Statistical Modeling and Analytics, 2(1), 21-33.

Reddy, S.-C. and Stuedlein, A.-W. (2017). Ultimate limit state reliability-based design of augered cast-in-place piles considering lower-bound capacities. Canadian Geotechnical Journal, 54, 1693-1703. 
Stuedlein, A.-W., Gibson, M.-D. and Horvitz, G.-E. (2008). Tension and Compression Micropile Load Tests in Gravelly Sand. Proceedings of the $6^{\text {th }}$ International Conference on Case Histories in Geotechnical Engineering, Rolla, USA.

Van Der Veen, C. (1953). .The Bearing Capacity of a Pile. Proceedings of 3rd ICSMFE. Zurich, Switzerland.

Vesic, A.-S. (1970). Tests on Instrumented Piles, Ogeechee River Site. Journal of the Soil Mechanics and Foundations Division, 96(2), 561-584.

Vesic, A.-S. (1977). Design of Pile Foundations, NCHRP Synthesis of Highway Practice 42, Washington, USA.

Walpole, R.-E., Myers, R.-H., Myers, S.-L. and Ye, K. (2012). Probability and Statistics for Engineers and Scientists (9th ed.), London, UK: Prentice Hall.

Wang, Y. and Cao, Z. (2015). Practical reliability analysis and design by Monte Carlo Simulation in spreadsheet, Phoon, K. and Ching, J., (2015) Risk and Reliability in Geotechnical Engineering. Taylor \& Francis Group, 301-335. 